\title{
A novel pathway for VLDL assembly in the mouse liver
}

\author{
Dissertation \\ zur Erlangung des Doktorgrades \\ der Mathematisch-Naturwissenschaftlichen Fakultäten \\ der Georg-August-Universität zu Göttingen
}

vorgelegt von

Anna Mleczko

aus Krakau

Göttingen 2006 
D7

Referent:

Korreferent:

Tag der mündlichen Prüfung:
Prof. Dr. Dr. h.c. Kurt von Figura Prof. Dr. Ernst Wimmer

2.11.2006 


\section{Contents}

$\begin{array}{ll}\text { Abbreviations } & 7\end{array}$

1 Introduction $\quad 9$

1.1 Lipoproteins . . . . . . . . . . . . . . . . . . . 9

1.2 Lipoprotein metabolism . . . . . . . . . . . . . . 10

1.3 Apolipoprotein B ................... 12

1.3.1 Structure and function . . . . . . . . . . . . . . 12

1.3.2 ApoB mRNA editing. . . . . . . . . . . . . 13

1.4 VLDL de novo assembly, secretion and the regulation . . . . . . . . . 14

1.4.1 VLDL de novo assembly . . . . . . . . . . . . . . . . . 14

1.4.2 VLDL transport and secretion . . . . . . . . . . . . 16

1.4.3 Regulation of VLDL de novo assembly and secretion . . . . . . 18

1.5 Central role of the liver in lipoprotein metabolism . . . . . . . . . . 20

1.5.1 Uptake of LDL . . . . . . . . . . . . . . . . . . . 20

1.5.2 Primary hepatocytes and hepatoma cell lines as a model of liver metabolism ................. . . 21

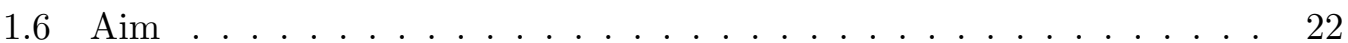

2 Material $\quad 23$

2.1 Laboratory equipment: . . . . . . . . . . . . . . . 23

2.2 Plasticware and membranes . . . . . . . . . . . . . . . . . . . 24

2.3 Chemicals, kits and ready-to-use reagents . . . . . . . . . . . . 24

2.3.1 Chemicals .................... 24

2.3.2 Reagents ....................... 24

2.3.3 Reagents for cell culture ................... 25

2.4 Radioactive isotopes . . . . . . . . . . . . . . . . 25

2.5 Primary antibodies ................... 25

2.6 Secondary antibodies . . . . . . . . . . . . . . 25 


\section{Contents}

2.7 Animals . . . . . . . . . . . . . . . . 26

3 Methods $\quad 27$

3.1 Animals . . . . . . . . . . . . . . . . . . 27

3.2 Cell culture . . . . . . . . . . . . . . . . . . . . . 27

3.2.1 Preparation of lipoprotein-deficient serum . . . . . . . . . . 27

3.2.2 Hepatocyte preconditioned medium preparation . . . . . . . . 28

3.2 .3 Isolation of hepatocytes . . . . . . . . . . . . . . 28

3.2.4 Cell culture of hepatocytes . . . . . . . . . . . . . . . 29

3.2.5 Cell culture of MEF . . . . . . . . . . . . . . . . . . 29

3.3 Lipoprotein biochemistry . . . . . . . . . . . . . . . . 30

3.3 .1 Isolation of LDL . . . . . . . . . . . . . . . . 30

3.3 .2 Iodination of LDL . . . . . . . . . . . . . . . 31

3.3.3 Fluorescence-labelled LDL preparation . . . . . . . . . . . . . 32

3.3.4 Labelling of LDL with ${ }^{3} \mathrm{H}$-cholesteryl linoleate . . . . . . . . 32

3.4 Endocytosis of $\mathrm{LDL} \ldots \ldots \ldots \ldots$

$3.4 .1{ }^{125}$ I-LDL uptake experiment . . . . . . . . . . . . 33

$3.4 .2{ }^{125}$ I-LDL pulse-chase uptake and chase experiment . . . . . . . 34

3.4.3 Fluorescence labelled LDL pulse-chase time procedure . . . . . 35

3.4.4 ${ }^{3}$ H-labelled LDL uptake experiment . . . . . . . . . . . . . 35

3.4.5 ${ }^{125} \mathrm{I}-\mathrm{LDL}$ pulse-chase time in vivo procedure with mouse liver

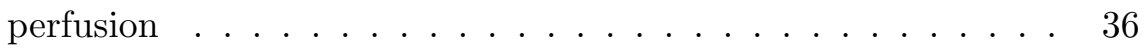

$3.4 .6{ }^{125} \mathrm{I}-\mathrm{LDL}$ pulse time procedure in living mouse $\ldots \ldots . . .36$

3.5 Seperation of lipoproteins according to their density by floatation gradient ultracentrifugation . . . . . . . . . . . . . . . 37

3.6 Protein analysis . . . . . . . . . . . . . . . . . . . . 38

3.6.1 Apolipoprotein B analysis . . . . . . . . . . . . . 38

3.6.2 Protein estimation with Bradford assay . . . . . . . . . . . 39

3.6 .3 Protein estimation with Lowry assay . . . . . . . . . . . . . . 39

3.6.4 TCA protein precipitation . . . . . . . . . . . . . 40

3.6 .5 SDS-PAGE . . . . . . . . . . . . . . . 40

3.6 .6 Western Blot . . . . . . . . . . . . . . . . 41

3.6.7 Subcellular fractionation . . . . . . . . . . . . . . . . . . 42

3.6 .8 Cell metabolic labelling . . . . . . . . . . . . . . . . . 44

3.6 .9 Immunoprecipitation . . . . . . . . . . . . . . . . . . 45

3.6.10 Visualization of radioactively labelled proteins after SDS-PAGE 46 
3.6 .11 Immunofluorescence . . . . . . . . . . . . . . . 46

3.7 Biochemical assays . . . . . . . . . . . . . . . . . 4 4 47

3.7.1 Enzymatic Quantification of Cholesterol . . . . . . . . . . . 47

$3.7 .2 \quad \beta$-Hexosaminidase enzymatic assay . . . . . . . . . . 47

3.7.3 Glucose enzymatic assay . . . . . . . . . . . . . . . . . 48

3.7 .4 Lactate dehydrogenase assay $\ldots \ldots \ldots$. . . . . . . . . 48

3.8 Lipid analysis . . . . . . . . . . . . . . . . . . . . . . . . . . 49

3.8.1 Lipid extraction according to Folch . . . . . . . . . . . . . 49

3.8.2 Lipid extraction according to Dole . . . . . . . . . . . . . . . 49

3.8.3 Thin Layer Chromatography _ . . . . . . . . . . . . . . . 50

4 Results $\quad 51$

4.1 Uptake and degradation of LDL by primary hepatocytes . . . . . . . 51

4.1.1 Metabolisation of LDL-derived apoliporotein B100 . . . . . . 51

4.1.2 Hydrolysis of the LDL-derived cholesteryl linoleate in primary hepatocytes . . . . . . . . . . . . . 54

4.2 Intracellular storage and recycling of endocytosed ${ }^{125} \mathrm{I}$-apoB100 in primary hepatocytes . . . . . . . . . . . . . . 56

$4.3{ }^{125} \mathrm{I}$-apoB storage and recycling in the mouse liver $\ldots \ldots$. . . . . 60

4.4 Recycling of LDL-derived ${ }^{125} \mathrm{I}$-apoB100 to ${ }^{125} \mathrm{I}$-VLDL in the living mouse 61

4.5 Cellular localisation of the lipidation of reutilised LDL-derived apoB100 63

4.5.1 Defining of LDL-derived apoB100 localisation using subcellular

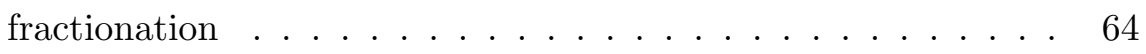

4.5.2 Defining of LDL-derived apoB100 localisation with confocal microscopy . . . . . . . . . . . . . . 6 65

4.5.3 The effect of Golgi-disturbing agents on the intact ${ }^{125} \mathrm{I}$-apoB100

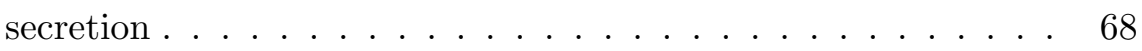

4.5.4 The effect of temperature on the secretion of LDL-derived ${ }^{125} \mathrm{I}-$ apoB100 by hepatocytes . . . . . . . . . . . . . 69

4.5.5 Effect of inhibition of MTP . . . . . . . . . . . 70

5 Discussion $\quad 73$

5.1 Metabolisation of LDL-derived apoB100 . . . . . . . . . . . 73

5.2 Recycling of endocytosed apoB100 in primary hepatocytes and in the mouse liver . . . . . . . . . . . . . . . . . . . 75

5.3 Cellular localisation of the lipidation of recycled LDL-derived apoB100

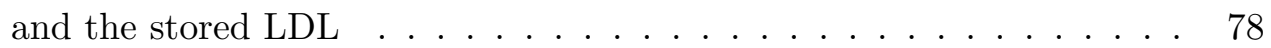




\section{Contents}

5.4 The significance of LDL-derived apoB recycling pathway in an organism 81

Summary

83

Acknowledgements

85

Bibliography

86 


\section{Abbreviations}

\begin{tabular}{|c|c|}
\hline ACAT & Acyl-CoA:cholesterol acyltransferase \\
\hline Apo & Apolipoprotein \\
\hline APS & Ammonium peroxide sulfate \\
\hline ARF1 & ADP ribolylation factor 1 \\
\hline BSA & Bovine serum albumin \\
\hline${ }^{\circ} \mathrm{C}$ & Grade Celsius \\
\hline $\mathrm{CE}$ & Cholesteryl ester \\
\hline CETP & Cholesteryl ester transfer protein \\
\hline $\mathrm{Ci}$ & Curie \\
\hline $\mathrm{cpm}$ & counts per minute \\
\hline $\mathrm{Da}$ & Dalton \\
\hline DAPI & Diamidino-2-phenylindole \\
\hline $\mathrm{dd}_{2} \mathrm{O}$ & double distilled water \\
\hline g & gravitation \\
\hline HDL & High Density Lipoproteins \\
\hline HP & Hepatic lipase \\
\hline HSPG & Heparin sulfate proteoglycan \\
\hline IDL & Intermediate Density Lipoproteins \\
\hline Lamp & Lysosome associated matrix protein \\
\hline LDL & Low Density Lipoproteins \\
\hline LDL-R & Low Density Lipoprotein receptor \\
\hline LPDS & Lipoprotein-deficient serum \\
\hline LPL & Lipoprotein lipase \\
\hline LRP & LDL-Receptor related protein \\
\hline $\mathrm{M}$ & Molar \\
\hline$\mu$ & micro, $-\left(\mathrm{x} 10^{-6}\right)$ \\
\hline $\mathrm{ml}$ & milliliter \\
\hline
\end{tabular}




\section{Abbreviations}

MTP

PAGE

PBS

rpm

SDS

TAG

VLDL

$\mathrm{w} / \mathrm{v}$
Microsomal transfer protein

Polyacrylamide gel electrophoresis

Phosphate-buffered saline

rotation per minute

Sodium dodecyl sulfate

Triacylglyceride

Very Low Density Lipoproteins

weight pro volume 


\section{Introduction}

\subsection{Lipoproteins}

Lipoproteins are soluble macromolecular complexes of lipids and specific proteins (apolipoproteins) that allow the transportion of hydrophobic lipids in the human circulation.

All lipoprotein particles have a common structure of a neutral lipid core, which contains triacylglycerols and cholesteryl esters, surrounded by a surface monolayer, which contains amphipatic phospholipids, unesterified cholesterol and apolipoproteins (Fig. 1.1). The hydrophilic heads of the phospholipids are in contact with the surrounding aequous environment and their hydrophobic part is directed towards the lipid core. Apolipoproteins contain helical regions, one surface of the helix contains hydrophobic amino acid residues while the other side is hydrophilic. These features give the apoprotein the ability to bind phospholipids and also interact with the aqueous environment, serving as a cofactor for enzymatic reactions and mediating the uptake and catabolism of plasma lipoproteins. The major apolipoproteins are apolipoprotein (apo) B, apoC-I, apoC-II, apoC-III, apoE, and apoA-I and apoA-II.

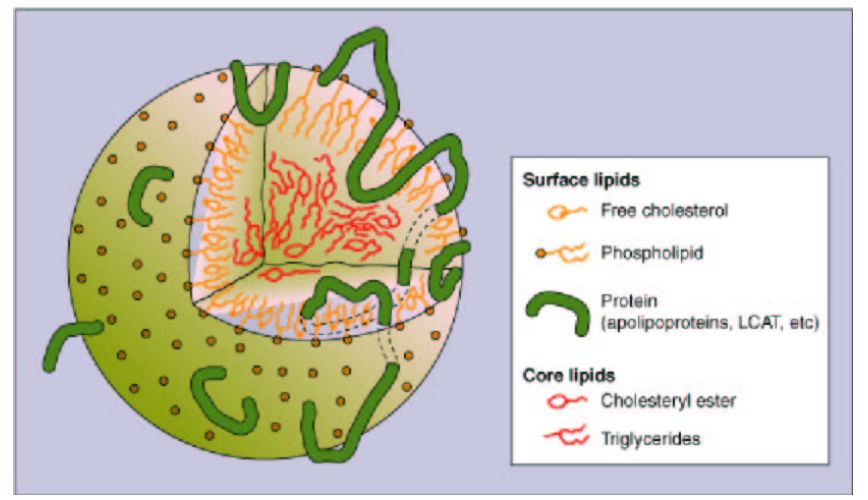

Figure 1.1: Lipoprotein structure, details are found in the text.

The major plasma lipoproteins are classified according to their density into five 


\section{Introduction}

lipoprotein classes: chylomicrons $(\mathrm{CH})$, very low-density lipoprotein (VLDL), intermediatedensity lipoprotein (IDL), low-density lipoprotein (LDL), and high-density lipoprotein (HDL). Each class has a characteric size, lipid composition and apolipoprotein content (cf. Table 1.1). Furthermore, heterogeneity exists within each class because of the constant remodeling of their composition, shape, size and exchange of protein and lipid constituents. In humans there are at least two physically distinct species of VLDL (VLDL1, VLDL2), as well as two subspecies od IDL (Musliner et al. 1986) and seven distinct subspecies of LDL (Krauss and Burke 1982).

\begin{tabular}{|c|ccccc|}
\hline & CH & VLDL & IDL & LDL & HDL \\
\hline $\begin{array}{c}\text { density range } \\
(\mathbf{g} / \mathbf{m l})\end{array}$ & $<0.95$ & $0.95-1.006$ & $1.006-1.019$ & $1.019-1.063$ & $1.063-1.210$ \\
$\begin{array}{c}\text { diameter } \\
(\mathbf{n m})\end{array}$ & $80-1200$ & $30-80$ & $25-35$ & $18-25$ & $5-12$ \\
apolipoproteins & AI, AII, AIV, & B-48/B-100, & B-48/B-100, & B-100 & AI, AII, C, E \\
B-48, C, E & C, E & C, E & & \\
dry weight (\%) & & & & & \\
- Protein & $1-2$ & 10 & 18 & 25 & 33 \\
- Triglyceride & 83 & 50 & 31 & 9 & 8 \\
- UC + CE & 8 & 22 & 29 & 45 & 30 \\
- PL & 7 & 18 & 22 & 21 & 29 \\
\hline
\end{tabular}

Table 1.1: Lipoprotein classes

\subsection{Lipoprotein metabolism}

Lipoprotein metabolism and trafficking proceeds along two pathways: the exogenous and the endogenous one (Fig. 1.2). The exogenous pathway involves the uptake of dietery lipids by the intestine followed by their transport via lipoproteins to liver, while the endogenous pathway involves the transport of lipids (cholesterol, triglycerides) from the liver to peripheral tissues.

Epithelial enterocytes lining the small intestine absorbe dietery lipids and assemble chylomicrons, the largest and lipid richest lipoprotein particles. Their lipid core contains triacylglycerols (TGs) of dietery origin. Chylomicrons are co-secreted into the lymph with apolipoprotein AI, AIV and B48, however after reaching the circulation the spontaneous transfer between them and HDLs results in the exchange of apoAs for apoC (I, II, III) and E. ApoCII is an activator of the lipolytic enzyme lipoprotein lipase (LPL), which mediates the lipolysis of the triacylglycerol core of chylomicrons. This 


\section{Introduction}

process leads to the formation of chylomicron remnants (Santamarina-Fojo 1998). These TG-depleted remnants still contain cholesteryl esters, apoB48, apoE and are taken up by the liver through the low-density lipoprotein related protein receptor (LRP-R) (Choi et al. 1991; Rohlmann et al. 1998).

The hepatic secretion of lipids is denoted as endogenous pathway. Its primary particles are VLDLs. They are assembled and secreted into the circulation by the liver in a continuous manner. Their protein moiety consists of one molecule of apoB100 and several molecules of apoC, the lipid part contains triglycerides, free and esterified cholesterol and phospholipids. Similarly to chylomicrons, they are enriched with apoE and additional apoC in the plasma. Delipidation of VLDL through the action of LPL and HP (hepatic lipase) produces VLDL remnants: smaller, dense and cholesterolrich IDL and smaller VLDL. (Gibbons 1990).

About half of IDL are directly cleared by the liver, through an apoE-mediated process. Interaction between apoE and the TG lipases with heparin sulfate proteoglycans (HSPG), the LDLR and low density lipoprotein receptor-related protein (LRP) are thought to modulate this clearance (Mahley and Ji 1999).

IDL has short half-life and is rapidly converted to LDL by cholesteryl ester tranfer protein (CETP), which exchanges apoB-associated triacylglycerol to apoAI-associated cholesteryl esters. The conversion to LDL involves not only further loss of TG, but also a depletion of apoE and the apoCs.

LDL is the major cholesterol-carrying lipoprotein. Its surface consists of a single molecule of apoB100, phospholipids and free cholesterol. The hydrophobic core contains mainly CE, small amounts of TG and free cholesterol. Contrary to other lipoproteins, the LDL particle has a long 24 hour half life before being cleared off the circulation: $50 \%$ by the liver and $50 \%$ by peripheral tissues. This clearance occurs via binding of apoB100 to LDL receptor and receptor-mediated endocytosis as described by Brown and Goldstein (1986).

A part of the endogenous lipid transport route consists of the transport of cholesterol from tissue stores, VLDL and chylomicrons to HDL particles - a process which is refered to as reversed cholesterol transport. HDL are synthesised in the liver and intestine as small, protein-rich particles containing relatively little cholesterol and cholesteryl esters. They can be also formed in the circulation during catabolism of VLDL and chylomicrons (Eisenberg 1984). HDL particles play an important role in the transport of excess cholesterol from peripheral tissue back to the liver where it can be re-used as a substrate for bile acids synthesis or secreted directly as a free cholesterol into the bile. This HDL-cholesterol uptake by the liver is mediated by 
scavenger receptor class B, type 1 (SR-B1) (Ji et al. 1997).

Taken together, the metabolisation of chylomicrons and VLDL particles releases free fatty acids which can be taken up by surrounding tissue for further use, whereas LDL and HDL play a crucial role in cholesterol homeostasis.

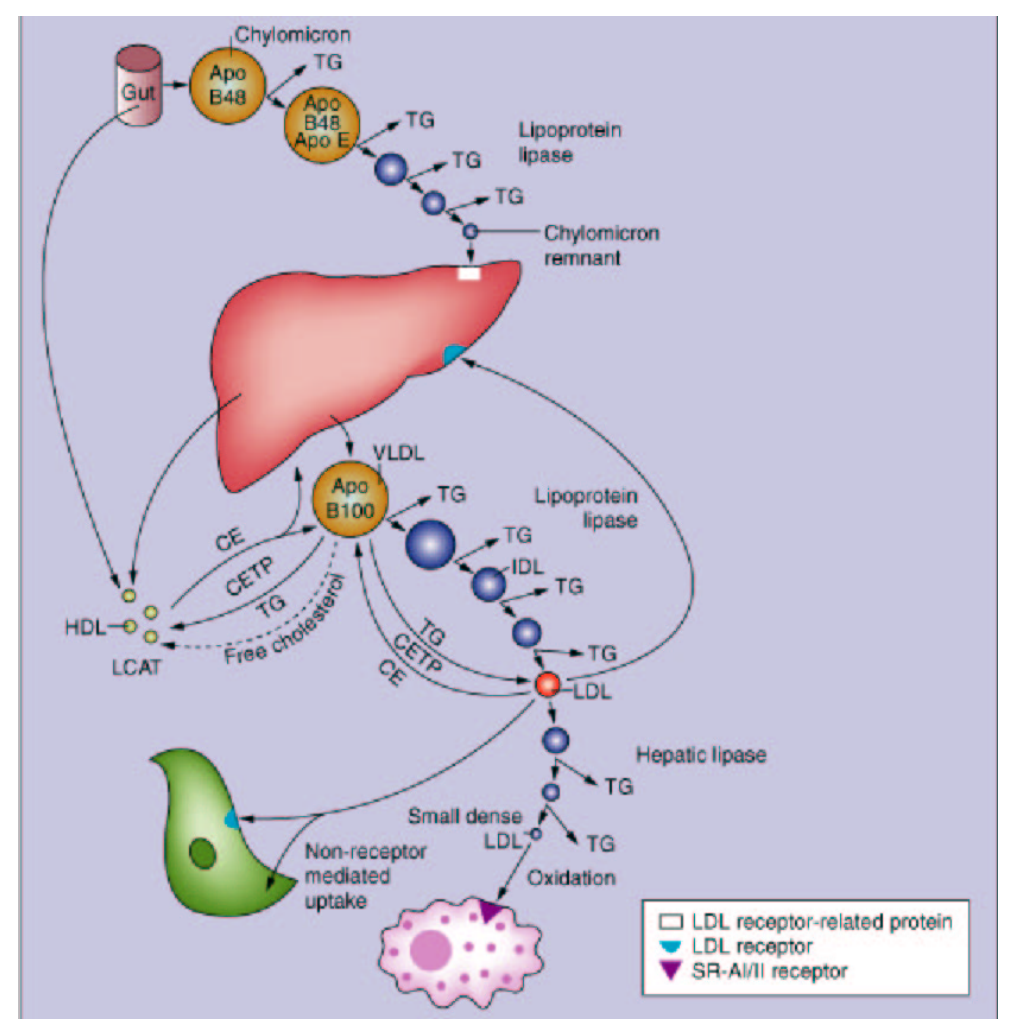

Figure 1.2: Lipoprotein metabolisation. Description in the text.

\subsection{Apolipoprotein B}

\subsubsection{Structure and function}

Apolipoprotein B is the major component of chylomicrons, LDL and VLDL. It is a large, hydrophobic and monomeric glycoprotein. It exists in two forms (Young 1990). ApoB100 is formed of 4536 aminoacids and has a molecular mass of $512 \mathrm{kDa}$ protein. The shorter form, apoB48, is a truncated, $250 \mathrm{kDa}$ protein, which is produced as a result of a post-transcriptional editing of the apoB mRNA (Powell et al. 1987). It is identical to the N-terminal portion of apoB100 but has only $48 \%$ of its aminoacids 


\section{Introduction}

and it lacks the domain that mediates interaction with the LDL receptor. As a result, apoB-48-containing particles follow a different metabolic pathway, they are cleared through apoE-LRP interaction (Herz and Willnow 1995) and have a higher turnover in the circulation than apoB-100-containing lipoproteins (Elovson et al. 1981).

Human VLDL particles, synthesised by the liver, contain only apoB100, whereas apoB48 is synthesised in the intestine as a chylomicron component. In rodents however, secreted VLDL which contain apoB48 is also synthesised in liver (Bisgaier and Glickman 1983; Glickman et al. 1986).

Unlike the other apolipoproteins, apoB is not exchanged between lipoproteins.

A bioinformatic analysis of the structure of apoB predicts pentapartite structure: $\mathrm{NH}_{3}-\alpha_{1}-\beta_{1}-\alpha_{2}-\beta_{2}-\alpha_{3}-\mathrm{COOH}$, consisting of N-terminal globular domain followed by amphipathic $\beta$-sheets and $\alpha$-helices (Segrest et al. 1994). The new data suggest that orginal N-terminal $\alpha_{1}$ globular domain should be expanded to 1000 residues (in the region of $\beta_{1}$ ) and renamed as the $\alpha_{1} \beta_{1}$ domain.

ApoB is required for the assembly and secretion of the TG-rich lipoproteins (VLDL and chylomicrons). It is also a major protein component of LDL and contains the domain required for interaction of this lipoprotein species with the LDL-receptor. Furthermore, apoB100 contains an unpaired cysteine residue at position 4326, which mediates a covalent interaction with apo(a). The covalent binding of apo(a) and LDL yields the highly atherogenic lipoprotein: lipoprotein (a) ( $\mathrm{Lp}(\mathrm{a})$ in humans) (Callow et al. 1994).

\subsubsection{ApoB mRNA editing}

The human apoB gene is located on chromosome 2p24, it spans $43 \mathrm{~kb}$ and has 29 exons and 28 introns (Scott et al. 1987).

ApoB-48 mRNA is created by a post-transcriptional and enzyme-dependent deamination, where a cystidine in a CAA codon specifying glutamine (amino acids position 2153) is replaced by a uracil, resulting in the formation of an in-frame stop codon (UAA) (Chen et al. 1987; Navaratnam et al. 1998). This reaction is catalised by a multicomponent cysteine deaminase comlex, that recognises the defined sequence elements flanking the edited base (Davies et al. 1989). The complex contains a catalytic subunit called APOBEC-1 (Teng et al. 1993). Apobec1 expression is not found in the human liver which explains the lack of apoB mRNA editing in this organ. 


\subsection{VLDL de novo assembly, secretion and the regulation}

\subsubsection{VLDL de novo assembly}

Human and murine VLDL particles are considered to be assembled in the liver in the same manner, although some subtle differences in the kinetics for the intracellular turnover and the needs for fatty acids to form VLDL cannot be excluded (Boren et al. 1994).

Hepatic assembly and secretion of apoB-containing VLDL requires a pool of lipids to form a monolayer surface and a neutral core, the transcription and translation of the structural protein apoB, and the presence of the rate-limiting enzyme MTP (microsomal transfer protein).

Although the source of triglyceride for VLDL assembly is still not fully clear, it has been demonstrated that the flow of newly synthesised TG into VLDL in the liver is relatively small. Instead, these TGs first enter the cytosolic stores (Lankester et al. 1998; Wiggins and Gibbons 1996). The stored TG are hydrolysed to diacylglycerols by triacylglycerol hydrolase (TGH) (Lehner and Verger 1997), which are then reesterified into triglycerols before being packaged in the core of the VLDL particle (Yang et al. 1996). The cholesterol esters found in VLDL core are generated by the action of ACAT2: liver and intestine acyl-CoA:cholesterol acyltransferase (Lee et al. 2000), which seems to be specialised for the production of cholesterol esters destinated to VLDL and chylomicron assembly (Anderson et al. 1998).

The process of VLDL assembly is co-translational: it begins as soon as the apoB polypeptide starts to translocate across the endoplasmic reticulum membrane. This unique translocation of newly synthesised apoB is coupled with the lipidation process and determines the fate of nascent apoB (Higashi et al. 2003). Due to its structural characteristics with an amphipathic $\alpha$-helix and $\beta$-strand domains, nascent apoB enters the lumen of ER in an ineffective and slow manner, resulting in a prolonged association with the ER membrane (Mitchell et al. 1998). This slow pace allows the cell to load apoB with core lipids. However, part of the translated apoB is degraded via ERAD (ER-associated degradation) (Rusinol et al. 1998). Because up to $50 \%$ of the newly sythesised apoB100 is degraded in fibroblasts and rat hepatocytes, it has been proposed that de novo synthesised primordial VLDL can undergo a lipidation or a degradation fate. Which of these fates the molecule follows seems to be determined not only by protein translocation, but also by the specific folding of apoB, which is regarded as a critical step that influences the rate of apoB lipidation. Disulfide bridges in the N-terminal domain seem to have an especially important function, as their 
disruption leads to misfolding and impaired lipidation (Huang and Shelness 1997; Tran et al. 1998). The assembly of the VLDL particles is considered to involve two steps (Fig. 1.3). First, in the ER, microsomal triglycerides transfer protein (MTP) binds to the N-terminal part of newly synthesised apoB (Bradbury et al. 1999) and facilitates the transfer of a small amounts of TG, CE, phospholipids, which results in the generation of small, HDL-dense VLDL precursors (Gordon et al. 1996). In the second step, the apoB-containing pre-VLDL particles fuse with a larger TG-rich lipid droplets to form mature VLDL (Tietge et al. 1999).

MTP is considered to be the most essential factor in early steps of VLDL assembly. It is a heterodimer, consisting of PDI-protein disulfide isomerase and a large, $97 \mathrm{kDa}$ protein, called M subunit. PDI is proposed to mantain the MTP complex in a soluble state, although its role appears to be rather elusive (Wetterau et al. 1991). MTP is found in the endoplasmic reticulum lumen, primarily of the liver and the intestine, but also in the heart (Boren et al. 1998; Nielsen et al. 1998). One recent study showed the localisation of MTP in the Golgi apparatus of rat intestine (Levy et al. 2002) and the activity of MTP in Golgi membranes in primary rat hepatocytes (Hebbachi et al. 1999).

MTP may function both as a chaperone, facilitating the translocation of apoB to the ER lumen (Du et al. 1999; Fleming et al. 1999), and as a lipid transfer protein, allowing apoB to assemble with lipids and to be secreted (Raabe et al. 1999).

Little is known about the second step of VLDL assembly: the process of bulk lipidation, the site where it occurs and the role of MTP in the final stage of maturation. MTP may play a role in the formation of TG droplets and helps to mediate the final lipidation at its site (Raabe et al. 1999). However, the fusion reaction itself with preVLDL particle seems to be MTP-independent (Gordon et al. 1996; Rustaeus et al. 1998). The conversion of primordial lipoprotein to mature VLDL particles appears to be dependent on the ADP ribosylation factor 1 (ARF1) mediated stimulation of phospholipase D (PLD) (Asp et al. 2000). Phospholipase D mediates the synthesis of phosphatidic acid, which is a precursor for triglyceride production. Thus, activation of phospholipase $\mathrm{D}$ may be important to provide phospholipids for VLDL triglyceride droplets synthesis (Asp et al. 2000). Another phospholipase: cytosolic calcium-independent phospholipase $\mathrm{A}_{2}\left(\mathrm{iPLA}_{2}\right)$ has been shown to be a cofactor in the maturation of VLDL in McA-RH7777 cells (Tran et al. 2000), but its detailed function is unclear.

Probably apoB has a few palmitoylation sites, although only one site at Cys-1085 has been shown to be actually used. It has been suggested that palmitoylation of apoB 
may provide a signal for targeting the protein to the bulk lipidation site (Zhao et al. 2000).

The intracellular site of the fusion process is clearly not identified. There are studies which propose the involvment of smooth ER (SER) (Alexander et al. 1976; Hamilton et al. 1998), rough ER (RER) (Rusinol et al. 1993), a specialised post RER, pre-Golgi compartment (Rusinol et al. 1994) and the Golgi complex (Bamberger and Lane 1990; Cartwright and Higgins 1995; Higgins 1988; Swift et al. 2001; Tran et al. 2002). The analysis of the lipidation state of apoB-containing particles in ER and Golgi compartments points to the Golgi as the site of VLDL-bulk lipidation. ApoB-containing molecules recovered from ER-derived vesicles are lipidated but the particles are not as buoyant as typical VLDL (density < 1.006) (Gusarova et al. 2003). ApoB-containing particles found in the Golgi area are larger and less dense (Swift et al. 2001). These findings strongly suggest that additional lipid loading of ER-derived VLDL lipoproteins requires a transport step and takes place in a post ER-compartment. However, whether this process occurs precisely in the Golgi or in a pre-Golgi compartment is still not clear.

There are reports which emphasised an even more pivotal role for the Golgi in the formation of TG-rich lipoproteins. They suggest that not only final lipidation, but also a substantial portion of the oligosacharide chains of apoB, along with various posttranslational modifications of both lipids and apoprotein moieties, is processed in the Golgi (Olofsson et al. 1987).

\subsubsection{VLDL transport and secretion}

The exit of the assembled primordial-VLDL/VLDL particles from the ER and secretory compartment may require a specialised machinery, since VLDLs (>100 nm) are much larger than average transport vesicles which only have a diameter of 60 $80 \mathrm{~nm}$ (Schekman and Mellman 1997). Some reports have shown the involvment of Sar1b in the trafficking of preVLDL/VLDL between the ER and the Golgi apparatus (Jones et al. 2003), reviewed by Brodsky et al. (2004). Sar1b is an ER-derived GTPase involved in COPII-mediated vesicle formation (Kuge et al. 1994). However, apoB-containing lipoproteins seem to be exported from the ER in vesicles a little distinct from classic COPII-dependent vesicles, which contain other hepatic secretory proteins. They are lacking the co-secreted proteins, like albumin and they seem to be much denser in spite of the presence of less-dense cargo-lipidated apoB (Gusarova et al. 2003). Thus, the apoB-containing vesicles could require additional coat pro- 


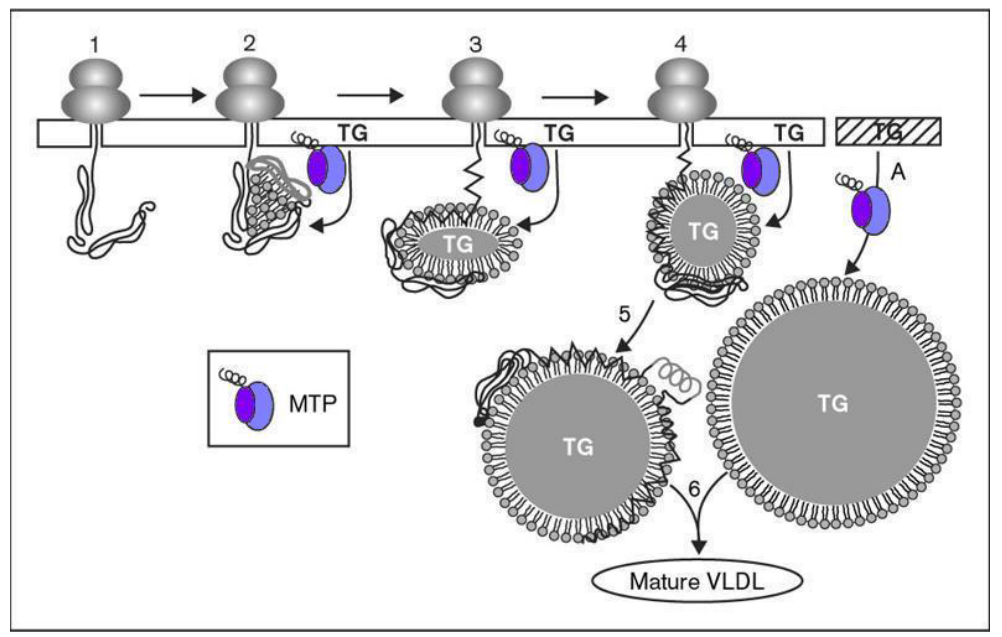

Figure 1.3: Model of VLDL assembly (adapted from Shelness and Sellers (2001)). Lipid-binding conformation of apoB (step 1). Recruitment of a small amount of phospholipid and triglyceride to apoB, mediated by MTP (step 2 ). Forming a neutral lipid core (step 3). Conversion to a spheric emulsion particle-VLDL precursor (step 4). Traffic VLDL-precursor to distal compartment in the secretory pathway (step 5). Lipid bulk formation in smooth ER (step A) mediated by MTP. Fusing of a VLDL-precursor and lipid bulk in post ER/Golgi compartment (step 6)

teins, which could compensate for low density of transported VLDL. Olofsson and co-workers have shown that dominat negative Arf1p can block VLDL formation (Asp et al. 2000). ARF1 is a member of the Ras superfamily of GTP-binding proteins and participates in the formation of COPI vesicles, which perform anterograde and retrograde transport between the ER and the Golgi and within the Golgi stacks.

These data suggest that COPII vesicles that contain apoB lipoproteins might quickly undergo a COPI-dependent pre-Golgi sorting step.

Another hypothesis proposes that lipoproteins leave the rough ER via Sar1/COPII transport vesicles which stay close to the ER and fuse in an ARF-dependent event to form the so-called vesicular tubular cluster (VTC) (or ER-Golgi intermediate compartment, ERGIC), (Lippincott-Schwartz et al. 1998). An ARF1-mediated mechanism in VLDL assembly would be explained by the formation of VTC and the role of VTC in sorting of pre-VLDL to the second step assembly compartment (Bannykh et al. 1998; Lavoie et al. 1999).

VLDL are secreted in two forms: VLDL1 and VLDL2, of which the former are larger, 


\section{Introduction}

lighter and TG-richer. The production of both VLDL fractions is regulated separately and independently by the liver (Packard and Shepherd 1997), although the mechanism underlying this process remains unknown. It has been proposed that the avability of fatty acids is an essential factor for the secretion of VLDL1. In the presence of sufficient amounts of fatty acids and TG most of pre-VLDL is supposed to be converted to VLDL1. This reaction involves an ARF-dependent transport step. When the fraction of pre-VLDL in the final lipidation compartment is increasing and exceeding VLDL1 lipidation capacity or during a shortage of fatty acids, triglycerides-poorer VLDL2 are generated and secreted (Asp et al. 2005).

\subsubsection{Regulation of VLDL de novo assembly and secretion}

\subsubsection{Degradation as a regulatory mechanism}

Regulation of apoB-containing lipoprotein assembly and secretion from hepatic cells is predominately a translational and a post-translational mechanism, that occurs in the endoplasmic reticulum (Ginsberg 1995). As mentioned above, the translocation of apoB across the ER membrane and lipidation are critical steps that determine the fate of nascent apoB and consequently the rate of secreted VLDL. When lipid synthesis or transfer is low the newly sythesised apoB fails to assemble into a lipoprotein particle, it remains membrane-associated in the ER compartment and is evantually degraded (Davis 1993; Ginsberg 1995). This is the fate for a significant amount of newly synthesised apoB (30\%-70 \%). A major mechanism for intracellular degradation of apoB is the proteasome-ubiquitin pathway. If the lipidation is inadequate, the nascent chain of apoB contacts cytosolic chaperones, such as Hsp70. The protein is retracted to the cytosol via the Sec61p complex, multiubiquitinated and then sorted to $26 \mathrm{~S}$ proteosome (Fisher et al. 1997; Yeung et al. 1996). The globular N-terminal domain of apoB does not seem to be retracted through the translocation channel. Instead it is cleaved off, released to the ER lumen and, at least under certain conditions, secreted (Du et al. 1994). The degradation of significant amounts of apoB has been observed in HepG2 cells (Du et al. 1994; Liao et al. 1998), McArdle7777 rat hepatoma cells (Cavallo et al. 1998; White et al. 1992), and primary cultures of rat (Borchardt and Davis 1987a; Sparks and Sparks 1990; Wang et al. 1995a) and hamster (Taghibiglou et al. 2000) hepatocytes. Nevertheless, the intracellular degradation of apoB is not an universal and inevitable mechanism, since in $\mathrm{CaCo} 2$ cells (human intestinal cell line) almost the whole amount of synthesised apoB100 and apoB48 manage to escape the proteasome pathway (Liao and Chan 2000). Thus, the phenomenon of apoB 
degradation is not due to an intrinsic property of the protein, but rather a feature of cultured hepatoma cell lines and hepatocytes.

\subsubsection{Lipid avability}

The major regulatory substrates in the VLDL assembly process are fatty acids. Fatty acids can be derived from three sources: from plasma fatty acids bound to albumin, from plasma triglyceride-fatty acids delivered via lysosomal hydrolysis of internalised remnant lipoproteins and from de novo lipogenesis (Zhang et al. 2004). However, the contribution each of these sources to the amount of triglycerides secreted in the form of lipoproteins remains unclear. Most of the studies concerning the effect of exogenous albumin-bound fatty acids as a direct stimulus of VLDL assembly and secretion gave contradictory findings, which can result from different doses and various kinds of fatty acids used in the experiments. Furthermore, the route of delivery of fatty acids might be critical for its influence on apoB secretion (Zhang et al. 2004). Changes of the nutritional and hormonal status of animals in in vivo experiments might also explain the differences.

It appears that in many studies stimulation with oleic acid increases apoB secretion, however without concomitant stimulation of triglycerides secretion (Pan et al. 2002; Zhang et al. 2004). Nevertheless, it seems that there is no clear correlation between simple altered flux of fatty acids, triglyceride content within the cells or in the liver and VLDL secretion.

\subsubsection{Role of LDL receptor in regulation of VLDL production}

The LDL receptor might have an interesting role in the regulation of VLDL secretion. It has been observed that apoB secretion from hepatocytes derived from LDL receptor-deficient mice was 3.5 fold higher than that from wild-type hepatocytes (Twisk et al. 2000). The authors hypothesied that intracellularly sequestered LDL-receptor might interact with nascent VLDL to target it to presecretory degradation.

\subsubsection{Modulators of apoB secretion}

The hepatic production of VLDL is subjected to hormonal regulation and can be also modulated by other substances.

Insulin, which is generally considered to increase fatty acid and triglyceride synthesis in the liver, has an inhibitory effect on VLDL secretion, at least in the short term 
(Bartlett and Gibbons 1988).

Thyroid hormones can regulate apoB secretion by modulating apoB mRNA editing and transcription. They were shown to increase apoB mRNA editing in vivo (Davidson et al. 1988), but have no effect in vitro (Lorentz et al. 1996). Growth hormone has direct effects on the production of apoB-containing lipoproteins in hepatocytes, including increased apoB mRNA editing, triglyceride synthesis and preferential secretion of apoB-48-VLDL (Linden et al. 2000). Glucocorticoids stimulate VLDL secretion in vivo (Krausz et al. 1981), and in isolated hepatocytes (Martin-Sanz et al. 1990). A synthetic glucocorticoid which can be easily used in cell culture conditions or during perfusion experiments is dexamethasone. Incubation of hepatic cells with dexamethasone promotes the secretion of apoB-containing lipoproteins by increasing the sythesis of apoB100 and apoB48 and by decreasing the intacellular degradation of newly synthesised apoB (Wang et al. 1995b).

\subsection{Central role of the liver in lipoprotein metabolism}

The liver is the central organ in the synthesis and catabolism of lipoproteins in the mammalian organism. It also plays a key role in maintance of lipid and lipoprotein homeostasis and is principally responsible for maintaining cholesterol balance. It is the place of VLDL assembly and secretion, as described above (1.4) and of pre-HDL/discoidal HDL synthesis. (1.2). The liver removes major proportions of chylomicron remnants, IDL and LDL from the circulation.

\subsubsection{Uptake of LDL}

The clearance of LDL cholesterol from the plasma is primarily mediated by LDL receptors. The LDL receptor is a single-chain transmembrane glycoprotein that specifically binds two proteins, apoB and apoE. LDL receptors are mainly expressed in the liver, however they are also present on the surface of nearly all peripheral cells where the uptake of plasma LDL provides cholesterol for membrane synthesis and other requirements of these cells.

It has been shown in fibroblasts and smooth muscle cells that after binding to the cell surface LDL receptors, LDL is internalised via clathrin-mediated endocytosis (Fig. 1.4). The clathrin coat of the vesicle is degraded and the receptor-LDL complex is delivered to early endosomes and then to late endosomes, where the LDL particle dissociates from its receptor. LDL receptors recycle back to the plasma membrane, 
while cholesteryl esters are hydrolysed in the late endosomal/lysosomal compartment (Brown and Goldstein 1986). The number of LDL receptors is controlled by a negative-feedback system. When the intracellular cholesterol concentration rises, the transcription of the LDLR gene is suppressed and LDL is retained in the circulation. When the cholesterol concentration falls, LDLR expression is upregulated and LDL uptake is enhanced.

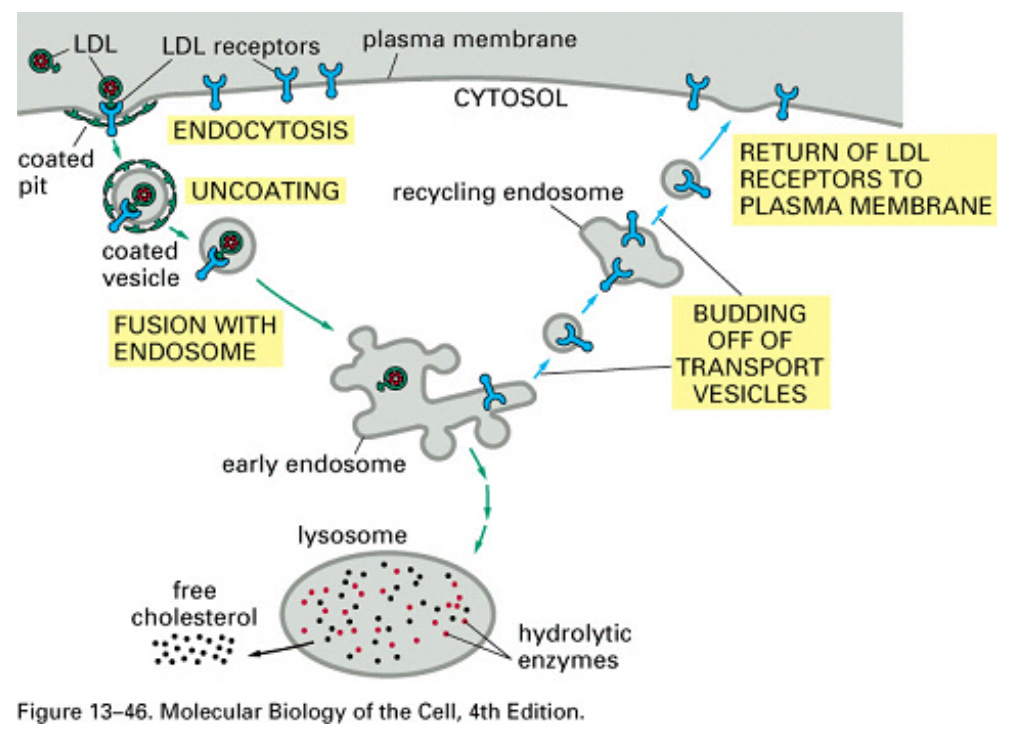

Figure 1.4: LDL receptor mediated endocytosis (Molecular Biology of the Cell, Bruce Alberts)

\subsubsection{Primary hepatocytes and hepatoma cell lines as a model of liver metabolism}

Hepatocyte cultures in vitro are an important tool for investigating liver function at the molecular level. However, the isolation and culturing process of liver cells is complicated and demands also advanced equipment. Specified cell culture conditions must be applied to mantain the physiological function of hepatocytes, like collagen coating plates, nutritious-rich medium. Furthermore primary hepatocytes have a very limited life span and must be freshly derived from mice for every experiment. That is the reason why hepatoma-derived cell lines are often used as a model for primary hepatocytes, including Hep3B, NPLC/PRF/5 (NPLC), Tong/HCC, Hep 10, huH1, 


\section{Introduction}

and huH2 and the most common HepG2 cell line (Forte et al. 1989). Although HepG2 has been found to retain many liver-specific functions and secretes many normal liver proteins, including apoB (Zannis et al. 1981), the lipoproteins that are secreted into the medium by that cell line differ in morphology and composition from those secreted by the liver. In contrast to primary rat and mouse hepatocytes no VLDLsized particles are detected within smooth endoplasmic reticulum or Golgi vesicles of HepG2 cells cultured under standardised conditions and very little material of the size or density of VLDL is observed in their medium (Thrift et al. 1986). After the stimulation by oleic acid the secretion of a triglyceride-rich VLDL-like particles in these cells is induced (Ellsworth et al. 1986).

Taking into account differences primary hepatocytes seem to be more adequate than hepatoma cells to a model to study the mechanism and the regulation of lipoprotein and apolipoprotein secretion in vitro.

\subsection{Aim}

The degradation of internalised LDL has been studied in human fibroblasts (Goldstein and Brown 1974), HepG2 hepatoma cells (Lombardi et al. 1993) and human hepatocytes (Edge et al. 1986). Several groups observed that in smooth muscle cells and fibroblasts a fraction of endocytosed LDL escapes the lysosomal degradation and is secreted in unaltered or only slightly altered form (Aulinskas et al. 1981; Greenspan and St Clair 1984), in a process termed retroendocytosis. Edge et al. (1986) also observed that in hepatocytes, less of the endocytosed apoB100 is degraded than in skin fibroblasts. Both observations indicate that the degradation of LDL-derived apoB100 may be not the only metabolic pathway for that protein.

The aim of this study was to analyse the metabolic fate of endocytosed LDL in primary mouse hepatocytes and in the mouse liver. To this end we wanted to determine the uptake and metabolism of the protein and lipid part of LDL by primary mouse hepatocytes. We have investigated the recycling of LDL-derived protein componentapoB100 under in vitro and in vivo conditions. Finally, in the present study we have begun to analyse the intracellular pathway of recycled LDL-derived apoB100 and its lipidation site. 


\title{
2 Material
}

\subsection{Laboratory equipment:}

\author{
Apparatus \\ Producer \\ Analytic balances type $1602 \mathrm{MP}, 1265 \mathrm{MP}$ \\ Sartorius, Goettingen \\ Aquapore RP-300 (C8, $2.1 \times 220 \mathrm{~mm}$ ) \\ Intelligent Dark Box II, Las-1000+ \\ Fuji, Japan \\ Ice machine \\ Ziegra Isernhagen \\ Eppendorf centrifuge Type 5415C and 5402 \\ Eppendorf, Hamburg \\ Beckmann, Muenchen \\ Beckmann, Muenchen \\ Ulracentrifuge L8-70M \\ Labofuge GL \\ Heraeus Sepatech \\ Ti 45, Ti 60, Ti 70 \\ Beckmann, Muenchen \\ TLA-100.3 \\ Beckmann, Muenchen \\ Electrophoresis chambers for \\ polyacrylamide gels \\ Bio-Rad, Hilden \\ Liquid scintillation counter 1900TR \\ Wizard 1470 Gamma counter \\ Packard, Frankfurt/Main \\ Perkin Elmer, Freiburg \\ Gel dryer \\ Bio-Rad, Hilden \\ Magnetic mixer \\ IKA Works, INC. \\ pH-Meter Beckmann \\ Muenchen \\ Photometer, UV \\ Eppendorf, Hamburg \\ Vortex \\ Confocal Laser Scanning Microscope \\ Genie Scientific Industries, USA \\ Leica, Bensheim \\ Cell Incubators \\ Phosphoimager Fujix BAS1000 \\ Labotecht \\ Fuji, Japan \\ Ultra turrax T8 \\ IKA Labortechnik, Staufenv \\ Tube slicer \\ Beckmann, Muenchen \\ Quick-seal polyallomer centrifugation tubes \\ Thermonixer \\ Beckmann, Muenchen \\ Eppendorf, Hamburg
}


SterilGard Hood, class II

HPTLC 60 plates

TLC plate scanner

Oxygenator
Baker Compaby Inc, sanford, Maine

Merck

Camag

B.Kump Duesseldorf

\title{
2.2 Plasticware and membranes
}

\author{
Material \\ Cell culture plasticware \\ Nitrocellulose membrane \\ Whatman GB002 paper \\ Whatman GB003 paper extra thick \\ Amicon Ultra
}

Producer

Greiner, Frickenhausen

Nalge Nunc International, Denmark

Schleich and Schuell, Dassel

Schleich and Schuell, Dassel

Schleich and Schuell, Dassel

Millipore Corporation, USA

\subsection{Chemicals, kits and ready-to-use reagents}

\subsubsection{Chemicals}

Boehringer/Roche, Mannheim

Merck, Darmstadt

Roth, Karlsruhe

Serva, Heidelberg

Sigma, Deisenhofen

\subsubsection{Reagents}

\section{Reagents}

Bio-Rad Protein Assay

DAKO fluorescent mounting medium

ECL Plus

Protease Inhibitor Cocktail

PD-10 Sephadex G-25 M column

PANSORBIN cells

Protein $\mathrm{G}$ agarose

\section{Producer}

Bio-Rad, Muenchen

DakoCytomation, USA

Amersham Biosciences

Sigma, Deisenhofen

Amersham Pharmacia Biotech

Calbiochem

Sigma, Deisenhofen 
Prestained Marker

Insulin

Rat tail collagen type VII

Percoll

Optiprep
Biorad, Muenchen

Sigma, Deisenhofen

Sigma, Deisenhofen

GE-Healthcare

Axis-Shield

\subsubsection{Reagents for cell culture}

\section{Reagents}

Dulbecco modified Eagle-Medium - DMEM

FBS - Fetal Bovine Serum

L-Glutamine - $100 \times$

Penicillin/Streptomycin - $100 \times$

Sodium pyruvate $-100 \times$

Trypsine/EDTA $-1 \times$

\section{Producer}

Sigma, Taufkirchen

PAN Biotech

Gibco/Invitrogen

Gibco/Invitrogen

Sigma

Gibco/Invitrogen

\subsection{Radioactive isotopes}

\section{Substance}

${ }^{35}$ S-Methionine/Cysteine mix

Sodium - ${ }^{125} \mathrm{I}$

${ }^{3} \mathrm{H}$-cholesteryl linoleate

\section{Producer}

Amersham Pharmacia Biotech

Hartmann Analytic

Hartmann Analytic

\subsection{Primary antibodies}

Santa Cruz, CA, USA

Nordic Immunology

BD Transductions Laboratories

\subsection{Secondary antibodies}

Goat anti-rabbit Horseradish peroxidase conjugate

Goat anti-mouse Horseradish peroxidase conjugate 
Goat anti-rabbit $\mathrm{Cy} 2$ conjugate

Goat anti-mouse $\mathrm{Cy} 2$ conjugate

Goat anti-rat $\mathrm{Cy} 2$ conjugate

Secondary antibodies were purchased from Dianova, Hamburg and BD Transductions Laboratories

\subsection{Animals}

C37B6 


\section{Methods}

\subsection{Animals}

Mice and rats were maintained under standardised room temperature $\left(20-24^{\circ} \mathrm{C}\right)$ and humidity in the institute's animal facility. The animals had free access to standard laboratory chow (rat and mouse standard diet) and water. Before the preparation of hepatocytes, the perfusion of livers or the injection of LDL at the tail vein, the animals were hungered for 4 hours.

\subsection{Cell culture}

\subsubsection{Preparation of lipoprotein-deficient serum}

\section{Buffer A}

$0.15 \mathrm{M} \mathrm{NaCl}$

$250 \mathrm{mM}$ EDTA

Potassium bromide (Roth)

$\mathrm{AgNO}_{3}$ (Sigma)

Lipoprotein-deficient serum (LPDS) was prepared from fetal-calf serum (FCS) by ultracentrifugation in self-generating potassium bromide gradient in a Beckman Ti70 rotor at $265000 \times \mathrm{g}$ for 32 hours at $4^{\circ} \mathrm{C}$. The density of FCS was adjusted to $\mathrm{d}=1.21 \mathrm{~g} / \mathrm{ml}$, using the formula given in 3.5. After centrifugation, the upper half of the solution was discarded (to $\mathrm{d}=1.21 \mathrm{~g} / \mathrm{ml}$ ) and the bottom half (LPDS) was dialyzed extensively against buffer A before use, to free the serum of potassium bromide. The reaction of silver nitrate with potassium bromide forms silver bromide $(\mathrm{AgBr})$, a pale-yellow, insoluble salt. To control the efficiency of dialysis an aliquot of $0.5 \mathrm{ml}$ LPDS was combined with $100 \mu \mathrm{l} 1 \%$ silver nitrate and the reaction was visually examined to exclude salt formation.

The efficiency of the lipoprotein-deficient serum preparation was controled by determination of cholesterol amount in LPDS sample. Routinely, less than $1 \%$ of normal 
FCS level of cholesterol was detectable in LPDS preparations.

Protein content of LPDS was determined by Bradford method with BSA as the standard (3.6.2) and serum was diluted with buffer A to a concentration of $50 \mathrm{mg} / \mathrm{ml}$ if needed. LPDS was filtered through a 0.22 micron filter and stored in $20 \mathrm{ml}$ portions at $-20^{\circ} \mathrm{C}$.

\subsubsection{Hepatocyte preconditioned medium preparation}

Dulbecco's Modified Eagle's Medium (Gibco)

Lipoprotein deficient serum (LPDS) (3.2.1)

Hepatocytes were cultured in DMEM/10 \% LPDS for 16 hours. The medium was removed, ultracentrifuged at $100000 \times \mathrm{g}$ and sterile filtered. It was stored at $-20^{\circ} \mathrm{C}$.

\subsubsection{Isolation of hepatocytes}

\section{Anaesthetic Mixture}

$1 \mathrm{ml}$ Rompun

$1 \mathrm{ml}$ Ketamin

$8 \mathrm{ml} 0.9 \% \mathrm{NaCl}$

Buffer 1, 10× stock

$1.4 \mathrm{M} \mathrm{NaCl}$

$50 \mathrm{mM} \mathrm{KCl}$

$8 \mathrm{mM} \mathrm{MgCl}_{2} 6 \times \mathrm{H}_{2} \mathrm{O}$

$16 \mathrm{mM} \mathrm{Na}_{2} \mathrm{HPO}_{4}$

$4 \mathrm{mM} \mathrm{KH}_{2} \mathrm{PO}_{4}$

Perfusion Buffer-KHB

$100 \mathrm{ml}$ Buffer 1

$2.1 \mathrm{~g} / 1 \mathrm{NaHCO}_{3}$

$0.745 \mathrm{~g} / 1$ EDTA

$2.97 \mathrm{~g} / \mathrm{l}$ Glucose

$0.846 \mathrm{~g} / 1$ Lactat (Sigma)

$0.022 \mathrm{~g} / \mathrm{l}$ Pyruvat (sigma)

sterile water to 1 litr

pH 7.4, steril filtered

Williams' E medium (Sigma)

Dulbecco's Modified Eagle's Medium (Gibco)

Fetal Calf serum (Gibco) 


\section{Collagen IV from rat (Sigma)}

Rat or mouse hepatocytes were prepared by liver perfusion with EDTA dissociation followed by Percoll centrifugation (Meredith 1988).

Mice and rats were anaesthetized with an anaesthetic mixture (40 $\mu \mathrm{g}$ Xylazinum and $200 \mu \mathrm{g}$ Ketamin per gram of body weight). A 23 gauge butterfly needle was inserted into the abdominal vena cava and the liver was perfused over portal vein with $500 \mathrm{ml}$ of Perfusion Buffer using a rate of $10 \mathrm{ml}$ per minute. After the perfusion, the liver was disrupted in $50 \mathrm{ml}$ Williams' E medium and filtered through a $100 \mu \mathrm{m}$ pore size nylon cell strainers. The cell suspension was centrifuged at $800 \times \mathrm{g}$ for 4 minutes to remove unviable and non-hepatocytic cells, floated on top of supernatant. The pellet of hepatocytes was resuspended in $8 \mathrm{ml}$ Williams E medium, mixed with $13.9 \mathrm{ml}$ Percoll and $2.1 \mathrm{ml}$ Buffer 1 and centrifuged again for 4 minutes at $1000 \times \mathrm{g}$, to remove unviable cells once more. The cell pellet was finally resuspended in $10 \mathrm{ml}$ Williams' E medium and viability of the cells was assessed by trypan blue exclusion. The cells were counted in a Bürker chamber and plated onto $100-\mathrm{mm}$ rat collagen IV-coated dishes at a density of 57000 viable cells per $\mathrm{cm}^{2}$ in Dulbecco's Modified Eagle's Medium (DMEM) supplemented with 10 \% FCS.

\subsubsection{Cell culture of hepatocytes}

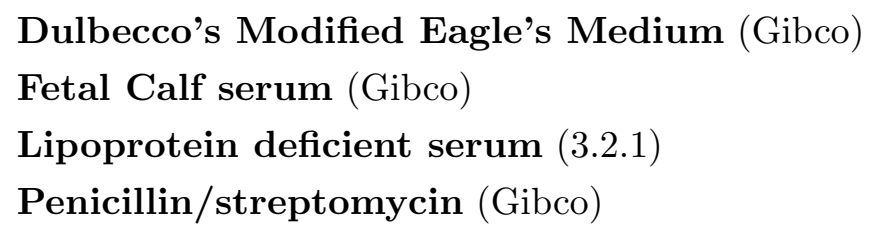

Hepatocytes were cultured at $37^{\circ} \mathrm{C}$ in $5 \% \mathrm{CO}_{2}$ in Dulbecco's Modified Eagle's Medium supplemented with $10 \%$ FCS and 100 units/ml penicillin/streptomycin, until the cells formed a monolayer (usually 4 hours). Then the medium was aspirated to remove unattached cells and a $5 \mathrm{ml}$ portion of DMEM with $10 \%$ LPDS was added. Hepatocytes were cultured under that conditions for the next 14 hours prior to in vitro experiments.

\subsubsection{Cell culture of MEF}

Dulbecco's Modified Eagle's Medium (Gibco)

Fetal Calf serum (Gibco) 


\section{Trypsin-EDTA (Gibco)}

Lipoprotein deficient serum (3.2.1)

MEF were routinely grown at $37^{\circ} \mathrm{C}$, in DMEM supplemented with $10 \% \mathrm{FCS}$, in 75 $\mathrm{cm}^{2}$ flasks. For experiments, the cells were dissociated from the flasks with $0.05 \%$ Trypsin/0.02 \% EDTA, transferred to 100-mm dishes and grown to $60 \%$ confluency in DMEM with 10 \% FCS. 14 hours before the experiment the cells were icubated in medium containing $10 \%$ LPDS, instead of whole calf serum.

\subsection{Lipoprotein biochemistry}

\subsubsection{Isolation of LDL}

Human plasma (University Hospital, Department of Transfusion)

Potassium bromide (Roth)

The characteristic densities of each lipoprotein class allow for its efficient isolation using floatation ultracentrifugation.

Low-density lipoproteins were isolated from human plasma in the $\mathrm{d}=1.019-1.063$

$\mathrm{g} / \mathrm{ml}$ density range by sequential ultracentrifugations (Goldstein et al. 1983).

All centrifugation steps were performed in QuickSeal centrifugation tubes (Beckmann) and appropriate gradient fractions were cut with tube slicer (Beckman).

The amount of $\mathrm{KBr}$ to be added in each step was calculated according to RADDING and STEINBERG (1960):

$$
(g) K B r=\frac{V\left(d_{f}-d_{i}\right)}{1-\left(0.312 \times d_{f}\right)},
$$

where:

$\mathrm{d}_{\mathrm{f}}$ is a desired density of the sample,

$d_{i}$ is an initial density of the sample,

0.312 is a specific volume of $\mathrm{KBr}$.

First, $200 \mathrm{ml}$ of plasma was adjusted to a density of $1.019 \mathrm{~g} / \mathrm{ml}$ with $\mathrm{KBr}$ and centrifuged at $400000 \times \mathrm{g}$ in a Beckman Ti70 rotor, at $4^{\circ} \mathrm{C}$ for 14 hours. The top layer containing VLDL and IDL particles was removed with a tube slicer.

The density of the remaining solution (containing LDL and HDL) was adjusted to a density of $1.063 \mathrm{~g} / \mathrm{mL}$ and was centrifuged at $450000 \times \mathrm{g}$ in a Beckman Ti90 rotor, at $4^{\circ} \mathrm{C}$ for 12 hours. The LDL, which floats at a relative density of 1.063 , was 
collected from the top of all gradient tubes, pooled and concentrated by additional recentrifugation, as before.

The resulting pure LDL fraction was applied onto a chromatography column (PD-10 Sephadex, Amersham) to remove $\mathrm{KBr}$ and eluted with PBS. The protein concentration was determined according to Bradford.

\subsubsection{Iodination of LDL}

Glycine buffer 1M, pH 10

Phosphate buffered saline

$10 \mathrm{mM}$ sodium phosphate $\mathrm{pH} 7.4$

$9 \%$ sodium chloride

pH 7.4

to $1000 \mathrm{ml}$ with water

Iodine monochloride solution

$10 \mu \mathrm{l} \mathrm{ICl}$

$2 \mathrm{M} \mathrm{NaCl}$

$0.1 \mathrm{M} \mathrm{HCl}$

Sodium ${ }^{125}$ I-iodine (Hartmann Analytic)

Low-density lipoproteins were iodinated according to iodine monochloride method (Bilheimer et al. 1972), which results in iodo-aromatic compounds formation. The iodine is introduced directly into aromatic molecules of aminoacid using iodine monochloride as donating agent.

$1 \mathrm{ml}$ phosphate - buffered saline (PBS) containing $5 \mathrm{mg}$ of freshly isolated LDL was adjusted to $\mathrm{pH} 10$ with $0.8 \mathrm{ml}$ glycine buffer. Then $0.5 \mathrm{mCi}{ }^{125} \mathrm{I}-\mathrm{Na}$ in $0.2 \mathrm{ml}$ glycine buffer was added, followed by $40 \mu \mathrm{l}$ iodine monochloride (ICl) solution. The reaction was gently mixed for 3 minutes.

The resulting iodinated lipoproteins were seperated from unbound ${ }^{125} \mathrm{I}-\mathrm{Na}$ by sequential chromatography on two PD-10 desalting columns (Amersham) and eluted with PBS.

The protein concentration was determined by Bradford assay (as described in 3.6.2) and the radioactivity was quantified using a Wizzard $\gamma$ counter (Perkin Elmer). The efficiency of isotope incorporation into the protein moiety of LDL was determined by protein precipitation with trichloric acid (TCA) at a final concentration of $12 \%$ (3.6.4) and a chloroform/methanol lipid extraction (3.8.1).

Routinely, there was less than $2 \%$ of the free iodine radioactivity and less than 2,5\% 
of lipid extractable radioactivity in the ${ }^{125} \mathrm{I}$-LDL preparations, which showed that $98 \%$ of the ${ }^{125}$ I-radioactivity were protein. The specific activities ranged from 300 to $600 \mathrm{cpm}$ per ng of protein. The ${ }^{125} \mathrm{I}-\mathrm{LDL}$ were kept at $4^{\circ} \mathrm{C}$ and used within 10 days.

\subsubsection{Fluorescence-labelled LDL preparation}

Cy3 mono - reactive dye (Amersham Bioscience)

$\mathrm{NaHCO}_{3} 1 \mathrm{M}$

PBS pH 7.4

Tris-HCl 1M, pH 7.4

The apolipoprotein part of LDL particles was covalently labelled with Cy3 dye according to the manufacturer's description (Amersham Bioscience).

N-hydroxysuccinimide (NHS)-ester functional group of the dye reacts with lysine residues of the protein, which results in covalent bonds between the dye molecules and the protein.

One tube of Cy3 dye (efficient to label $1 \mathrm{mg}$ of protein) was resuspended in $100 \mu \mathrm{l}$ PBS, just prior to starting the reaction. The reactive dye solution was combined to $1 \mathrm{mg}$ of LDL (diluted in $1 \mathrm{ml}$ of PBS), together with $120 \mu \mathrm{l} \mathrm{NaHCO}_{3}$. The dye labelling reaction was incubated for 30 minutes at room temperature, protected from light, and stopped by addition $200 \mu \mathrm{l}$ Tris- $\mathrm{HCl} \mathrm{pH}$ 7.4.

Fluorescence labelled LDL was purified using a PD-10 chromatography column and eluted in $1.5 \mathrm{ml}$ of PBS. The protein concentration was determined using the Bradford assay (3.6.2).

\subsubsection{Labelling of LDL with ${ }^{3} \mathrm{H}$-cholesteryl linoleate}

$1 \alpha, \mathbf{2} \alpha-{ }^{\mathbf{3}} \mathbf{H}$-cholesteryl linoleate (Amersham)

Bovine Albumine Serum fatty-acid free (Sigma) $2 \%$ in PBS (w/v)

PBS

EDTA $10 \mathrm{mM}$, pH 8.0

Human Cholesteryl Ester Transfer Protein -CETP (kindly gifted)

Cholesteryl Ester Transfer Protein can mediate the processes of remodelling of lipoproteins, such as transfer and exchange of lipids. In the method, described below, BSA-linked esterified cholesterol is transfered by this protein to low-density lipoproteins.

LDL was labelled with ${ }^{3} \mathrm{H}$-cholesteryl linoleate using the method of Paananen et al. 
(1995).

$100 \mu \mathrm{Ci}$ of ${ }^{3} \mathrm{H}$-cholesteryl linoleate in $100 \mu \mathrm{l}$ toluen was evaporated to dryness under a gentle stream of nitrogen and resuspended in $100 \mu \mathrm{l} \mathrm{BSA} .100 \mu \mathrm{l}$ EDTA and a portion of LDL $(5 \mathrm{mg} / \mathrm{ml})$ was added, followed by $50 \mu \mathrm{l}$ CETP solution. The reaction was incubated overnight at $30^{\circ} \mathrm{C}$ with gentle rotation. ${ }^{3} \mathrm{H}$-cholesteryl linoleate labelled LDL was purified with PD-10 chromatography column and eluted in PBS.

The protein concentration was determined using the Bradford assay (3.6.2). The activity of incorporated ${ }^{3} \mathrm{H}-\mathrm{CL}$ was $2095-4631 \mathrm{cpm} / \mathrm{nmol}$. The incorporation rate of cholesteryl linoleate was $0.40-0.49$ pmol per ng LDL. Greater than $98 \%$ of the ${ }^{3} \mathrm{H}$ from labelled LDL was in the lipid part of LDL, as was controled by Folch extraction.

\subsection{Endocytosis of LDL}

\subsection{1 ${ }^{125}$ I-LDL uptake experiment}

Experiments were initiated after the hepatocytes had been incubated for 16 hours with DMEM containing $10 \%$ LPDS. The culture medium was then replaced with $5 \mathrm{ml}$ of fresh medium with different doses of ${ }^{125} \mathrm{I}-\mathrm{LDL}$ (as indicated) and with or without a 30-fold excess of unlabelled LDL. The cells were allowed to endocytose

${ }^{125} \mathrm{I}-\mathrm{LDL}$ for different durations at $37^{\circ} \mathrm{C}$, in cell culture incubator.

The culture medium from the pulse period was removed for the determination of

${ }^{125} \mathrm{I}$-LDL degradation. The cells were then washed 3 times with $5 \mathrm{ml}$ of buffer B and once with $5 \mathrm{ml}$ of buffer $\mathrm{C}$, following a 1 hour incubation with $5 \mathrm{ml}$ of buffer $\mathrm{D}$ at $4^{\circ} \mathrm{C}$, with gentle rotation, to release the LDL-receptor bound LDL. The cells were rinsed with PBS, dissociated with trypsin-EDTA, pelleted by centrifugation and solubilised in $0.1 \mathrm{M} \mathrm{NaOH}$.

As a control to determine a $\gamma$-radioactive autoradiolysis, ${ }^{125} \mathrm{I}$-LDL was incubated without the cells in preconditioned medium (described in 3.2 .2 ) at $37^{\circ} \mathrm{C}$, at the same concentration and for the same durations as in the pulse experiment.

\subsubsection{Determination of LDL cell surface binding, internalisation and degradation during the pulse period}

The fraction of cell surface associated LDL was assessed by measuring the radioactivity in buffer D.

The amount of internalised LDL after the pulse period was determined by the radioac- 


\section{Methods}

tivity in the cell lysate. The cellular total protein content was determined according to Lowry et al. (1951)

To determine the degradation rate of ${ }^{125} \mathrm{I}-\mathrm{LDL}, 1 \mathrm{ml}$ aliquots of pulse media were subjected to TCA precipitation (described in 3.6.4). To a $1 \mathrm{ml}$ of TCA-soluble fraction (supernatant solution) $10 \mu \mathrm{l}$ of $40 \%$ (w/v) KI and $40 \mu \mathrm{l}$ of $30 \% \mathrm{H}_{2} \mathrm{O}_{2}$ were added. After incubation at room temperature for 10 minutes, the mixture was extracted with $2 \mathrm{ml}$ of chloroform to remove free iodine. $0.5 \mathrm{ml}$ of aqueous fraction was kept for scintillation counting (Wizzard gamma counter).

The same procedure was undertaken with cell-free controls. The difference between cells incubated with ${ }^{125} \mathrm{I}$-LDL and cell-free controls was regarded as an estimate of the hydrolysis of lipoprotein protein.

The final radioactivity count values were transformed to ng of ${ }^{125} \mathrm{I}$-apoB, taking into account the specific activity of ${ }^{125} \mathrm{I}-\mathrm{LDL}$ used in each experiment. All values were also normalized to the total cell protein.

\subsection{2 ${ }^{125}$ I-LDL pulse-chase uptake and chase experiment}

Hepatocytes were cultured on $10 \mathrm{~cm}$ plates in lipoprotein deficient medium fo 16 hours. A dose of $5 \mu \mathrm{g} / \mathrm{ml}{ }^{125} \mathrm{I}$-LDL was added to a $5 \mathrm{ml}$ portion of DMEM/10\% LPDS for 1 hour. Under sterile conditions, the medium was removed and the cells were washed with the same buffers, as in the pulse experiment omitting buffer D. Fresh non-radioactive DMEM/LPDS was added to the dish and the cells were incubated for 10 hours (or up to 24 hours). The chase medium was then removed, the cells were washed and incubated with $5 \mathrm{ml}$ of buffer D for 1 hour. Finally the cells were trypsinised and lysed in $0.1 \mathrm{M} \mathrm{NaOH}$. Because the fraction of membrane-bound LDL which was not removed by the washing step can shed off the membrane into the medium during the chase period, two plates with cells were trypsynised just after the pulse time and the amount of ${ }^{125} \mathrm{I}-\mathrm{LDL}$ released by trypsine was determined. This value was substract from the TCA-precipitable medium radioactivity obtained from the chase points.

In the experiments with BFA and monensin treatment, hepatocytes on two 10-cm plates/condition were pulsed with $10 \mu \mathrm{g} / \mathrm{ml}^{125} \mathrm{I}$-LDL for 1 hour, washed and chased in DMEM/LPDS for 8 hours. During chase period BFA was added to final concentration of $5 \mu \mathrm{g} / \mathrm{ml}$ and monensin to $20 \mathrm{mM}$. Two 10-cm hepatocyte plates, were used as control and chased in DMEM/LPDS without the drugs. After the chase the medium was collected, pooled and a $0.5 \mathrm{ml}$ aliquot was used to determine the hydrolysis rate while the remaining media were analysed usingflotation ultracentrifugation gradient 
(3.5). The cells were solubilised in $0.1 \mathrm{M} \mathrm{NaOH}$ and the intracellular amount of ${ }^{125} \mathrm{I}-$ apoB was determined.

The pulse-chase experiment with low temperature conditions was performed essentialy in the same manner. The hepatocytes on two 10 -cm plates were pulsed with $10 \mu \mathrm{g} / \mathrm{ml}$ ${ }^{125} \mathrm{I}-\mathrm{LDL}$ at $16^{\circ} \mathrm{C}$ for 1 hour and chased for 8 hours at $16^{\circ} \mathrm{C}$. Two other hepatocyte plates were pulsed with the same amount of ${ }^{125} \mathrm{I}-\mathrm{LDL}$ for 1 hour at $37^{\circ} \mathrm{C}$, following the 8 hour chase at $16^{\circ} \mathrm{C}$. As a control two plates with the cells were pulsed and chased at standard, $37^{\circ} \mathrm{C}$ temperature. The analysis of media and cell lysate was performed as it was described above.

\subsubsection{Determination of LDL cell surface binding, internalisation, secretion and degradation during the chase period}

$1 \mathrm{ml}$ of collected chase media were first measured for $\gamma$-decay and then subjected to TCA precipitation. The TCA-soluble fractions were further analysed to determine LDL hydrolysis rate (as described in pulse experiment). The TCA-precipitable fractions (pellets) were also counted, as they reflected the intact ${ }^{125}$ I-material that had been secreted by the cells during the chase period. The sum of iodine counts coming from hydrolysis, shedding and secretion should be equal or close to the total number of counts, measured at the beginning in $1 \mathrm{ml}$ of chase medium.

The fraction of cell membrane-bound and intracellular LDL was determined, as in the pulse time experiment.

\subsubsection{Fluorescence labelled LDL pulse-chase time procedure}

Mouse or rat hepatocytes were seeded on round coverslips at a density of 150000 cells per coverslip and cultured in DMEM/10 \% LPDS for 12 hours. After this time $10 \mu \mathrm{g} / \mathrm{ml} \mathrm{Cy3-conjugated} \mathrm{LDL} \mathrm{was} \mathrm{added} \mathrm{and} \mathrm{the} \mathrm{cells} \mathrm{were} \mathrm{incubated} \mathrm{for} 2$ hours at $37^{\circ} \mathrm{C}$ in $5 \% \mathrm{CO}_{2}$, under light protection. After removing the pulse medium, the cells were carefully washed 3 times with PBS and further incubated with a portion of fresh DMEM/10 \% LPDS medium for 1 or 4 hours. After each chase time the cells were again washed and subjected to immunofluorescence analysis.

Some cells were analysed immediately after removing the pulse medium.

\subsection{4 ${ }^{3} \mathrm{H}$-labelled LDL uptake experiment}

Hepatocytes were cultured in DMEM/10 \% LPDS for 16 hours, after which a fresh portion of medium containing $50 \mu \mathrm{g}{ }^{3} \mathrm{H}-\mathrm{CL}-\mathrm{LDL} / \mathrm{ml}$ (labelled as described in 3.3.4) 
was added for different durations, up to 10 hours. After each pulse time point, the cells were washed 3 times with buffer B and once with buffer C. Finally they were trypsynised and lysed in $0.1 \mathrm{M} \mathrm{NaOH}$.

The total protein content was determined according to Lowry et al. (1951) (3.6.3). The lysate was neutralised with $0.1 \mathrm{M} \mathrm{HCl}$ and its lipid content was extracted (3.8.2) and analysed with TLC (3.8.3).

\subsection{5 ${ }^{125}$ I-LDL pulse-chase time in vivo procedure with mouse liver perfusion}

The liver was perfused as described by Schliess et al. (1997) with some modifications. Mice were anaesthesised by an injection of $40 \mu \mathrm{g}$ Xylazinum and $200 \mu \mathrm{g}$ Ketamin per gram of body weight. The liver was perfused with KHB buffer (3.2.3) with a flow rate of $5 \mathrm{ml} / \mathrm{min}$. After 30 minutes, ${ }^{125} \mathrm{I}-\mathrm{LDL}$ was injected into the perfusion flow (using an automatic perfusor) for 20 minutes at a concentration of $10 \mu \mathrm{g}$ per ml perfusion buffer. Then KHB alone was given for 3 minutes, followed by 9 minute perfusion with KHB supplemented with $100 \mathrm{U} / \mathrm{ml}$ heparin. Finally KHB alone was given for 45-120 minutes.

The flow-out from the ligated, cannulated upper Vena cava inferior was collected in $15 \mathrm{ml}$ fractions, every 3 minutes. The organ's viability was monitored by measurement the glucose concentration and the lactic dehydrogenase activity in every fraction. Only data from experiments with a maximum LDH activity of $200 \mathrm{mU} / \mathrm{ml}$ and glucose levels below $200 \mathrm{nmol}$ per $\mathrm{ml}$ perfusion flow-through were analysed. After the experiment, the liver was weighed and its protein content and its total radioactivity were determined. The perfusion flow-out was subjected to further analysis.

\subsection{6 ${ }^{125} \mathrm{I}-\mathrm{LDL}$ pulse time procedure in living mouse}

In a single experiment nine mice were intravenously injected through the portal vein with $1.5 \mu \mathrm{g}{ }^{125} \mathrm{I}$-LDL per gramm body weight. One hour after the injection, 3 mice were killed, their blood and livers were taken. At the same time point, the remaining 6 mice were injected with $500 \mathrm{ng}$ Tyloxapol (Triton WR-1339) per gramm body weight, which prevented the catabolism of triglyceride-rich lipoproteins (VLDL) by lipoprotein lipase (Ishikawa and Fidge 1979). Three mice were killed 1 hour after the triton injection and three mice 4 hours thereafter. The blood from each animal was collected in tubes with heparin and centrifuged at $1000 \times \mathrm{g}$ for 5 minutes to separate serum. The livers were removed, weighed and their ${ }^{125} \mathrm{I}$-apoB content was determined. 
The serum samples were subjected to floatation ultracentrifugation gradient.

\subsection{Seperation of lipoproteins according to their density by floatation gradient ultracentrifugation}

${ }^{125} \mathrm{I}$-apoB - containing lipoproteins secreted into the cell culture medium or present in mouse plasma and perfusion flow-out were analysed by sequential floatation ultracentrifugation (Schumaker and Puppione 1986). At solvent densities higher than the lipoprotein density, lipoprotein particles float at rates dependent on their densities and sizes. Thus, the lipoprotein classes are seperated by stepwise increases in the solvent density through the addition of salts such as KBr. The particles of the least density (VLDL) float on the top of KBr gradient, while the lipoproteins of higher density are localised lower in the gradient tube.

$1 \mathrm{ml}$ of concentrated medium sample or $1 \mathrm{ml}$ of mouse plasma was first brought to a density of $1.3 \mathrm{~g} / \mathrm{ml}$ by the addition of solid potassium bromide $(\mathrm{KBr})$. The sample was then underlayered into a discontinuous $\mathrm{KBr}$ gradient, that was formed by layering from the bottom of the tube the following different densities of $\mathrm{KBr}$ solutions:

\begin{tabular}{cc} 
volume & density of KBr sol \\
\hline $3.2 \mathrm{ml}$ & $1.2 \mathrm{~g} / \mathrm{ml}$ \\
$3.3 \mathrm{ml}$ & $1.063 \mathrm{~g} / \mathrm{ml}$ \\
$3.8 \mathrm{ml}$ & $1.019 \mathrm{~g} / \mathrm{ml}$ \\
$1.1 \mathrm{ml}$ & $1.006 \mathrm{~g} / \mathrm{ml}$
\end{tabular}

The tubes were subjected to ultracentrifugation in a SW-40 rotor (Beckmann) at $130000 \times \mathrm{g}$ for 16 hours at $14^{\circ} \mathrm{C}$.

As a $\mathrm{KBr}$ quenching control, one tube was loaded with $1 \mathrm{ml}$ of unlabelled concentrate obtained from the same amount of non-radioactive preconditioned medium as radioactive chase samples. As an additional control for in vitro experiments, ${ }^{125} \mathrm{I}$-LDL was incubated at $37^{\circ} \mathrm{C}$ in preconditioned medium at a concentration of $5 \mu \mathrm{g} / \mathrm{ml}$ for the same duration as the chase period and also concentrated. Controls were centrifuged in the same way as samples.

After ultracentrifugation, fractions of $500 \mu \mathrm{l}$ were collected from each tube and their radioactivity was determined.

To each KBr quenching control fraction, ${ }^{125} \mathrm{I}-\mathrm{LDL}$ with an activity of $25000 \mathrm{cpm}$ was added, mixed and $\gamma$-decay measurements were performed. The ratio of this $\mathrm{KBr}-$ quenched measurements to the orginal $25000 \mathrm{cpm}$ was calculated and fraction values obtained from sample gradients were adequately normalised by multiplying with the 
reciprocal of the quenching ratio.

\subsection{Protein analysis}

\subsubsection{Apolipoprotein B analysis}

\subsubsection{Depipidation of apoB}

Sodium deoxycholate (DOC) $3.6 \mathrm{mM}$

Trichloroacetic acid (TCA) $4.9 \mathrm{M}$

Diethyl eter $1 \mathrm{mg} / \mathrm{ml}$

Sample buffer

$0.125 \mathrm{M}$, pH 6.8 Tris buffer

$4 \%$ SDS

$10 \% \beta$ mercaptoethanol $(\mathrm{v} / \mathrm{v})$

$20 \%$ glycerol

$0.05 \%$ bromophenol blue

Pooled KBr gradient fractions containing VLDL or LDL particles were delipidated according to Mindham and Mayes (1992).

Lipoprotein sample was shaken with $10 \mathrm{ml}$ of diethyleter for 2 minutes. DOC $(0.2 \mathrm{ml})$ and TCA $(0.2 \mathrm{ml})$ were added and mixed briefly. The contents were allowed to settle and the organic phase of diethyleter was carefully removed by aspiration, the remaining phase was evaporated using a gentle stream of nitrogen. The lower phase, containing apolipoproteins B, was centrifugated at $3000 \times \mathrm{g}$ for 20 minutes. The supernatant was decanted. Pelleted apolipoproteins were dissolved in sample buffer and neutralized by dropwise addition of $0.5 \mathrm{M} \mathrm{NaOH}$. After the incubation at $80^{\circ} \mathrm{C}$ for 5 minutes the samples were subjected to SDS-PAGE.

\subsubsection{Seperation of ${ }^{125} \mathrm{I}$-apoB by SDS-PAGE}

The apolipoprotein samples were analysed by polyacrylamide gel electrophoresis in the presence of SDS, as described by Laemmli (1970).

The samples were dissolved in SDS-PAGE sample buffer and resolved on a gradient gel. A linear gel gradient in the range of 3-16\% was poured with 3 and $16 \%$ resolving gel solution, using Gradient Former (Bio-rad).

Electrophoresis was run at $100 \mathrm{~V}$ in a chamber filled with $1 \times$ electrophoresis buffer, for 1.5 hour. The gel was dried and subjected to autoradiography. 


\title{
3.6.2 Protein estimation with Bradford assay
}

\author{
Bovine Albumin Serum 1mg/ml \\ Bio-Rad Bradford reagent (Bio-Rad)
}

The Bradford protein assay is a procedure for the determination of protein concentrations in solutions that depends upon the change in absorbance in Coomassie Blue G-250 upon binding of protein (Bradford 1976).

A standard curve was made using BSA in the range of 2-16 $\mu$ g per reaction. 2-5 $\mu \mathrm{l}$ of the sample was used for the protein determination. The sample and standard curve reaction volumes were made up to $800 \mu \mathrm{l}$ with water. $200 \mu \mathrm{l}$ of the BioRad reagent was added, reactions were vortexed and incubated for 5-10 min at room temperature. Then $200 \mu \mathrm{l}$ from each tube was pipetted into ELISA strips and optical density was measured at $595 \mathrm{~nm}$ in the ELISA reader.

\subsubsection{Protein estimation with Lowry assay}

Bovine Albumin Serum 1mg/ml

Solution A

$2 \% \mathrm{Na}_{2} \mathrm{CO}_{3}$ in $0.1 \mathrm{M} \mathrm{NaOH}(\mathrm{w} / \mathrm{v})$.

Solution B1

$1 \% \mathrm{CuSO}_{4} \times 5 \mathrm{H}_{2} \mathrm{O}\left(\right.$ in $\left.\mathrm{H}_{2} \mathrm{O}\right)(\mathrm{w} / \mathrm{v})$

Solution B2

$2 \% \mathrm{NaK}$ tartrate (in $\left.\mathrm{H}_{2} \mathrm{O}\right)(\mathrm{w} / \mathrm{v})$

Folin \& Ciocalteu's phenol reagent, 2 M (Sigma)

Under alkaline conditions, copper complexes with protein. When folin phenol reagent (phospho-molybdic-phosphotungstic reagent) is added, it binds to the protein. Bound reagent is slowly reduced and changes color from yellow to blue (Lowry et al. 1951).

3-5 $\mu \mathrm{l}$ of analysing samples and bovine serum albumin in the range of 2-16 $\mu \mathrm{g}$ (standard samples) were made up to $100 \mu \mathrm{l}$ with water. A mixture of solutions A, B1, B2 in the ratio 100:1:1 was freshly prepared and $0.8 \mathrm{ml}$ of it was added to each tube. After 10 minute incubation at room temperature, $100 \mu \mathrm{l}$ of Folin reagent (diluted 1:2 in water) was added and the samples were allowed to incubate for next 20 minutes. $200 \mu \mathrm{l}$ from each reaction tube was pipetted into ELISA strips and optical density was measured at $620 \mathrm{~nm}$ in the ELISA reader. 


\subsubsection{TCA protein precipitation}

TCA precipitation was used to estimate the amount of radioactivity incorporated into proteins.

For this purpose trichloroacetic acid (TCA) was added into the samples to a final concentration of $10-12 \%(\mathrm{v} / \mathrm{v})$. After 45 minute incubation on ice and centrifugation at $10000 \times$ g for 30 minutes, the pellet or supernatant was subjected to the next procedures.

\subsubsection{SDS-PAGE}

\section{$10 \mathrm{ml}$ Stacking Gel}

$6.1 \mathrm{ml} \mathrm{H}_{2} \mathrm{O}$

$1.3 \mathrm{ml} 30 \%$ acrylamide/bis-acrylamide (29:1) solution

$2.5 \mathrm{ml} \mathrm{0.5} \mathrm{M} \mathrm{Tris-HCl} \mathrm{pH} \mathrm{6,8}$

$100 \mu 110 \%$ SDS

$50 \mu 110 \%$ ammonium persulfate (APS)

$5 \mu \mathrm{lN}$ 'N'N'-tetramethylethylene diamine (TEMED)

$10 \mathrm{ml}$ Resolving Gel (10\%)

$4.1 \mathrm{ml} \mathrm{H}_{2} \mathrm{O}$

$3.3 \mathrm{ml} 30 \%$ acrylamide/bis-acrylamide (29:1) solution

$2.5 \mathrm{ml} 0.5 \mathrm{M}$ Tris-HCl pH 6.8

$100 \mu \mathrm{l} 10 \%$ SDS

$50 \mu 110 \%$ APS

$5 \mu \mathrm{l}$ TEMED

Protein Sample buffer

$10 \%$ Glycerol

$50 \mathrm{mM}$ Tris- $\mathrm{HCl} \mathrm{pH} 6.8$

$2 \mathrm{mM}$ EDTA

$2 \% \operatorname{SDS}$

$144 \mathrm{mM} \beta$-mercaptoethanol

$0.05 \%$ bromophenol blue

$10 \times$ electrophoresis buffer

$30.3 \mathrm{~g}$ Tris base

$144 \mathrm{~g}$ glycine

$100 \mathrm{ml} 10 \%$ SDS

filled with $\mathrm{H}_{2} \mathrm{O}$ to $1 \mathrm{l}$ 


\section{Methods}

SDS denaturates the polypeptide complex structure and provides a net negative charge which attracts the whole complex towards an anode (positively charged electrode) in an electric field. Since the polypeptide binds to SDS in proportion to its relative molecular mass, the final separation depends entirely on the differences in relative molecular mass of the polypeptides.

A discontinuous SDS-PAGE was performed according to Laemmli (1970).

SDS-PAGE was performed using Bio-Rad Mini-PROTEAN 3 unit and $1 \mathrm{~mm}$ combs. Discontinuous electrophoresis consisted of a $10 \%$ separating gel and a $4 \%$ stacking gel, prepared as indicated. The separating gel solution was carefully pipetted down between the glass plates, overlayed with $\mathrm{ddH}_{2} \mathrm{O}$ and allowed to polymerize at room temperature for $30 \mathrm{~min}$. After pouring off the overlaying $\mathrm{dd}_{2} \mathrm{O}$, the stacking gel solution was pipetted down and a comb was inserted. The gel was allowed to polymerize for $60 \mathrm{~min}$. The comb was removed and wells were rinsed with $\mathrm{ddH}_{2} \mathrm{O}$, which was discarded by aspiration.

Protein samples were solubilised and reduced in sample buffer, boiled at $95^{\circ} \mathrm{C}$ for 5 min and loaded onto the gel. Prestained molecular weight marker (range 15 000-250 000, Bio-rad) was used as standard. Electrophoresis was run at $90 \mathrm{~V}$ in a chamber filled with $1 \times$ electrophoresis buffer, typically for 1-1.5 hours.

\subsubsection{Western Blot}

\section{Transfer Buffer}

$3.03 \mathrm{~g}$ Tris base

$14.4 \mathrm{~g}$ glycine

$200 \mathrm{ml}$ methanol

filled with $\mathrm{H}_{2} \mathrm{O}$ to $1 \mathrm{l}$

\section{PBST}

\section{$0.1 \%$ Tween 20 in PBS}

\section{Blocking buffer}

$5 \%$ slim milk powder in PBST

Western blotting (or immunoblotting) allows to identify specific antigens recognised by polyclonal or monoclonal antibodies.

Following SDS-PAGE, the gel was shortly soaked in transfer buffer. A piece of nitrocellulose membrane $(0.2 \mu \mathrm{m}$, Bio-Rad) and 2 pieces of Whatman No.1 paper were cut to the same size as the gel and submerged in transfer buffer for 5 minutes before blotting. The Whatman papers, membrane and gel were placed in the blotting casette 
in an appropriate order and put into the blotting apparatus (Bio-Rad Mini-Protein System), filled with transfer buffer. The proteins in the gel were allowed to transfer for 1 hour at a constant current of 100 V. Pre-stained marker (Bio-rad) was run on the gels to serve as internal marker for transfer and molecular weight measurement. The membrane was stained with $0.2 \%$ Ponceau Red in $15 \%$ acetic acid solution for 5 minutes to visual protein bands and rinse afterwards in water until protein bands were distinct.

To block the non-specific binding sites, the blotted membrane was incubated in 50 $\mathrm{ml}$ of blocking buffer for 1 hour at room temperature with gentle shaking and washed once for 10 minutes in PBST solution. The membrane was then probed overnight at $4^{\circ} \mathrm{C}$ with the primary antibodies, at appropriate dilution in blocking buffer (indicated in table) and washed six times per 5 minutes in PBST solution. To detect bound antibodies, horseradish peroxidase-conjugated antibodies were diluted 1:2000 in blocking buffer and used as the secondary antibodies. The membrane was soaked in the secondary antibody solution with gentle shaking for 0.5 hour at room temperature and then washed six times for 5 minutes in PBST solution. The blot was developed using Super Signal enhanced chemiluminescence reagents (Pierce) and the fluorescence was detect with a CCD-camera.

\begin{tabular}{c|c|c} 
Target protein & Host & Dilution \\
\hline anti-mouse Calnexin & mouse & $1: 500$ \\
anti-mouse Syntaxin6 & mouse & $1: 5000$ \\
anti-mouse Rab5 & rabbit & $1: 400$ \\
anti-mouse Rab11 & rabbit & $1: 500$
\end{tabular}

Table 3.1: Primary antibodies used in Western Blot experiments

\begin{tabular}{c|c|c} 
Target species/conjugate & Host & Dilution \\
\hline anti-mouse HRP-conjugate & goat & $1: 2000$ \\
anti-rabbit HRP-conjugate & goat & $1: 2000$
\end{tabular}

Table 3.2: Secondary antibodies used in Western Blot experiments

\subsubsection{Subcellular fractionation}

\section{Homogenization buffer}


$0.25 \mathrm{M}$ sucrose

$1 \mathrm{mM}$ EDTA

$10 \mathrm{mM}$ Hepes/NaOH

pH 7.4

OptiPrep solution $60 \%(\mathrm{w} / \mathrm{v})$ iodixanol solution in water

All manipulations were carried out at $4^{\circ} \mathrm{C}$.

After in vivo liver perfusion, $0.2 \mathrm{~g}$ of the liver tissue was cut and homogenised in homogenization buffer, by using 7-10 tight strokes of a $7 \mathrm{ml}$ dounce tissue grinder (Wheaton, USA) and additional 5 passages through a 20 gauge needle. A mixture of protease inhibitors (Sigma) was added to minimize proteolysis.

Cell debris and unlysed cells were pelleted by low-speed centrifugation. The postnuclear and postmitochondrial supernatant was prepared by centrifugation of cleared homogenate at $3000 \times \mathrm{g}$ (in TLA 100.3 rotor) for 10 minutes at $4^{\circ} \mathrm{C}$.

OptiPrep is a ready-made solution of iodixanol, 5,5'-[(2-hydroxy-1-3 propanediyl)bis(acetylamino)] bis [N,N'-bis(2,3dihydroxypropyl-2,4,6-triiodo-1,3-benzenecarboxamide], designed for isolation of biological particles. The discontinuous OptiPrep gradient was formed by layering from the bottom of the tube $1 \mathrm{ml}$ of OpiPrep solution of the following concentrations: $30 \%, 25 \%, 20 \%, 15 \%, 12,5 \%, 10 \%, 7,5 \%, 5 \%, 2,5 \%$ (diluted in Homogenization buffer). The postmitochondrial homogenate was carefully loaded on the top of the gradient and centrifuged at $4^{\circ} \mathrm{C}$ fo 30 minutes at $126000 \times \mathrm{g}$ in SW41 rotor.

10 fractions of $1 \mathrm{ml}$ were collected from top to bottom and their radioactivity was determined. The purity of gradient fractions was assesed by determination of the specific activities and recoveries of the marker proteins for the corresponding organelles (as indicated in table 1.3). Protein concentration was determined using the Bradford method (Bio-rad) (3.6.2). The density of each fraction was determined using the pycometer calibrated for $1 \mathrm{ml}$ volume.

\begin{tabular}{c|c} 
Organelle & Protein \\
\hline ER & Calnexin \\
Golgi & Syntaxin 6 \\
early endosomes & Rab5 \\
recycling endosomes & Rab11 \\
lysosomes & $\beta$-Hexasaminidase
\end{tabular}

Table 3.3: Marker proteins 


\subsubsection{Cell metabolic labelling}

DMEM methionine and cysteine-free

${ }^{35} \mathrm{~S}-\mathrm{L}-\mathrm{methionine}$ and ${ }^{35} \mathrm{~S}-\mathrm{L}-\mathrm{cysteine}$ solution (Hartmann Analytic)

Cysteine-HCl (Serva)

Methionine (Serva)

Lysis buffer

Tris-HCl 50 mM, pH 7.4

NP-40 $1 \%$

Na-deoxycholate $0.25 \%$

$\mathrm{NaCl} 150 \mathrm{mM}$

EDTA $1 \mathrm{mM}$

Continuous labelling experiments were performed to determine the synthetic and secretion rate of albumin and de novo apoB by hepatocytes in cell culture.

After the initial overnight culturing period, hepatocytes, plated on $6 \mathrm{~cm}$ plates, were washed twice with PBS and incubated in methionine (Met) and cysteine (Cys) - free DMEM for 1 hour, to diminish the cellular pool of both amino acids in the cells. After this incubation, the media were replaced with $2.5 \mathrm{ml}$ of Met- and Cys - free DMEM per plate, containing $200 \mu \mathrm{Ci}$ of ${ }^{35} \mathrm{~S}$-L-methionine and ${ }^{35} \mathrm{~S}$-L-cysteine metabolic labelling solution, for 30 minutes pulse period. The media were then removed, the cells were washed 3 times with PBS and a portion of DMEM containing $10 \mathrm{mM}$ non-radioactive methionine and cysteine was added to each plate. Hepatocytes were cultured under these conditions for 8 hours (chase period).

At the end of chase period media were collected and briefly centrifuged to remove any cells and the cell monolayers were lysed in lysis buffer.

An aliquot of the chase media was taken to immunoprecipitate albumin and the rest was subjected to floatation gradient ultracentrifugation to determine the rate of secretion of newly synthesised apoB.

In the experiments with microsomal transfer protein inhibitor (MTP), $100 \mu \mathrm{M}$ MTP inhibitor resuspended in DMSO added to culture dishes to obtain final concentrations of $100 \mathrm{nM}, 250 \mathrm{nM}$ and $500 \mathrm{nM}$. MTP inhibitor was present in the medium 12 hours prior to pulse time and during the next steps of metabolic labelling experiment. The analysis of media was performed as it is described above. 


\subsubsection{Immunoprecipitation}

\section{PIMM}

$0.2 \%$ SDS

10 BSA

$0.5 \%$ Na-deoxycholat in PBS

$1 \%$ Triton-X-100

\section{IMM}

$0.5 \%$ Na-deoxycholat in PBS

$1 \%$ Triton-X-100

\section{Washing buffer}

$10 \mathrm{mM}$ Tris- $\mathrm{HCl} \mathrm{pH} 8,5$

$0.6 \mathrm{M} \mathrm{NaCl}$

$0.1 \%$ SDS

$0.05 \%$ Nonidet P-40

\section{IMM-KCl}

$2 \mathrm{M} \mathrm{KCl}$ in IMM buffer

\section{$2 \times$ Sample buffer}

$155 \mathrm{mg}$ DTT

$1 \mathrm{~g}$ SDS

$25 \mathrm{ml}$ 0,5M Tris- $\mathrm{HCl} \mathrm{pH} 6.8$

$10 \mathrm{ml}$ Glycerin

$15 \mathrm{ml}$ Water

Immunoprecipitation was carried out to determine the amount of ${ }^{35} \mathrm{~S}$-labelled albumin secreted into the chase supernatants.

For this purpose $0.8 \mathrm{ml}$ of PIMM buffer was added to each tube containing $1 \mathrm{ml}$ of the cell culture media from the chase period. Media were incubated at $4^{\circ} \mathrm{C}$ with gentle rotation for 2 hours and then centrifugated at $10000 \times \mathrm{g}$ for 5 minutes to remove any unsolubilised proteins. The resultanting supernatants were incubated with rabbit anti-mouse albumin antisera (Nordic Immunology) for 12 hours at $4^{\circ} \mathrm{C}$ and the immunoreaction complex was precipitated by 1 hour incubation with $20 \mu \mathrm{l}$ of protein A - agarose (Pansorbin, Calbiochem). After short centrifugation, the pelleted antibody-antigen complex was washed with $1 \mathrm{ml}$ Washing buffer, $1 \mathrm{ml}$ IMM, $1 \mathrm{ml}$ KCl-IMM and twice with $1 \mathrm{ml} 0.1 \times$ PBS. The immunoprecipitate was resuspended in $20 \mu \mathrm{l}$ of sample buffer and $20 \mu \mathrm{l}$ of water and heated for $5 \mathrm{~min}$ at $100^{\circ} \mathrm{C}$ to release pansorbin. Released Pansorbin particles were pelleted at $10000 \times \mathrm{g}$ for 1 minute and 
the supernatant was subjected to SDS-PAGE.

\subsubsection{Visualization of radioactively labelled proteins after SDS-PAGE}

Gel fractionated ${ }^{35} \mathrm{~S}$ - or ${ }^{125}$ I-labelled proteins were visualised by autoradiography. After SDS-PAGE gels were shortly washed in $\mathrm{ddH}_{2} \mathrm{O}$ and dried using gel drier (Biorad). The gels were then exposed on to a Fuji phosphoimaging screen overnight or longer period at room temperature. The signal captured on the screen was digitalised using a BAS 100 phosphoimager and visualised using the software Image reader (FujiFilm, Vers. 1.4 E).

\subsubsection{Immunofluorescence}

para-formaldehyde (PFA)

2 g PFA

$5 \mathrm{ml} \mathrm{H}{ }_{2} \mathrm{O}$

$100 \mu \mathrm{l}$ of $1 \mathrm{M} \mathrm{NaOH}$

incubation at $60^{\circ} \mathrm{C}$ for $1 \mathrm{~h}$

stored $4^{\circ} \mathrm{C}$

$0.5 \%$ saponin-PBS

$\mathrm{NH}_{4} \mathrm{Cl} 50 \mathrm{mM}$

Blocking buffer

$1 \% \mathrm{BSA}$

$0.1 \%$ saponin

in PBS

DAKO mounting medium

Hepatocytes were seeded on coverslips at a density of 150000 cells/coverslip. After finishing of the Cy3-labelled LDL pulse - chase experiment (3.3.3) the cells were were washed once with PBS and fixed with $4 \%$ PFA for 20 minutes at room temperature. After two washes with PBS, aldehyde groups were blocked by $50 \mathrm{mM} \mathrm{NH}_{4} \mathrm{Cl}$ for $10 \mathrm{~min}$ at room temperature. The cells were again washed twice with PBS and permeabilised for $10 \mathrm{~min}$ at room temperature with $0.5 \%$ saponin in PBS. After this step, all PBS solutions contained $0.1 \%$ saponin. Cells were incubated for at least 30 min in blocking buffer and incubated with appropriate primary antibody (diluted in blocking buffer), for 1 hour at $37^{\circ} \mathrm{C}$. Then cells were washed twice with PBS/saponin and incubated with secondary antibody coupled with flurochrome for $30 \mathrm{~min}$ at $37^{\circ} \mathrm{C}$ (primary and secondary antibodies used in the experiments are shown in table ??. 
Cells were then washed again several times in PBS/saponin, incubated for 1 minute with DAPI dye (which was diluted 1:10 000 in PBS) and washed with PBS.

Finally, the coverslips were placed upside-down on object slides in embedding buffer (DAKO mounting medium).The slides were protected from light to dry overnight and sealed with nail-polish the next day.

Confocal images were taken on Leica TCS SP2 AOBS laser scan microscope.

\begin{tabular}{c|c|c} 
Target protein & Host & Dilution \\
\hline anti-mouse Lamp1 & rat & $1: 50$ \\
anti-mouse Rab5 & rabbit & $1: 25$ \\
anti-rat TGN38 & mouse & $1: 50$ \\
anti-rat Calnexin & mouse & $1: 50$
\end{tabular}

Table 3.4: Primary antibodies used in immunofluorescence experiments

\begin{tabular}{c|c|c} 
Target species/conjugate & Host & Dilution \\
\hline anti-mouse Cy-2 conjugate & goat & $1: 100$ \\
anti-rat Cy-2 conjugate & goat & $1: 200$ \\
anti-rabbit Cy-2 conjugate & goat & $1: 100$
\end{tabular}

Table 3.5: Secondary antibodies used in immunofluorescence experiments

\subsection{Biochemical assays}

\subsubsection{Enzymatic Quantification of Cholesterol}

To determine the cholesterol amount with Roche/Hitachi enzymatic assay, an aliquot of fetal calf serum (FCS) or lipoprotein deficient serum (LPDS) was mixed with $500 \mu \mathrm{l}$ of the Roche/Hitachi assay solution. Aqueous solutions in $1 \%$ Triton X-100 containing $0,1,2,5,10$ and $20 \mu \mathrm{g}$ of cholesterol were included as quantity standards. After incubation at $37^{\circ} \mathrm{C}$ for 5 minutes, the absorbance at $500 \mathrm{~nm}$ was measured and the unkown cholesterol amounts were calculated. Each measurement per reaction was performed in duplicate.

\subsection{2 $\beta$-Hexosaminidase enzymatic assay}

\section{Substrate}


$1 \mathrm{mM}$ p-nitrophenyl N-acetyl-beta-D-glucosamine in $0.05 \mathrm{M}$ citrate buffer (pH 4.5)

\section{Stop buffer}

Glycine $1 \mathrm{M} \mathrm{pH} 10$

$10 \mu \mathrm{g}$ total protein (in a maximum of $50 \mu \mathrm{l}$ lysate) pipetted into $200 \mu \mathrm{l}$ of $0.9 \% \mathrm{NaCl}$ and $100 \mu \mathrm{l}$ of substrate substituted with $1 \%$ triton X-100. Samples were incubated for $1 \mathrm{~h}$ at $37^{\circ} \mathrm{C}$ and the reaction was stopped by addition $0.5 \mathrm{ml}$ Stop buffer. A blank reaction (substrate solution without cell lysate) was also run. The absorbance was read at $405 \mathrm{~nm}$ against substrate blank and the activity of $\beta$-Hexosaminidase was calculated.

\subsubsection{Glucose enzymatic assay}

\section{R1}

$180 \mathrm{mM}$ HEPES

0.9 M Pottasium chloride

990U/1 Glucose dehydrogenase

\section{R2}

18 mM NAD

Glucose concentration was determined with the Ecoline S assay. Glucose is oxidized to gluconolactone in the presence of NAD by glucose dehydrogenase. During this oxidation, an equimolar amount of NAD is reduced to NADH. The consequent increase in absorbance at $360 \mathrm{~nm}$ is directly proportional to glucose concentration. Two components of the assay: $\mathrm{R} 1$ and $\mathrm{R} 2$ were mixed in the ratio 4:1. $0.5 \mathrm{ml}$ so prepared reagent was added to $50 \mu \mathrm{l}$ of perfusion flow-out sample, mixed and incubated for 15 minutes at room temperature. The absorbance was measured at $360 \mathrm{~nm}$.

\subsubsection{Lactate dehydrogenase assay}

\section{In vitro toxicology assay kit lactate dehydrogenase based (Sigma)}

The increasing activity of LDH in cell culture medium serves as an indicator of membrane integrity loss, resulting from cell demage. Lactate dehydrogenase activity was determined with Toxicology Assay Kit, that is based on the reduction of NAD by the action of $\mathrm{LDH}$. The resulting NADH is utilized in the conversion of a tetrazolium dye to a coloured, measured spectrophotometrically, compound. 
LDH assay mixture was prepared by mixing equal volumes of LDH substrate, cofactor and dye solution. $1 \mathrm{ml}$ of this solution was added to $0.5 \mathrm{ml}$ of perfusion flow-out sample and incubated at room temperature for 20 minutes, with protection from light. The reation was terminated by the addition of $0.3 \mathrm{ml} 1 \mathrm{M} \mathrm{HCl}$ and the absorbance was read at $490 \mathrm{~nm}$ against pure assay mixture.

\subsection{Lipid analysis}

\subsubsection{Lipid extraction according to Folch}

Chloroform pro analysi (Roth)

Methanol pro analysi (Roth)

Lipoprotein lipids from LDL radioactive labelling preparations were extracted by the classical method of Folch et al. (1957).

Lipoprotein sample diluted in PBS was mixed with methanol and two volumes of chloroform (to achieve a chloroform:methanol ratio of 2:1 (v/v)). After vortexing, the mixture was centrifuged at low speed to separate the two phases. The lower chloroform phase containing pure lipid extract was subjected to scintillation counting.

\subsubsection{Lipid extraction according to Dole}

Dole reagent

$40 \mathrm{ml}$ isopropanol

$10 \mathrm{ml}$ heptane (Roth)

$1 \mathrm{ml} 1 \mathrm{M} \mathrm{H}_{2} \mathrm{SO}_{4}$

Heptane (Roth)

After ${ }^{3} \mathrm{H}$-cholesteryl linoleate LDL uptake experiment cellular lipids were extracted according to Dole (1956).

Cell lysate in $0.1 \mathrm{M} \mathrm{NaOH}$ was first neutralized with $0.1 \mathrm{M} \mathrm{HCl}$. To $1 \mathrm{ml}$ of this sample $5 \mathrm{ml}$ of Dole reagent was added. The mixture was vigorously vortexed and allowed to settle for 10 minutes, after which $2 \mathrm{ml}$ of heptane and $3 \mathrm{ml}$ of water were added and the mixture was shaken. After phase seperation the upper organic phase, containing lipids, was collected and dried under a gentle stream of nitrogen. The lipids were resuspended in a small volume of methanol and used for further analysis. 


\section{Methods}

\subsubsection{Thin Layer Chromatography}

Lipis samples were loaded onto the silica coated glass (Silica gel $60 \mathrm{~F}_{254}$, Merck) by a robot CAMAG Linomat5. Chromatography was performed with the solvent system of pure tetrachloromethane which can separate cholesterol and cholesterolesters from other lipid species. After seperation, the glass plate was placed in a chamber with a few crystals of iodine. Iodine has a high vapor pressure for a solid and because of its high affinity for both unsaturated and aromatic compounds it can be used for the visualization of organic compounds. A TLC plate remained within the chamber until it developed dark brown spots of seperated lipids. The individual spots were precisiouly scraped and measured for ${ }^{3} \mathrm{H}$-counts. 


\section{Results}

\subsection{Uptake and degradation of LDL by primary hepatocytes}

To describe the metabolisation of endocytosed LDL in murine hepatocytes, classical endocytosis experiments were performed.

\subsubsection{Metabolisation of LDL-derived apoliporotein B100}

The metabolisation of LDL over time was assesed in the following manner: mouse embryonic fibroblasts (MEF) were grown in DMEM suplemented with lipoprotein deficient serum (LPDS) for 16 hours. At zero time point fresh medium containing $5 \mu \mathrm{g} / \mathrm{ml}$ of ${ }^{125} \mathrm{I}-\mathrm{LDL}$ was added and the cells were allowed to endocytose ${ }^{125} \mathrm{I}-\mathrm{LDL}$ for different durations, up to 10 hours. The amount of endocytosed, hydrolysed and membrane bound ${ }^{125} \mathrm{I}-\mathrm{LDL}$ was obtained as described in 3.4.1.1 and expressed as ng ${ }^{125}$ I-LDL per mg total cell protein, as shown in Fig. 4.1a. During the first 2 hours of incubation the MEF accumulated $3 \mathrm{ng}{ }^{125} \mathrm{I}$-LDL per mg cell protein and reached a steady state at that level. The amount of hydrolysed ${ }^{125} \mathrm{I}$-apoB100 increased continuously over time in a linear fashion. More specifically, $80 \%$ of the apoB taken up by the cells was hydrolysed ( $20 \mathrm{ng}$ of $25 \mathrm{ng}{ }^{125} \mathrm{I}-\mathrm{LDL} / \mathrm{mg}$ cell protein). The level of dextran sulfate releasable ${ }^{125}$ I-LDL was low (less than 2 ng per mg of cell protein) and constant over the time.

When primary mouse hepatocytes were incubated for up to 10 hours with $5 \mu \mathrm{g}^{125} \mathrm{I}$ LDL per $\mathrm{ml}$ of medium, the total uptake of LDL was four times higher than in fibroblasts (Fig. 4.1b). In contrass to fibroblasts, hepatocytes accumulated most of the endocytosed ${ }^{125}$ I-apoB100 (90\% after 10 hours of the endocytosis) in the cells. The material accumulated in a linear fashion over time and the hydrolysis was at low, constant level, less than $10 \%$ of the total uptake. Cell-surface associated ${ }^{125} \mathrm{I}-$ radioactivity was similarly low as observed in MEF.

To describe the influence of ${ }^{125} \mathrm{I}-\mathrm{LDL}$ concentration on the metabolisation of LDL, 

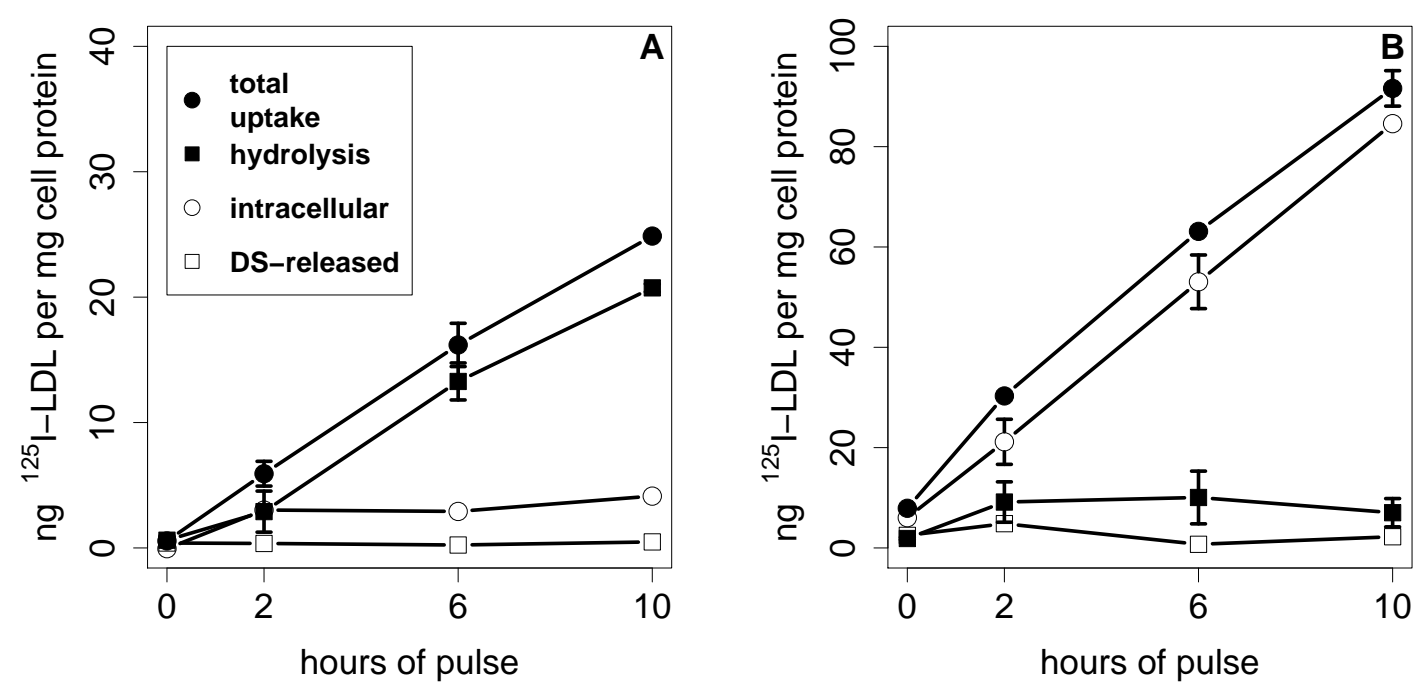

Figure 4.1: Relation of ${ }^{125} \mathrm{I}-\mathrm{LDL}$ endocytosis time to the extent of its binding and metabolisation in mouse embryonic fibroblasts (MEF, A) and primary mouse hepatocytes (B). Cells were prepared and cultured as described in the methods section. Cells were allowed to endocytose ${ }^{125} \mathrm{I}-\mathrm{LDL}$ at a concentration of $5 \mu \mathrm{g} / \mathrm{ml}$ for the durations indicated at the abscissae. The plots show data from representative experiments. Bars indicate two standard deviations from the mean and are shown where they exceed the size of the plotting symbols. DS-dextran sulfate.

primary hepatocytes were grown in medium containing LPDS and incubated for 1 hour with doses of ${ }^{125} \mathrm{I}$-LDL ranging from $0-100 \mu \mathrm{g} / \mathrm{ml}$, with or without 30 fold excess of unlabelled LDL to compare the LDL-R mediated ${ }^{125} \mathrm{I}-\mathrm{LDL}$ to unspecific endocytosis.

Most of the endocytosed radioactive material accumulated within the cells (Fig. 4.2a) independently of the ${ }^{125} \mathrm{I}-\mathrm{LDL}$ concentrations in the medium. The uptake was mostly receptor-dependent and reduced to less than $15 \%$ by a 30 fold excess of unlabelled LDL. Uptake of ${ }^{125}$ I-LDL by hepatocytes was dose dependent and was saturable with half maximal uptake at $19 \mu \mathrm{g} \mathrm{LDL} / \mathrm{ml}$, similar to the $\mathrm{K}_{\mathrm{m}}$-value of $16 \mu \mathrm{g} \mathrm{LDL} / \mathrm{ml}$ reported earlier for cultured human hepatocytes (Kosykh et al. 1985). The hydrolysis rate of LDLR-dependently endocytosed ${ }^{125} \mathrm{I}$-apoB100 was lower than $5 \%$ under all concentrations (Fig. 4.2b), whereas the hydrolysis of LDL taken up via unspecific endocytosis was not saturable up to $100 \mu \mathrm{g}{ }^{125} \mathrm{I}-\mathrm{LDL} / \mathrm{ml}$.

Further LDL endocytosis experiments with low concentrations of ${ }^{125} \mathrm{I}-\mathrm{LDL}$ were 

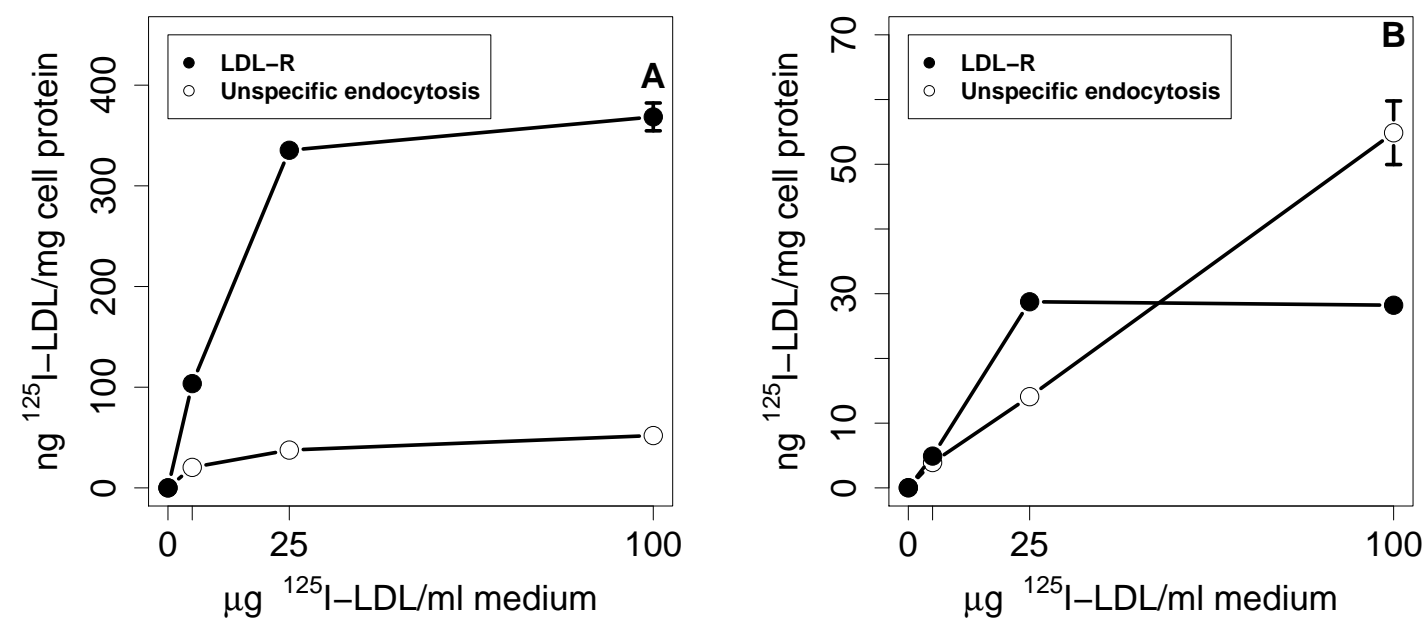

Figure 4.2: Relation of the concentration of ${ }^{125} \mathrm{I}-\mathrm{LDL}$ present in the medium during endocytosis period to the extent of its binding and metabolisation in primary mouse hepatocyte. Cells were prepared and cultured as described in the methods section. Cells were allowed to endocytose ${ }^{125} \mathrm{I}-\mathrm{LDL}$ at the concentrations indicated at the abscissae for 1 hour. To assess the fraction of LDL internalised independently of the LDL-receptor, uptake was measured in the presence of a 30-fold excess of unlabelled LDL $(150 \mu \mathrm{g} / \mathrm{ml})$. A: The intracellular level of ${ }^{125} \mathrm{I}-\mathrm{LDL}$ endocytosed via LDL-receptor and via unspecific endocytosis. B: The amount of ${ }^{125}$ I-LDL that were hydrolysed after LDL-receptor mediated endocytosis and after unspecific endocytosis. Please note the difference of scale between the two plots. Bars indicate two standard deviations from the mean and are shown where they exceed the size of the plotting symbols.

performed to determine whether the endocytosis of low amounts of LDL influences the LDL-metabolisation pattern of apoB100 in mouse hepatocytes and to determine the minimal dose of LDL required to achieve an intracellular accumulation of radioactive material sufficient to follow its fate in a chase-period.

The cells were incubated for 1 hour with ${ }^{125} \mathrm{I}-\mathrm{LDL}$ up to $10 \mu \mathrm{g} / \mathrm{ml}$, under the same conditions as in the previous experiments.

The intracellular accumulation of LDL-R internalised, LDL-derived apoB100 was proportional to the amount of ${ }^{125} \mathrm{I}-\mathrm{LDL}$ present in the medium (Fig. 4.3a). Similary to the previous experiment, the LDL-R mediated endocytosis accounted for around $80 \%$ of total uptake. The amount of free ${ }^{125}$ I-tyrosine radioactivity in the collected media 

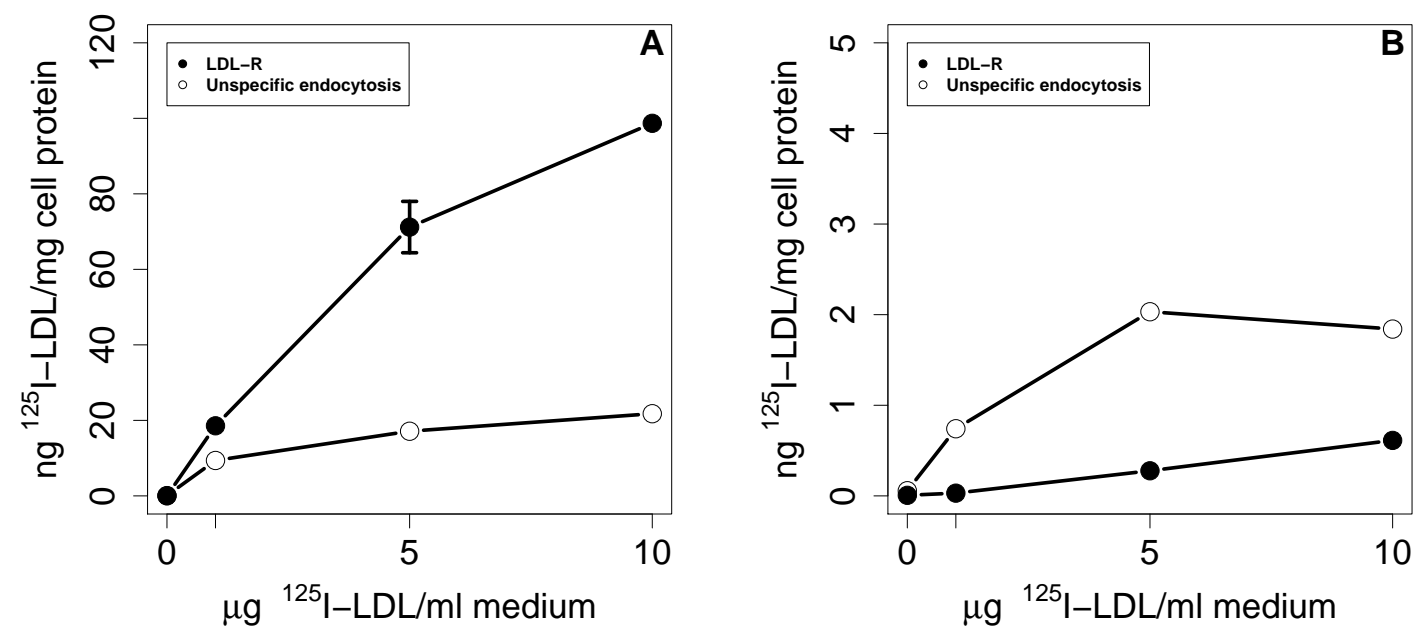

Figure 4.3: Relation of the concentration of ${ }^{125} \mathrm{I}-\mathrm{LDL}$ present in the medium during endocytosis period to the extent of its binding and metabolisation in primary mouse hepatocyte. Cells were prepared and cultured as described in the methods section. Cells were allowed to endocytose ${ }^{125} \mathrm{I}-\mathrm{LDL}$ at the concentrations indicated at the abscissae for 1 hour. To assess the fraction of LDL internalised independently of the LDL-receptor, uptake was measured in the presence of a 30-fold excess of unlabelled LDL $(150 \mu \mathrm{g} / \mathrm{ml})$. A: The intracellular level of ${ }^{125} \mathrm{I}-\mathrm{LDL}$ endocytosed via LDL-receptor and via unspecific endocytosis. B: The amount of ${ }^{125} \mathrm{I}$-LDL that were hydrolysed after LDL-receptor mediated endocytosis and after unspecific endocytosis. Please note the difference of scale between the two plots. Bars indicate two standard deviations from the mean and are shown where they exceed the size of the plotting symbols.

did not exceed $0.8 \mathrm{ng}{ }^{125} \mathrm{I}-\mathrm{LDL} / \mathrm{mg}$ cell protein and was independent on the LDL concentration in the pulse medium (Fig. 4.3b). The fraction of ${ }^{125} \mathrm{I}-\mathrm{LDL}$ internalised via unspecific endocytosis and subsequently hydrolysed was higher than $0.8 \mathrm{ng}{ }^{125} \mathrm{I}-$ LDL/mg cell protein.

\subsubsection{Hydrolysis of the LDL-derived cholesteryl linoleate in primary hepatocytes}

Because primary mouse hepatocytes degrade only a small part of the endocytosed LDL-derived apoB100, we examined whether they hydrolyse the LDL-bound cholesteryl 
esters.

Hepatocytes grown in DMEM with $10 \%$ LPDS for 16 hours, were incubated at $37^{\circ} \mathrm{C}$ in medium supplemented with $50 \mu \mathrm{g} / \mathrm{ml}^{3} \mathrm{H}$-cholesteryl linoleate labelled LDL, for up to 10 hours (described in 3.4.4). Lysosomal cleavage of LDL-derived ${ }^{3} \mathrm{H}$-cholesteryl linoleate liberates free ${ }^{3} \mathrm{H}$-cholesterol, that can be in turn converted to cholesterol oleate in the ER. After each time point, total lipids were extracted from the cells and free cholesterol and cholesteryl esters linoelate and oleate was analysed (3.8.3, 3.8.2). Figure 4.4 shows that hydrolysis started soon after the beginning of the pulse period and after 1 hour of incubation the cells hydrolysed half of the endocytosed cholesteryl linoleate ( $60 \mathrm{pmol}{ }^{3} \mathrm{H}$-cholesterol per mg cell protein). After 10 hours, the degradation rate increased to $60 \%$. The reesterification of free ${ }^{3} \mathrm{H}$-cholesterol to ${ }^{3} \mathrm{H}$-cholesteryl oleate was detectable after 1 hour of endocytosis (not shown). These results demonstrate that in contrast to LDL-bound apoB100, LDL-derived cholesteryl esters are rapidly degraded after LDL-receptor mediated endocytosis in primary hepatocytes.

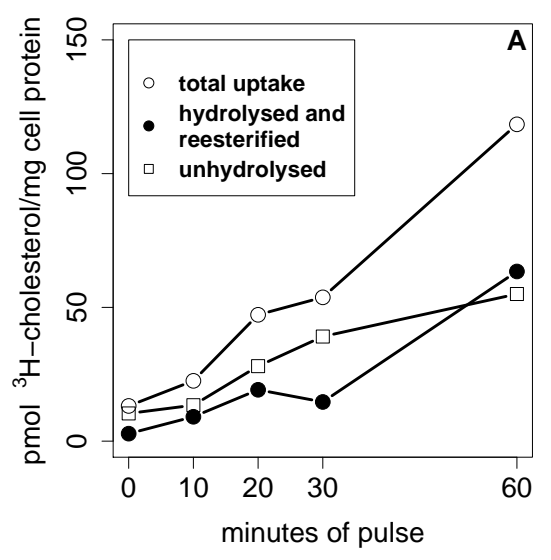

Figure 4.4: Time course of hydrolysis of ${ }^{3} \mathrm{H}$-cholesteryl linoleate bound to LDL by mouse hepatocytes. The cells were incubated with $50 \mu \mathrm{g}{ }^{3} \mathrm{H}-\mathrm{CL}-\mathrm{LDL}$ for the durations indicated at the abscissa. The values are expressed in pmol ${ }^{3} \mathrm{H}$-cholesterol per mg cell protein. Total uptake is the sum of ${ }^{3} \mathrm{H}$ cholesterol, ${ }^{3} \mathrm{H}$-cholesteryl linoleate and ${ }^{3} \mathrm{H}$-cholesteryl oleate. Hydrolysed and reesterified is the sum of ${ }^{3} \mathrm{H}$-cholesterol and ${ }^{3} \mathrm{H}$-cholesteryl oleate. 'Unhydrolysed' is the amount of ${ }^{3} \mathrm{H}$-cholesteryl linoleate. 


\subsection{Intracellular storage and recycling of endocytosed ${ }^{125} \mathrm{I}$-apoB100 in primary hepatocytes}

The observation that after 10 hours of LDL endocytosis, primary mouse hepatocytes hydrolyse $60 \%$ of the LDL-bound cholesteryl esters but only $10 \%$ of the LDL-derived

${ }^{125}$ I-apoB100 suggests that most of the apoB moiety of the internalised LDL is seperated from the cholesteryl esters targeted to the lysosomes and does not follow the intacellular degradation pathway. To analyse whether hepatocytes resecrete intact LDL-derived ${ }^{125} \mathrm{I}$-apoB that they accumulate during endocytosis, pulse-chase experiments were performed (3.4.2).

Hepatocytes were grown in medium supplemented with $10 \%$ LPDS for 16 hours. DMEM/LPDS was replaced with fresh medium containing $5 \mu \mathrm{g}{ }^{125} \mathrm{I}-\mathrm{LDL} / \mathrm{ml}$. The cells were then incubated for 1 hour at $37^{\circ} \mathrm{C}$ (pulse period). The culture medium from the pulse period was removed and the cells were washed thoroughly with buffer B, containing albumin, and once with buffer $\mathrm{C}$ without albumin. This was followed by incubation of the hepatocytes in DMEM/10 \% LPDS at $37^{\circ} \mathrm{C}$ for different durations (chase period) without ${ }^{125} \mathrm{I}-\mathrm{LDL}$.

The hydrolysis level of LDL-derived apoB100 and the amount of TCA-protein resecreted ${ }^{125} \mathrm{I}$-apoB100 was determined by counting the levels of TCA-soluble ${ }^{125} \mathrm{I}$ tyrosine and of TCA-insoluble radioactivity in the medium after each time point of the chase respectively. The pool of internalised ${ }^{125} \mathrm{I}$-apoB100 remaining in the cells after the chase period was also determined. The fraction of the membrane bound ${ }^{125} \mathrm{I}-$ LDL which were not removed by washing after the pulse period was estimated using two control cell dishes trypsynised immediately after the pulse step (4.2). This fraction amounted to $7.1 \mathrm{ng}$ (mean of two dishes, $\mathrm{sd}=0.54$ ) could shed off the membrane during chase and was substracted from the TCA precipitable ${ }^{125} \mathrm{I}$-apoB radioactivity recovered in the chase medium. The results of the experiment are shown in Fig. 4.5a. During the 1 hour of pulse the cells had accumulated $49 \mathrm{ng}$ of ${ }^{125} \mathrm{I}$-LDL per mg cell protein. After 24 hour chase period the amount of LDL that underwent hydrolysis or was recovered in the medium as intact apoB was essentially equivalent to the amount of radioactive material remaining in the cells, that was $27 \mathrm{ng}$ of ${ }^{125} \mathrm{I}-\mathrm{LDL}$ per $\mathrm{mg}$ cell protein. Approximately $37 \%$ of the internalised iodine material (20 ng/mg cell protein) had been secreted through direct release of TCA-precipitable ${ }^{125} \mathrm{I}$-material and the remaining $12 \%$ ( $7 \mathrm{ng} / \mathrm{mg}$ cell protein) through degradation. The release of TCA-soluble ${ }^{125} \mathrm{I}$-tyrosine reached a steady state $(6 \mathrm{ng} / \mathrm{mg}$ cell protein $)$ after the first 10 hours of the chase. This indicates that during the chase period, when no fresh 


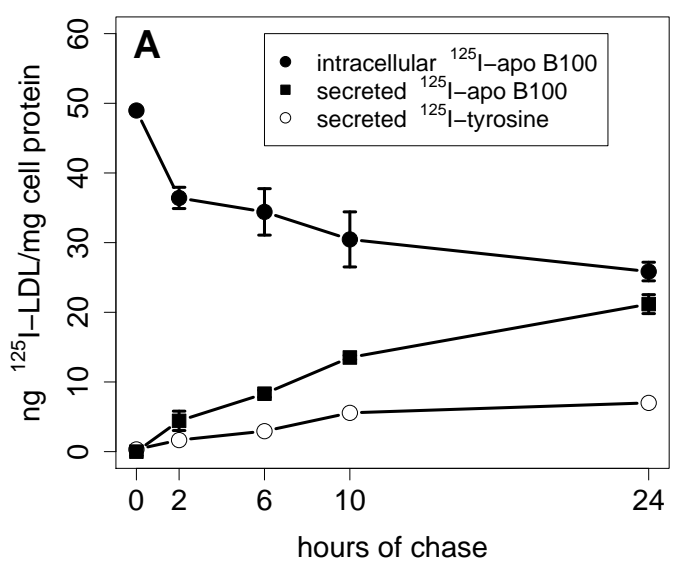

Figure 4.5: Fate of endocytosed ${ }^{125} \mathrm{I}-\mathrm{LDL}$ in primary mouse hepatocytes.A: Cells were prepared and cultured in DMEM/LPDS prior to an incubation with $5 \mu \mathrm{g} / \mathrm{ml}$ of ${ }^{125} \mathrm{I}-\mathrm{LDL}$ for 1 hour (pulse). The cells were washed and incubated in fresh DMEM/LPDS for the time periods indicated at the abscissa (chase). After each chase period, the medium was removed and the amount of secreted as intact, hydrolysed and intracellular ${ }^{125} \mathrm{I}$-apoB100 was determined. All values represent the mean of three dishes per condition. Errorbars indicate two standard deviations from the mean and are shown where they exceed the size

LDL reached the cells, degradation of the LDL-derived apoB stayed at a low and constant level, similar to the results obtained from the pulse experiments. In contrast to that, the amount of intact ${ }^{125} \mathrm{I}$-apoB released into the chase medium continued to increase throughout the 24 hour chase period of the experiment, yielding finally a 3 times higher secreted fraction than the level of ${ }^{125}$ I-tyrosine. To characterise the nature of the secreted ${ }^{125} \mathrm{I}$-TCA-insoluble radioactivity, an analysis of the chase medium was performed, employing floatation ultracentrifugation method (3.5), which allows to fractionate lipoprotein particles according to their density.

After overnight culture, hepatocytes on four $75 \mathrm{~cm}^{2}$ dishes were incubated with medium containing $5 \mu \mathrm{g}{ }^{125} \mathrm{I}-\mathrm{LDL} / \mathrm{ml}$ for 1 hour, washed and chased in $5 \mathrm{ml}$ medium with $10 \%$ LPDS for 10 hours. The secretions of the chase period were collected and $1 \mathrm{ml}$ aliquots were taken to measure the secretion of TCA soluble and insoluble radioactive material. Intracellular ${ }^{125} \mathrm{I}$-apoB accumulation was also determined. The values were within the range shown in Fig.4.5A. The remaining chase supernatans from 4 dishes were pooled, concentrated (3.5) and loaded onto a $\mathrm{KBr}$ gradient in the density range of $1.006-1.25 \mathrm{~g} \mathrm{KBr} / \mathrm{ml}$. 
To exclude that incubation with medium is sufficient to shift the density of ${ }^{125}$ I-LDL to that of ${ }^{125} \mathrm{I}$-VLDL, ${ }^{125} \mathrm{I}$-LDL was incubated at the concentration of $5 \mu \mathrm{g} / \mathrm{ml}$ for 10 hours at $37^{\circ} \mathrm{C}$ in medium preconditioned by hepatocytes (3.2.2). The resulting control sample was concentrated and also loaded onto the gradient. As an additional control $500000 \mathrm{cpm}$ of plain ${ }^{125} \mathrm{I}-\mathrm{LDL}$ in $0.5 \mathrm{ml}$ of PBS was also analysed. Half milliliter fractions from sample and control gradients were collected from the top to the bottom of the ultracentrifugation tube and subjected to liquid scintillation $\gamma$ counting, and the $\gamma$-quenching effect of potassium bromide was corrected for, as described in 3.5. The results shown in Fig. $4.6 \mathrm{~b}$ are expressed as percent of the total $\gamma$ decay per fraction.

While no radioactive material was found in the very low density $(\leq 1.006 \mathrm{~g} / \mathrm{ml})$ top two fractions from control preconditioned medium incubation and the plain ${ }^{125} \mathrm{I}-\mathrm{LDL}$ gradient centrifugations, the very low density fractions of the concentrated chase secretion contained $7 \%$ of the total protein bound radioactivity. Likewise, in the chase gradient $6 \%$ of the radioactive material was found with the intermediate density fractions 3-5 (1.006 - $1.039 \mathrm{~g} / \mathrm{ml})$, contrary to the control gradient profile. However, most of the protein bound radioactivity $(87 \%)$ was associated with the low density fractions $(1.04-1.06 \mathrm{~g} / \mathrm{ml})$, where also signal of ${ }^{125} \mathrm{I}-\mathrm{LDL}$ controls was exclusively localized, as it was expected.

These data suggest that most $(87 \%)$ of the protein bound radioactivity is secreted as LDL but a small fraction as VLDL (7 \%) and IDL (6\%).

To demonstrate that the radioactivity detected in the VLDL- and LDL- fractions indeed resided in the apoB protein, aliquots from VLDL and LDL density $\mathrm{KBr}$ gradient fractions were delipidated, seperated by 3-16\% SDS-PAGE gel and visualised by autoradiography.

The result in Fig. 4.6c clearly shows that exclusively apoB100 was present in the VLDL fraction (lane 2) and there was no detectable ${ }^{125} \mathrm{I}$-apoE contamination. The same result was obtained for LDL density gradient fractions (lane 3). This clearly demonstrated that only apoB100 moieties of ${ }^{125} \mathrm{I}-\mathrm{VLDL}$ and ${ }^{125} \mathrm{I}$-LDL were associated with radioactivity.

Because HDL-derived internalised apolipoprotein E can easily be recycled to VLDL (Heeren et al. 2001), careful consideration had to be given to the possibility that recycling TCA-precipitable radioactivity detected in the LDL uptake experiments was not actually internalised as part of HDL particles. ${ }^{125}$ I-HDL-apoE contamination might result from a possible soilure of the human LDL fraction with HDL particles during the isolation procedure and its sebsequent iodination but the results described 

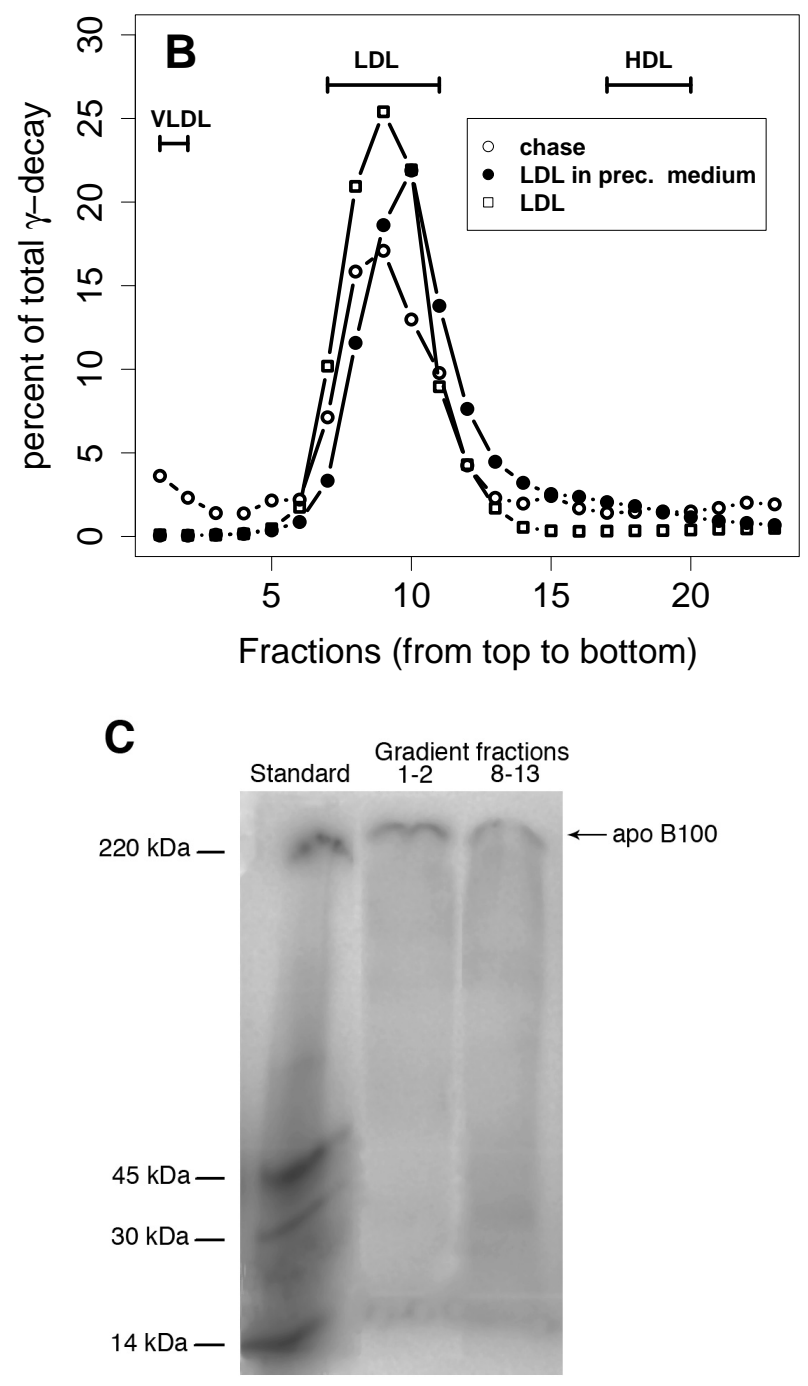

Figure 4.6: Nature of secreted ${ }^{125} \mathrm{I}$-apoB in primary mouse hepatocytes.B: Chase media from four $75 \mathrm{~cm}^{2}$ dishes incubated with $5 \mu \mathrm{g} / \mathrm{ml}{ }^{125} \mathrm{I}-\mathrm{LDL}$ for one hour and chased in DMEM/LPDS for 10 hours were collected, pooled, concentrated, loaded onto a KBr-gradient, ultracentrifuged and analysed as described in the text. The abscissa shows the fraction number (from top to bottom), the ordinate the proportion of radioactivity of each fraction normalised for KBr quenching. The plot shows the result for chase media and controls $\left(5 \mu \mathrm{g} / \mathrm{ml}{ }^{125} \mathrm{I}\right.$-LDL incubated for 10 hours in hepatocytepreconditioned medium and ${ }^{125}$ I-LDL without any incubation). Equal amounts of radioactivity were loaded for every condition. C Autoradiography of a $3-16 \%$ SDS-PAGE loaded with delipidated ${ }^{125}$ I-apolipoproteins from the floatation ultracentrifugation shown in B. Lane 1: ${ }^{125}$ Imolecular weight standard, lane 2: gradient fractions 1-2 (VLDL), lane 3: gradient fractions 8-13 (LDL). 
above exclude this possibility.

\section{3 ${ }^{125} \mathrm{I}$-apoB storage and recycling in the mouse liver}

To show that endocytosed LDL-derived apoB is recycling to assemble VLDL in the intact liver and to assess the importance of this apoB reutilisation for lipoprotein assembly, the liver was perfused with ${ }^{125} \mathrm{I}$-LDL.

The liver was perfused with KHB buffer supplemented with $10 \mu \mathrm{g} / \mathrm{ml}{ }^{125} \mathrm{I}-\mathrm{LDL}$ for 20 minutes and with KHB only for 3 minutes (wash step), followed by KHB/heparin for 9 minutes to release LDL receptor bound LDL. Finally the liver was perfused for one hour more with KHB (3.4.5).

To estimate the uptake and metabolisation of ${ }^{125}$ I-LDL by the liver, the amount and lipoprotein classes (LDL, IDL, VLDL) of intact apoB100 and the amount of hydrolysed ${ }^{125} \mathrm{I}$-apoB100 were determined in the collected fractions. The radioactive material remaining in the liver after the end of perfusion was also measured.

In a typical perfusion experiment, most of the radioactivity recovered during the pulse represents LDL that passes the liver without binding to the cells. Radioactive material detected in the chase fractions can orginate either from LDL bound to the surface of the liver cells and released during the perfusion or from apoB100 that has been internalised and then degraded and finally from apoB100 recycling after endocytosis. Fig. 4.7a shows a representive profile of the protein bound and the TCA-soluble (hydrolysis) radioactivity collected during the chase. Already in the first chase fraction (32 minutes after starting the pulse), TCA-soluble radioactive material was detectable, indicating that ${ }^{125} \mathrm{I}-\mathrm{LDL}$ was hydrolysed in the lysosomes. The fraction of ${ }^{125}$ I-tyrosine increased slightly during the first 12-18 minutes of chase and then decreased slowly. The intact ${ }^{125}$ I-radioactivity dropped rapidly in 1-4 fractions, then decreased slowly until fraction 10, when it started to be almost even to the level of tyrosine.

To analyse in which lipoprotein form the liver secreted protein-associated ${ }^{125}$ I-radioactivity, the fractions were pooled as indicated in Fig. 4.7a and the lipoprotein classes were determined by floatation ultracentrifugation (3.5). During the entire chase time, hepatocytes secreted intact ${ }^{125} \mathrm{I}$-apoB100 in the form of VLDL, IDL and LDL, as shown in Fig. 4.7b. ${ }^{125} \mathrm{I}$-apoB recovered from the first pool represents mostly nonendocytosed ${ }^{125} \mathrm{I}-\mathrm{LDL}$, released or washed out from the cell membranes and was not taken into account for calculation of the relationship between secreted lipoproteins. The liver secreted ${ }^{125} \mathrm{I}$-VLDL, ${ }^{125} \mathrm{I}$-IDL and ${ }^{125} \mathrm{I}$-LDL at the ratio of approximetely 
3:1:4 during the chase period. The secretion rate of all lipoproteins declined rapidly during the first 20 minutes (pool 1-3) and remained almost constant afterwards.

The total uptake of ${ }^{125} \mathrm{I}$-LDL by the liver and the relationship between ${ }^{125} \mathrm{I}$-apoB remaining in the cells after 1 hour of chase, secreted after degradation to free aminoacids or secreted in the form of lipoproteins was determined in four independent perfusion experiments (Table 4.1). Because it was again not possible to distinguish between ${ }^{125} \mathrm{I}-\mathrm{LDL}$ that was washed out and that has been retroendocytosed in the first minutes of the chase, the amount of secreted ${ }^{125} \mathrm{I}-\mathrm{LDL}$ was estimated excluding the LDL found in the heparin wash fraction (first 12 minutes of the chase). During the pulse period the liver endocytosed between 1 and $4 \mu \mathrm{g}$ of ${ }^{125} \mathrm{I}-\mathrm{LDL}$ per gramme liver. During the chase an average of $9.5 \%(\mathrm{sd}=1.6)$ of the internalised radioactivity was secreted. $2.7 \%$ were secreted in TCA-soluble form (hydrolysis- $27 \%$ of the ${ }^{125}$ I-secretion) and $7 \%$ were secreted as TCA-insoluble radioctivity ( $73 \%$ of the ${ }^{125}$ I-secretion). Roughly half of the non-hydrolysed ${ }^{125} \mathrm{I}$-apoB100 was resecreted as LDL and the other half was used by the cells to assemble VLDL and IDL.

Table 4.1: Uptake of LDL-derived ${ }^{125}$ I-apo B100 within 20 minutes of pulse and metabolization during a $1 \mathrm{~h}$ chase period in the perfused liver

Internalised ${ }^{125} \mathrm{I}$-material recovery after $1 \mathrm{~h}$ chase as

\begin{tabular}{|c|c|c|c|c|c|c|c|c|c|c|c|}
\hline \multirow[b]{2}{*}{ Exp. } & \multirow[t]{2}{*}{$\begin{array}{l}\text { Total uptake } \\
\text { (ng) }\end{array}$} & \multirow[t]{2}{*}{$\begin{array}{l}\mathrm{ng}{ }^{125} \mathrm{I}- \\
\text { protein/liver }\end{array}$} & \multicolumn{4}{|c|}{$\begin{array}{l}{ }^{125} \mathrm{I}- \\
\text { tyrosine }\end{array}$} & \multicolumn{2}{|c|}{ IDL } & \multicolumn{2}{|c|}{$\mathrm{LDL}^{1}$} & \multirow[b]{2}{*}{ total $\%^{3}$} \\
\hline & & & $\mathrm{ng}$ & $\%^{2}$ & ng & $\%^{2}$ & ng & $\%^{2}$ & ng & $\%^{2}$ & \\
\hline 1 & 1386 & 1255 & 40 & 29 & 27 & 19 & 10 & 7 & 62 & 45 & 9.5 \\
\hline 2 & 1079 & 953 & 34 & 22 & 40 & 27 & 15 & 10 & 63 & 41 & 11.7 \\
\hline 3 & 4194 & 3810 & 84 & 28 & 100 & 33 & 34 & 11 & 83 & 28 & 9.1 \\
\hline 4 & 2758 & 2543 & 69 & 27 & 65 & 26 & 23 & 9 & 98 & 38 & 7.8 \\
\hline $\begin{array}{l}\text { Mean \% of } \\
\text { secreted }\end{array}$ & 0 & 0 & & 27 & & 26 & & 9 & & 38 & 100 \\
\hline $\begin{array}{l}\text { Mean } \% \text { of } \\
\text { internalised }\end{array}$ & 100 & 90.5 & & 2.5 & & 2.5 & & 1 & & 3.5 & 9.5 \\
\hline
\end{tabular}

\subsection{Recycling of LDL-derived ${ }^{125} \mathrm{I}$-apoB100 to ${ }^{125} \mathrm{I}-\mathrm{VLDL}$ in the living mouse}

To demonstrate that VLDL is synthesised from endocytosed LDL-derived apoB100 in the living mouse, nine mice where intravenously injected with ${ }^{125} \mathrm{I}-\mathrm{LDL}$, as desribed 

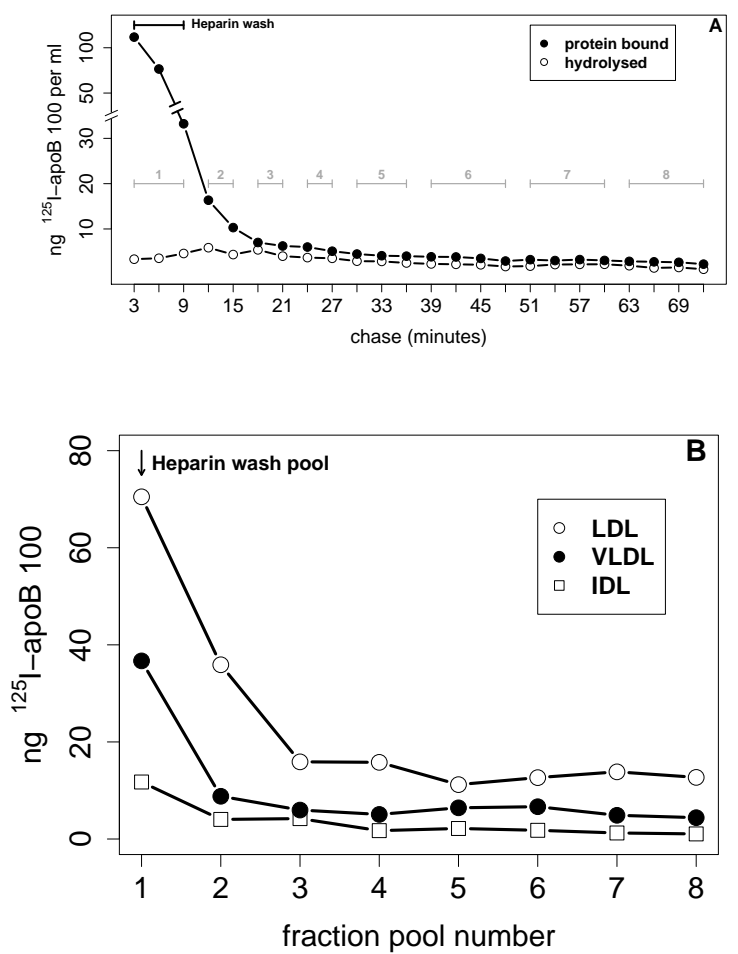

Figure 4.7: Uptake and metabolisation of ${ }^{125}$ I-LDL in the perfused mouse liver. The plot shows one representative experiment. The liver was perfused with $5 \mathrm{ml} \mathrm{KHB} /$ minute as described in the methods section. ${ }^{125} \mathrm{I}-\mathrm{LDL}$ was perfused at a concentration of $10 \mu \mathrm{g}$ per $\mathrm{ml}$ KHB for 20 minutes. The liver was washed with heparin as described and perfused for 1 hour with KHB (chase period). Fractions were collected every 3 minutes to obtain a fraction size of $15 \mathrm{ml}$. A Secretion of ${ }^{125} \mathrm{I}$-apoB100 and ${ }^{125} \mathrm{I}$-tyrosine by the liver after the pulse period (ordinate: $\mathrm{ng}{ }^{125} \mathrm{I}$-apoB100 per $\mathrm{ml}$, abscissa: minutes of chase). The fractions were pooled and concentrated as indicated by the numbered horizontal grey bars. $\mathbf{B}^{125} \mathrm{I}$-Lipoprotein classes determined in the perfusate. The pools (abscissa) were separately analysed by floatation ultracentrifugation. Ordinate: Absolute amount of ${ }^{125} \mathrm{I}$-apoB100 per pool. 
in 3.4.6. One hour after the injection, 3 mice were killed. At this time point, the remaining 6 mice were injected with Triton WR-1339 to inhibit the lipolytic catabolization of VLDL (Ishikawa and Fidge 1979). Mice were killed 1 and 4 hours after the triton injection. The amount of ${ }^{125} \mathrm{I}$-apoB100 in the liver and ${ }^{125} \mathrm{I}-\mathrm{VLDL}$ and ${ }^{125} \mathrm{I}-\mathrm{LDL}$ in the serum of each animal was determined. In this experiment the fraction of retroendocytosed ${ }^{125} \mathrm{I}-\mathrm{LDL}$ could not be estimated due to the presence of high amount of injected LDL in the blood.

As shown in Table 4.2, the amount of I-apoB100 found in the liver and the level of injected ${ }^{125} \mathrm{I}-\mathrm{LDL}$ in the serum decreased over time, pointing out that the liver constantly not only internalised ${ }^{125} \mathrm{I}$-LDL but also secreted radioactive material. The half life of endocytosed apoB100 in the liver was longer than 4 hours. 1 hour after the injection of ${ }^{125} \mathrm{I}-\mathrm{LDL}, 45 \mathrm{ng}$ of ${ }^{125} \mathrm{I}-\mathrm{VLDL} / \mathrm{ml}$ were found in the serum $(0.39 \%$ of the total ${ }^{125} \mathrm{I}$-apoB100), and its level steadily increased over time, reaching a level of $4.37 \%$ of the total ${ }^{125} \mathrm{I}$-apoB secretion 4 hours after triton injection. These results show that in the living mouse LDL-derived apoB100 is reutilised to assemble VLDL particles. The constant rise of the absolute and relative amount of ${ }^{125} \mathrm{I}-\mathrm{VLDL}$ in the serum indicates that it could be a quantitatively important part of the ${ }^{125} \mathrm{I}$-apoB100 secretion by the liver.

Table 4.2: Assembly of VLDL from LDL-derived apoB100 in the living mouse. Animals were injected with $1.5 \mu \mathrm{g}{ }^{125} \mathrm{I}$-LDL per gramme body weight and with 500 ng Triton W 1339 per gramme 1 hour after the first injection. Four animals were killed 0,1 or 4 hours after the Triton injection, respectively.

\begin{tabular}{l||rr|rrr|rr}
\hline \multicolumn{1}{c||}{} & \multicolumn{4}{c}{ Time (minutes) after injection of Triton ... } \\
\multicolumn{1}{c||}{ Amount of } & \multicolumn{2}{c|}{0} & \multicolumn{2}{c}{60} & \multicolumn{2}{c}{240} \\
\hline${ }^{125}$ I-apoB100 in the total liver $(\mathrm{ng})$ & 5485 & $(92)$ & 4985 & $(234)$ & 3337 & $(386)$ \\
${ }^{125}$ I-LDL in the serum $(\mathrm{ng} / \mathrm{ml})$ & 12784 & $(2880)$ & 8532 & $(53)$ & 5805 & $(197)$ \\
${ }^{125}$ I-VLDL in the serum (ng/ml) & 51 & $(33)$ & 110 & $(13)$ & 254 & $(66)$ \\
as \% of total ${ }^{125}$ I-apoB100 & 0.39 & & 1.28 & & 4.37 &
\end{tabular}

ब Values are means of four replicates, standard deviations given in parentheses.

\subsection{Cellular localisation of the lipidation of reutilised LDL-derived apoB100}

The results from in vitro experiments and in vivo studies show that LDL-derived apoB100 is endocytosed, stored within the cells and partly recycled as VLDL particles. To accomplish this, apoB100 needs to be loaded with new lipid cargo molecules, 
triacylglycerols, prior to secretion as VLDL. To identify the site of lipidation of reutilised apoB100 within the cell, several experiments were performed using subcellular fractionation, immunofluorescence methods as well as methods to inhibit the intracellular trafficking.

\subsubsection{Defining of LDL-derived apoB100 localisation using subcellular fractionation}

The intracellular localisation of the stored LDL-derived apoB100 was analysed using subcellular fractionation (3.6.7). The mouse liver was perfused with a total amount of $1 \mathrm{mg}{ }^{125} \mathrm{I}$-LDL for 20 minutes, washed with heparin and chased just for 30 minutes, to ensure that a maximum of non-internalised ${ }^{125} \mathrm{I}-\mathrm{LDL}$ is washed out while keeping a high level of intracellular ${ }^{125} \mathrm{I}$-apoB100. The preparation and characterisation of subcellular fractions from mouse liver was performed using a discontinuous sedimentation velocity iodixanol gradient as described in 3.6.7. 10 fractions were collected from each gradient. The ${ }^{125} \mathrm{I}$-apoB content of each fraction was determined with a gamma counter. In Fig. 4.8 the seperation of cellular compartments along the gradient is shown, together with the distribution of ${ }^{125} \mathrm{I}$-apoB. A content of marker proteins was determined using western blot (3.6.6) and enzymatic assays (3.7.2).

The application of a sedimentation velocity gradient allowed to resolve trans-Golgi network (syntaxin6) from ER (calnexin) and lysosomes ( $\beta$-hexasaminidase) and early endosomes (Rab5). Rab 11, which is enriched in the recycling endosomes, co-sendimented with TGN and the early endosome fraction.

$75 \%$ of the radioactive material was detected in fractions $3-10$, while $25 \%$ was found in the top two fractions and did not colocalise with any of the organelle markers that were used. Control experiment with ${ }^{125} \mathrm{I}-\mathrm{LDL}$ showed that fully lipidated ${ }^{125} \mathrm{I}-\mathrm{LDL}$ particles did not enter into the gradient, probably due to their low density (data not shown). We therefore assume that the non-sedimenting ${ }^{125} \mathrm{I}$-apoB in the top fractions represents lipidated apoB100 lipoprotein particles released from organelles and vesicles during the fractionation procedure. The majority of the sedimenting ${ }^{125} \mathrm{I}$ apoB100, $48 \%$, was contained in the TGN- and recycling endosomes-associated fractions (fraction 3-4), showing colocalisation with Syntaxin6 and Rab11 respectively. $13 \%$ (fraction 8-9) colocalised with Rab5, Rab11, $\beta$-hexosaminidase and calnexin. The minor radioactivity found in the bottom fraction probably represented aggregated material.

Syntaxin6 is primarily associated with long tubular membranes of the TGN and also a part of cellular recycling endosomes complex is located close to the TGN. 
Thus, observed colocalisation indicated that about half of endocytosed LDL-derived apoB100 is localised at the TGN, while less than one sixth is present in the endosomal/lysosomal compartment.
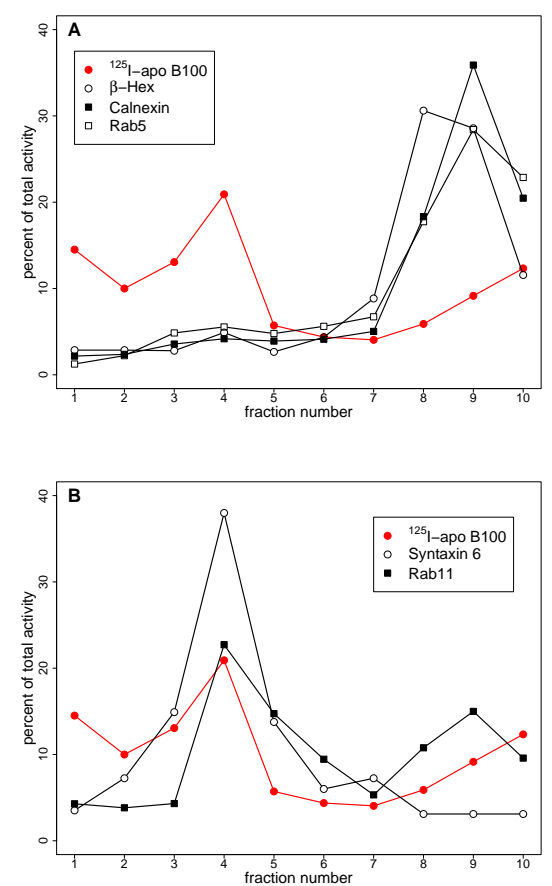

Figure 4.8: Subcellular fractionation of a perfused liver after ${ }^{125} \mathrm{I}$-apoB100 endocytosis. Subcellular fractionation using a 2.5-30\% discontinuous iodixanol gradient was performed and analysed as described in the methods section. The ordinates shows activites (radioactivity for ${ }^{125} \mathrm{I}$-apoB100 (A, B), enzymatic activity for $\beta$-hexosaminidase (A) and relative luminescense for the proteins Calnexin, Rab5 (both A), Syntaxin 6 and Rab11 (both B) detected by Western-Blot). The fractions were collected from top (fraction 1) to bottom (fraction 10). The plot shows one representative experiment (of three replicates).

\subsubsection{Defining of LDL-derived apoB100 localisation with confocal microscopy}

To confirm subcellular fractionation results, the cellular localisation of internalised apoB was determined by confocal microscopy. Hepatocytes were allowed to endocytose $10 \mu \mathrm{g} / \mathrm{ml}$ Cy3-labelled LDL for 2 hours, following 1 or 4 hours of chase (described 


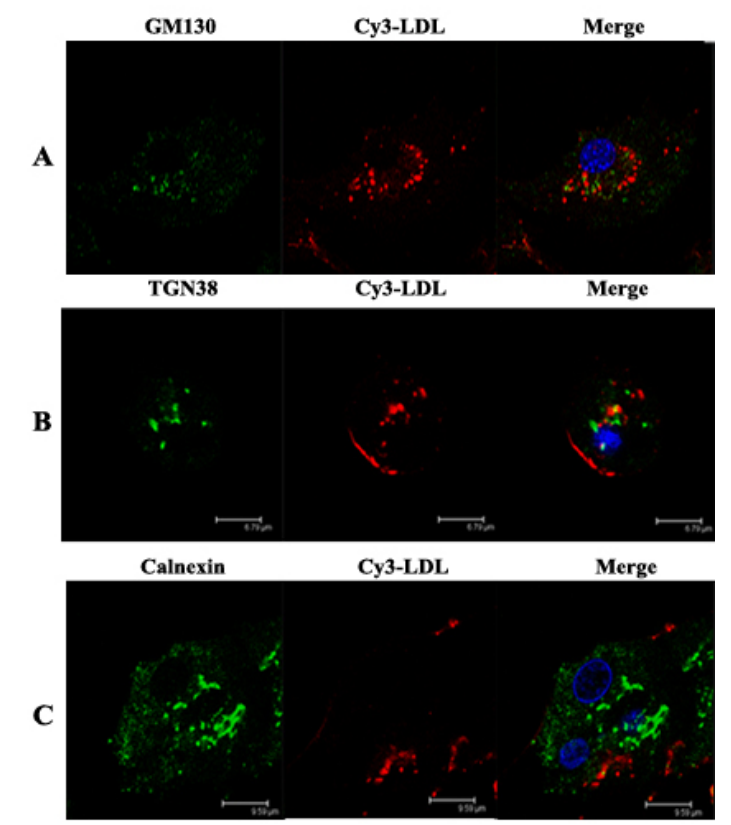

Figure 4.9: Subcellular localisation of LDL-derived apoB100 in hepatocytes after Cy3LDL endocytosis. Mouse $(\mathbf{A})$ or $\operatorname{rat}(\mathbf{B}, \mathbf{C})$ hepatocytes were pulsed with $10 \mu \mathrm{g} / \mathrm{ml} \mathrm{Cy3-conjugated} \mathrm{LDL} \mathrm{(red} \mathrm{fluorescence)} \mathrm{for} 2$ hours at $37^{\circ} \mathrm{C}$ as described in the methods section. After fixation and permeabilisation, GM130 (cis-Golgi protein) (A), TGN38 (trans-Golgi network protein) (B) and calnexin (ER protein) (C) were detected and showed green immunofluorescence. The merge images showed the colocalisation, if detected. Nuclei were stained with Dapi (blue).

in 3.4.3).

Fluorescently labelled apoB was seen in the cells as internalised bright punctuate staining. In many cells apoB staining was seen in a perinuclear structure closely resembling the Golgi complex. However the Golgi-associated localisation was not confirmed by double-immunostaining experiment with a anti-GM130 antibody, a marker for the cis-Golgi (Fig. 4.9). In a few cells, a subtle colocalisation could be detected, but because of its weakness it is probably an artefact (Fig. 4.9). Association with trans-Golgi marker, TGN38, was also not detectable (Fig. 4.9). Immunostaining with calnexin did not show the localization of endocytosed apoB in the endoplasmic reticulum. A similar result was obtained for early endosome staining using an anti-Rab5 antibody (Fig. 4.10). As shown in Fig. 4.10 Cy3-apoB did not (or rather minimal) colocalise with Lamp1 protein, a marker for late endosomes/lysosomes compartment, 


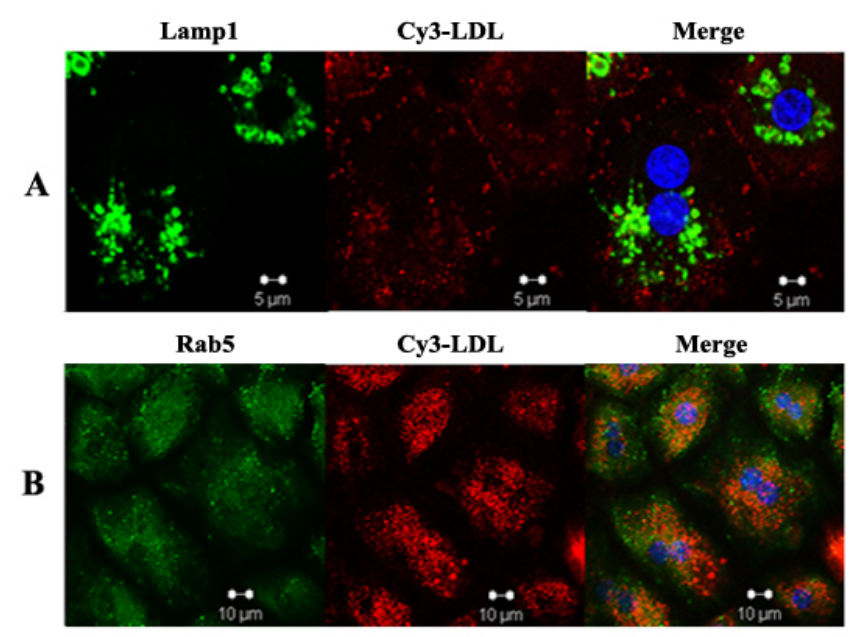

Figure 4.10: Subcellular localisation of LDL-derived apoB100 in hepatocytes after Cy3-LDL endocytosis. Mouse hepatocytes (A, B) were pulsed with $10 \mu \mathrm{g} / \mathrm{ml} \mathrm{Cy3-conjugated} \mathrm{LDL} \mathrm{(red} \mathrm{fluorescence)} \mathrm{for} 2$ hours at $37^{\circ} \mathrm{C}$ as described in the methods section. After fixation and permeabilisation, Lamp1 (late endosomal/lysosomal marker protein) (A), Rab5 (early endosome protein) (B) were detected and showed green immunofluorescence. The merge images showed the colocalisation, if detected. Nuclei were stained with Dapi (blue).

confirming the observation that hepatocytes hydrolyse only a small fraction of internalised LDL.

Thus, the immunofluorecence experiments are not conclusive, as they do not reveal a convincing colocalisation with any organelle marker used. It cannot be excluded that the amount of LDL-derived apoB100, that is stored within in vitro cultured cells and destinated to lipidation is too low to be detected by fluorescence at the level of a single cell. It should be noted that the subcellular fractionation experiment, which has shown partly storage of apoB100 in TGN network, was performed on mouse liver. The previous data confirmed that the amount of apoB100 recycled as VLDL particles is more significant in mouse than in cultured hepatocytes (4.3). The detection of apoB100 localisation would probably be easier using a Cy-3-LDL-perfused liver than in in vitro conditions. 


\subsubsection{The effect of Golgi-disturbing agents on the intact ${ }^{125} \mathrm{I}$-apoB100 secretion}

To further analyse the intracellular localisation of endocytosed apoB100, the influence of Golgi-disturbing agents on the apoB-recycling process was examined. After allowing the hepatocytes to endocytose ${ }^{125} \mathrm{I}-\mathrm{LDL}$ for 1 hour, the cells were chased for 8 hours in the presence of $5 \mu \mathrm{g} / \mathrm{ml}$ brefeldin A or $20 \mathrm{mM}$ monensin (3.4.2). The hepatocytes pulsed with ${ }^{125} \mathrm{I}$-LDL and chased in medium without drugs were included as controls. This experimental setup is similar to the protocol described in 3.4.2 and allows to quantify the amount of LDL-derived ${ }^{125} \mathrm{I}$-apoB that was recycled as VLDL particles and the fraction of retroendocytosed ${ }^{125} \mathrm{I}-\mathrm{LDL}$ (3.5).

Brefeldin A (BFA) is a fungal antibiotic that has been shown to inhibit protein transport from ER to Golgi in mammamial cells. In addition, it has been reported to affect the morphology of the Golgi complex and to cause a redistribution of many of its proteins to the ER. Monensin is known to alter the structure of the Golgi apparatus and has been shown to be an inhibitor of trans-Golgi function (Dinter and Berger 1998). The results are presented in table 4.3 .

In the absence of drugs, during 8 hour chase hepatocytes secreted $3.55 \mathrm{ng}{ }^{125} \mathrm{I}-$ $\mathrm{apoB} / \mathrm{mg}$ total cell protein in the form of VLDL, whereas $100 \mathrm{ng}$ of apoB was retroendocytosed as LDL particles. In the presence of monensin there was a $54 \%$ decrease in apoB recycling as VLDL particles, as compared to the secretion result obtained fron non-treated cells. The amount of retroendocytosed ${ }^{125} \mathrm{I}-\mathrm{LDL}$ was $45 \%$ lower under these conditions. Monensin, by disturbing the $\mathrm{H}^{+}$-ATPase would be expected to raise the $\mathrm{pH}$ of lysosomes, which might result in decreasing lysosomal degradation (Yanagishita and Hascall 1985). Indeed, the monensin incubation resulted in the inhibition of ${ }^{125} \mathrm{I}$-apoB100 hydrolysis to $50 \%$. Under BFA treatment the ${ }^{125} \mathrm{I}$-VLDL secretion was inhibited by $57 \%$ and ${ }^{125}$ I-LDL retroendocytosis by $43 \%$. The amount of hydrolysed ${ }^{125} \mathrm{I}$-apoB was decreased by $15 \%$.

These results indicated that both drugs inhibited the LDL-derived ${ }^{125} \mathrm{I}$-apoB100 recycling pathway. BFA as well as monensin supressed the secretion of ${ }^{125} \mathrm{I}$-apoB as VLDL by half and inibited also ${ }^{125}$ I-LDL retroendocytosis but with lower effect than ${ }^{125}$ I-VLDL secretion. Monensin also inhibited the lysosomal hydrolysis. 


\begin{tabular}{|c|c|c|c|}
\hline & $\begin{array}{c}\text { - BFA } \\
\text { - monensin }\end{array}$ & + BFA & + monensin \\
\hline secreted ${ }^{\mathbf{1 2 5}} \mathrm{I}-\mathrm{VLDL}$ & 3.55 & 1.53 & 1.64 \\
secreted ${ }^{\mathbf{1 2 5}} \mathrm{I}-\mathrm{LDL}$ & 100 & 57 & 55 \\
secreted ${ }^{\mathbf{1 2 5}} \mathrm{I}$-tyrosine & 17.7 & 15 & 8.8 \\
\hline
\end{tabular}

Table 4.3: The effect of Golgi-disturbing agents on the ${ }^{125} \mathrm{I}$-apoB100 secretion and hydrolysis. All values are expressed as $\mathrm{ng} / \mathrm{mg}$ cell protein and represent the mean of two replicates.

\subsubsection{The effect of temperature on the secretion of LDL-derived 125 I-apoB100 by hepatocytes}

In mammalial cells, there are transport steps along both the endocytotic and exocytotic pathway which are selectively sensitive to low temperature. Although the internalisation of ligand proceeds at a temperature between $15^{\circ} \mathrm{C}-20^{\circ} \mathrm{C}$, internalised ligands accumulate on the endocytic route instead of being delivered to lysosomes at low temperatures. Similarly, below $20^{\circ} \mathrm{C}$ exocytosis is inhibited and the transport of many proteins from trans-Golgi cisternae to the cell surface is arrested.

To address the question which transport route is needed to target LDL-endocytosed

\begin{tabular}{|c|c|c|c|}
\hline & $\mathbf{3 7}^{\circ} \mathbf{C}$ pulse & $\mathbf{3 7}^{\circ} \mathbf{C}$ pulse & $\mathbf{1 6}^{\circ} \mathbf{C}$ pulse \\
& $\mathbf{3 7}^{\circ} \mathbf{C}$ chase & $\mathbf{1 6}^{\circ} \mathbf{C}$ chase & $\mathbf{1 6}^{\circ} \mathbf{C}$ chase \\
\hline secreted ${ }^{125} \mathrm{I}-\mathrm{VLDL}$ & 3.39 & 0.97 & 0.98 \\
secreted ${ }^{\mathbf{1 2 5}} \mathrm{I}-\mathrm{LDL}$ & 108 & 70 & 129 \\
secreted ${ }^{\mathbf{1 2 5}} \mathrm{I}$-tyrosine & 10.7 & 3.2 & 3.3 \\
\hline
\end{tabular}

Table 4.4: The effect of temperature on the ${ }^{125} \mathrm{I}$-apoB100 secretion and hydrolysis. All values are expressed as ng/mg cell protein and represent the mean of two replicates.

${ }^{125} \mathrm{I}$-apoB to its lipidation site, hepatocytes were pulsed with ${ }^{125} \mathrm{I}-\mathrm{LDL}$ at $37^{\circ} \mathrm{C}$ or at $16^{\circ} \mathrm{C}$ for 1 hour and chased for 8 hours, at both temperature conditions, respectively (3.4.2).

Incubation of the cells at $37^{\circ} \mathrm{C}$ during pulse and at $16^{\circ} \mathrm{C}$ during chase resulted in the severe inhibition of apoB-recycling as VLDL, as compared to the control cells which were chased at $37^{\circ} \mathrm{C}$ (table 4.4 ). The ${ }^{125} \mathrm{I}-\mathrm{VLDL}$ secretion was decreased to approximately $29 \%$ of the control. Under these conditions the retroendocytosis of ${ }^{125} \mathrm{I}-\mathrm{LDL}$ was slightly reduced by $35 \%$ and the amount of hydrolysed ${ }^{125} \mathrm{I}$-apoB was reduced by $70 \%$.

When hepatocytes were pulsed at $16^{\circ} \mathrm{C}$ and chased at $16^{\circ} \mathrm{C}$ the recycled ${ }^{125} \mathrm{I}-\mathrm{VLDL}$ 
secretion was inhibited by $70 \%$. The retroendocytosis of ${ }^{125}$ I-LDL, however was enhanced by $20 \%$ of the control at $37^{\circ} \mathrm{C}$.

These results indicated that low temperature prevents the targeting of ${ }^{125} \mathrm{I}$-apoB to its recycling compartment.

\subsubsection{Effect of inhibition of MTP}

The early events in the assembly of de novo synthesised apoB-containing VLDL are dependent on the microsomal triglyceride transfer protein (MTP). MTP facilitates the transfer of TG into the nascent apoB during the first step of VLDL assembly in lume $\mathrm{n}$ of ER and possibly plays a role in forming and stabilising lipid droplets (Raabe et al. 1999). In the second VLDL-assembly step bulk lipid is incorporated into a VLDL precursor to form a mature VLDL particle. According to some studies the final lipidation step takes a place in post-ER and Golgi compartment and appears to be MTP independent, or at least MTP is not obligatory (Gusarova et al. 2003; Tran et al. 2002).

Thus, if lipidation of reutilised apoB100 occurs in Golgi, the secretion of VLDL particles should not be as sensitive to MTP inhibition as the de novo synthesis of VLDL. CP-346086 is a synthetic MTP inhibitor, which was reported to inhibit de novo apoBcontaining lipoprotein secretion from liver in mouses and rats (Chandler et al. 2003). To first confirm its effect on VLDL de novo secretion in primary mouse hepatocytes, hepatocytes were pulse-labelled with ${ }^{35} \mathrm{~S}$-methionine/cysteine and the cells were chased for 8 hours (as described in 3.6.8) together with concentrations of the MTP inhibitor ranging from 0 to $500 \mathrm{nM}$. The amount of ${ }^{35}$ S-labelled de novo synthesised VLDL secreted into the medium was assesed by separation of lipoproteins with floatation ultracentrifugation (3.5) and measuring the radioactivity in the obtained gradient fractions.

The effect of different concentrations of the MTP inhibitor on the release of VLDL during the chase period is shown in Fig. 4.11. There was a stepwise decrease in the amount of de novo synthesised VLDL with increasing concentration of the inhibitor. These results indicate that treatment with $500 \mathrm{nM}$ MTP inhibitor is sufficient to reduce the secretion of newly synthesised apoB associated with VLDL to $20 \%$ of control.

To exclude the possibility that inhibition of MTP had an inhibitory effect on general protein secretory system in hepatocytes, the amount of albumin secreted into the medium was determined by immunoprecipitation (shown in Fig. 4.12). The secretion of albumin was not decreased under all concentrations of inhibitor, which indicates 


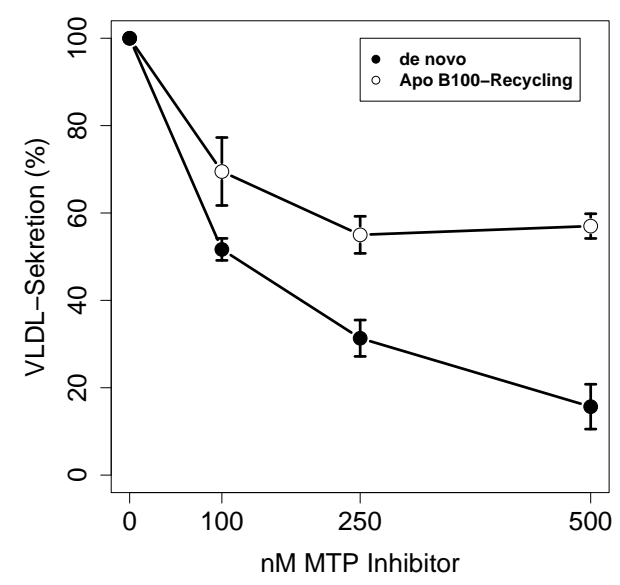

Figure 4.11: Effect of MTP inhibition on the secretion of newly synthesised apoB as VLDL and on the apoB100-recycling in primary mouse hepatocytes. Hepatocytes were pulse-labelled with ${ }^{35}$ Smethionine/cysteine and chased, as described in the method section, in the presence of MTP inhibitor at the concentrations indicated at the abscissa. The amount of ${ }^{35}$ S-labelled de novo synthesised VLDL was determined using floatation ultracentrifugation gradient. Hepatocytes were pulsed with ${ }^{125} \mathrm{I}-\mathrm{LDL}$ and chased, as described in the method section, in the presence of MTP inhibitor at the concentrations indicated at the plot. The amount of ${ }^{125} \mathrm{I}-$ VLDL, secreted into the medium was assesed by separation of lipoproteins with floatation ultracentrifugation. The values are expressed as a $\%$ of VLDL secretion, related to the VLDL secretion in the cells cultured without MTP inhibitor and represent the mean of two dishes per condition. Errorbars indicate two standard deviations from the mean.

that its effect was specific to the assembly mechanism of VLDL. During the treatment with the MTP inhibitor no significant change in the amount of total cellular protein was observed.

To analyse the influence of the MTP inhibitor on apoB recycling, hepatocytes were pulsed with $10 \mu \mathrm{g}{ }^{125} \mathrm{I}-\mathrm{LDL}$ for 1 hour and chased for 8 hours in the absence or presence of up to $500 \mathrm{nM}$ MTP inhibitor. The results are presented in Fig. 4.11. Different doses of the MTP inhibitor did not impair LDL-derived apoB100-VLDL secretion to the same extend as the de novo-VLDL secretion pathway. $250 \mathrm{nM}$ inhibitor supressed the amount of recycled apoB-containing VLDL just to $50 \%$. Contrary to de novo VLDL synthesis, the inhibitory effect is already saturated at $250 \mathrm{nM}$. Increasing the inhibitor to $500 \mathrm{nM}$ did not cause further reduction in the amount of secreted ${ }^{125} \mathrm{I}$ - 
VLDL.

These results suggest that lipidation of reutilised apoB100 can only take place in a compartment, with MTP-independent lipidation mechanisms, presumably in the Golgi network.

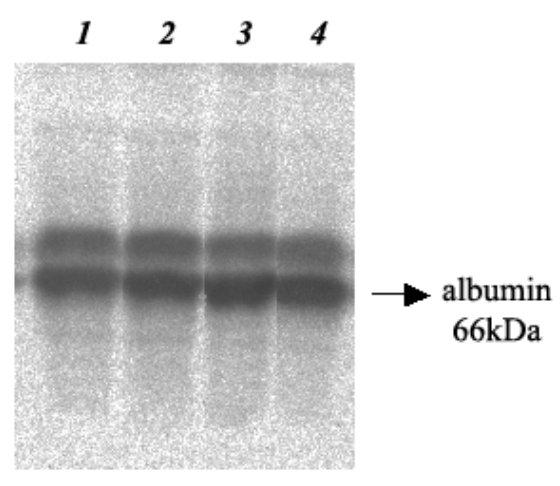

Figure 4.12: The effect of MTP inhibitor on the general protein secretion in primary mouse hepatocytes. Hepatocytes were pulse-labelled with ${ }^{35}$ Smethionine/cysteine in the presence of MTP inhibitor. The amount of albumin secreted into the medium under each MTP inhibitor concentration was determined by immunoprecipitation. The doses of MTP inhibitor: 1- control without MTP inhibitor, 2- 100nM, 3- 250nM, 4500nM. 


\section{Discussion}

\subsection{Metabolisation of LDL-derived apoB100}

VLDL are triglyceride-rich lipoprotein particles, which contain apolipoprotein B100 and apolipoprotein E and are synthesised and secreted by the liver. After entering the bloodstream VLDLs interact with lipoprotein lipases, which catalyse the hydrolysis of triacylglycerides. The final product of VLDL catabolism in the circulation is LDL, the major cholesterol transporting lipoprotein in the plasma. About half of LDL particles are cleared directly by the liver through LDL receptor-mediated endocytosis, while the rest are taken up by the peripheral tissue via the same mechanism. The protein moiety of $\mathrm{LDL}$, apoB, is a critical ligand for this uptake mediating the recogniction of the LDL molecule by its receptor.

It is well established that after endocytosis skin fibroblasts and other peripheral cell types catabolise LDL to free amino acids, free cholesterol and other lipids (Goldstein and Brown 1974). But it has been shown, around twenty years ago, that primary human hepatocytes catabolise the protein moiety of LDL at a much lower rate than skin fibroblasts (Edge et al. 1986). Relatively inefficient degradation of LDL-derived apoB100 was also reported in HepG2 cells (Lombardi et al. 1993). However, the fate of the non-catabolised apoB100 has never been analysed so far and is addressed in this thesis.

We confirmed and extended the findings of Edge and Lombardi by showing that in mouse hepatocytes after 10 hours of LDL uptake, $60 \%$ of LDL-derived cholesteryl ester was degraded to free cholesterol (Fig. 4.4) or reesterified to cholesteryl oleate, but just a small fraction of LDL-derived apoB100 was routed to the lysosomal compartment and degraded. The hydrolysis rate of apoB100 accounted for less than $10 \%$ of the total LDL uptake, independently of the time of LDL endocytosis (Fig. 4.1b). In agreement with these results the delivery of LDL-derived apoB100 to the late endosomal and lysosomal compartment was almost not detectable with immunofluorescence microscopy (Fig. 4.10). Different concentrations of LDL present in the media during the uptake experiment did not alter the degradation level of apoB, which was 


\section{Discussion}

less than $10 \%$ in the range of LDL doses up to $100 \mu \mathrm{g} / \mathrm{ml}$ (Fig. 4.2b). Furthermore, the endocytosis of LDL at relatively low concentrations of $1-10 \mu \mathrm{g} / \mathrm{ml} \operatorname{did}$ not enhance the degradation rate of LDL-derived apoB100 either (Fig. 4.3b). This indicates that the low rate of apoB100 hydrolysis is not due to a saturation of the cells with high amounts of LDL during endocytosis which could exceed their hydrolysis capacity. Most of the LDL was endocytosed via LDL receptor-mediated endocytosis and a small fraction (less than $15 \%$ ) was internalised by LDL receptor-independent pathways (Fig. 4.2a, 4.3a), as it was observed also in other reports (Shepherd and Packard 1986). The alternative pathway of LDL uptake, independent of the LDL receptor, possibly involves the participation of cell surface heparan sulfate proteoglycans (HSPGs) (Hurt-Camejo et al. 1997; Williams and Fuki 1997). It has been already proved that apoE-containing lipoprotein remnants can interact with HSPG and are either transferred to the lipoprotein-receptor related protein (LRP) for internalisation or are taken up directly by HSPG (Mahley and Ji 1999). What role the direct HSPG pathway may play in the uptake of apoB100-containing particles is not certain. However, a contribution of the LRP and HSPG-LRP pathway in apoB48-associated lipoprotein clearance has been already demonstrated (Rohlmann et al. 1998; Veniant et al. 1998).

We could observe the differences in LDL-receptor dependent and independent metabolisation of LDL particles. The LDL-degradation rate was twice higher for LDL-receptor independent endocytosis than for LDL-receptor mediated endocytosis (Fig. 4.3b). The LDL receptor-independent hydrolysis was not saturable up to a concentration of $100 \mu \mathrm{g} / \mathrm{ml} \mathrm{LDL}$, opposite to the LDL receptor-dependent one, which was saturable at a dose of $25 \mu \mathrm{g} / \mathrm{ml} \mathrm{LDL}$ (Fig. 4.2b). These data suggest that two distinctive intracellular targeting mechanisms are used depending of the LDL-uptake mode. This finding is supported by the studies of Fuki et al. (2000) which show that catabolism of a ligand after HSPGs internalisation is distinct from its catabolism after receptor mediated endocytosis.

Instead of being degraded the LDL-derived apoB100 accumulated within the hepatocytes in a linear fashion over time (Fig. 4.1b). The uptake of LDL was saturable with half maximal uptake at $19 \mu \mathrm{g} \mathrm{LDL} / \mathrm{ml}$. This result was similar to the $\mathrm{K}_{\mathrm{m}}$-value of $16 \mu \mathrm{g} \mathrm{LDL} / \mathrm{ml}$ reported earlier for cultured human hepatocytes (Kosykh et al. 1985). 


\subsection{Recycling of endocytosed apoB100 in primary hepatocytes and in the mouse liver}

To analyse the fate of the apoB100 endocytosed by and accumulating within hepatocytes, we allowed cells to endocytose ${ }^{125} \mathrm{I}-\mathrm{LDL}$ and followed its metabolisation during a chase period, when no fresh LDL could be taken up. Cultured hepatocytes that had endocytosed ${ }^{125}$ I-LDL for 1 hour secreted $37.5 \%$ of the internalised intact LDLderived ${ }^{125} \mathrm{I}$-apoB100 while $12.5 \%$ were degraded within 24 hours of chase (Fig. $4.5 \mathrm{a}$ ). Intact apoB100 can exclusively be secreted in association with lipids as a lipoprotein particle. The ${ }^{125} \mathrm{I}$-apoB100 recovered from the chase medium was associated with VLDL, IDL and LDL in a ratio of 1:1:12 (Fig. 4.5b).

In fibroblasts a fraction of LDL internalised via receptor-mediated endocytosis can escape lysosomal degradation and be re-secreted from the cells in unchanged or just slightly altered form (Aulinskas et al. 1981; Greenspan and St Clair 1984). This process has been termed as retroendocytosis and can easily explain the secretion of ${ }^{125} \mathrm{I}$-LDL during the chase period in primary hepatocytes. However, the detection of ${ }^{125} \mathrm{I}-\mathrm{VLDL}$ in the chase medium indicates that in hepatocytes, LDL-derived apoB100 is reutilised and secreted as VLDL-triglyceride rich lipoproteins after loading with triglycerides. The notion of this loading process is also supported by the finding that primary hepatocytes secreted apoB containing particles of intermediate density, IDL (Fig. 4.6). The latter may represent lipoprotein particles that are secreted in an intermediate triacylglyceride-loading state. The secretion of such loading intermediate IDL by HepG2 cells and hepatocytes has been reported previously (Packard et al. 2000; Pease and Leiper 1996).

In our attempt to examine the physiological relevance of in vitro findings for the situation in vivo, we performed perfusion experiments in the mouse liver. The liver of anaesthesised mice was pulsed with $10 \mu \mathrm{g}{ }^{125} \mathrm{I}$-LDL per ml perfusion buffer for 20 minutes. The additional washing and heparine treatment steps were supposed to remove maximum of LDL that passed the liver without being internalised and cellbound LDL. Consequently, it can be assumed that perfusate collected after heparine step contained mostly the material released by the cells of the liver.

During one hour chase period the liver metabolised or secreted just $9.5 \%$ of the internalised LDL-derived apoB100 (Table 4.1). The finding that only a small fraction of the total endocytosed apoB100 was metabolised or secreted by the liver indicates that most of LDL-derived apoB100 is stored within intracellular compartment, from which it is subsequently targeted slowly to degradation site or for secretion. In ad- 


\section{Discussion}

dition, it demonstrates a long half-time of endocytosed LDL-derived apoB100 in the mouse liver. This finding was also observed in primary hepatocyte culture, where $50 \%$ of internalised ${ }^{125} \mathrm{I}$-apoB remained within the cells after 24 hours of chase period (Fig.4.5a).

During mouse liver perfusion, after 1 hour of chase, the liver hydrolysed $2.5 \%$ of endocytosed LDL-derived apoB100, while $7 \%$ was secreted as intact apoB100 (Table 4.1). Intact apoB represented VLDL, IDL and LDL particles, which were secreted at a ratio 3:1:4 (Fig. 4.7b). This result proves that like hepatocytes in in vitro studies, a viable and intact mouse liver is able to reutilise LDL-derived apoB100 to assemble VLDL and IDL particles. Furthermore, a part of the internalised LDL is retroendocytosed.

It is not possible to compare in vitro and in vivo experiments in the terms of absolute amounts of uptaken, hydrolysed or secreted apoB100. Nevertheless, the secretion of different lipoprotein classes and the hydrolysis rate relative to the total secretion can be compared. The ratio of secretion of hydrolysed and intact apoB100 was the same in primary hepatocytes and in the mouse liver and accounted for $25 \%$ to $75 \%$. Thus, the amount of LDL-derived apoB100 released by the cells as lipoprotein particles exceeds the fraction which is destinated to lysosomal degradation.

The quantitive relationship between the secreted recycled-apoB containing particles (VLDL and IDL) and retroendocytosed apoB molecules (LDL) was $14 \%$ to $86 \%$ in in vitro studies. In vivo, however, the apoB100 associated lipoproteins were secreted in the ratio of $50 \%$ (VLDL/IDL) to $50 \%$ (LDL). Apparentely, the process of VLDL assembly by apoB recycling is more significant in the viable liver than under in vitro conditions. However the finding that the apoB100 hydrolysis rate is the same in both systems indicates the importance of the apoB-recycling.

To prove the reutilisation of LDL-derived apoB100 for VLDL synthesis we determined its fate after intravenous injection of ${ }^{125}$ I-LDL into living mice followed by pharmacological inhibition of the VLDL catabolisation using Triton WR-1339. Injected ${ }^{125} \mathrm{I}-$ LDL were removed from the circulation via hepatic uptake and endocytosed LDLderived apoB100 accumulated within the liver. In the plasma of the animals the amount of ${ }^{125}$ I-VLDL increased over time after the injection of ${ }^{125}$ I-LDL (Table 4.2) while the amount of ${ }^{125} \mathrm{I}$-apoB found in the liver decreased. Thus, the in vivo studies clearly demonstrate that VLDL is assembled from endocytosed LDL-derived apoB100 and secreted into the circulation in the living mouse.

It has been previously assumed that all VLDL found in the circulation is assembled in the liver using de novo synthesised apoB. However, the findings described in this 


\section{Discussion}

thesis show that a certain part of the VLDL found in the circulation is assembled using recycled apoB100. But the data presented here are not sufficient to quantifiy the relationship of VLDL assembled from recycling apoB100 to VLDL formed from de novo synthesised apoB. The semi-quantitative liver perfusion experiments could underestimate the importance of apoB100-recycling for several reasons. The liver perfusion and the i.v. LDL-injection experiments demonstrate that recycling apoB100 utilised for VLDL assembly has a long half life in the hepatocytes. Upon perfusion with or i.v. injection of radiolabelled LDL, the liver must thus contain a pool of previously synthesised, VLDL-secreted and LDL-endocytosed unlabelled apoB. Because unlabelled apoB from this pool contributes to the VLDL assembly, the secreted ${ }^{125}$ I-VLDL only represents a part of the total VLDL assembled using recycling apoB. Another reason for the underestimation of this process is the possibility of reutilisation of radiolabelled apoB molecules: one ${ }^{125} \mathrm{I}$-apoB molecule could undergo several cycles of endocytosis as LDL, recycling and secretion as VLDL making it hard to estimate the relationship of the two VLDL assembly processes. Yet another reason for an underestimation could be an unphysiologically low ${ }^{125}$ I-LDL-dose in the experiments as the LDL concetrations found in the serum are often higher than the concetrations we could achieve with radiolabelled LDL. Taken together, the obtained data allow us to assume that a considerable amount of newly synthesised apoB associated with VLDL particles and converted into LDL in the circulation can be recycled to form VLDL lipoproteins.

Recycling of ligand internalised by receptor-mediated endocytosis, as observed for apoB100, has been reported previously, e.g. for transferrin. Iron-loaded transferrin remains bound to its receptor throughout the recycling pathway ans is released in iron-free form upon returning to the cell surface (Daro et al. 1996). Studies show that another apolipoprotein, internalised triglyceride rich lipoproteins-derived apoE is efficiently recycled in hepatocytes (Rensen et al. 2000). However, the mechanism underlying this resecretion differs from those, observed in this thesis. ApoE recycling requires the internalisation of HDL-derived apoA-I and its targeting to apoE/cholesterol containing endosomes. This intracellular association of apoA-I with apoE-cholesterol complexes can then lead to the formation and secretion of apoEenriched HDL molecules (Heeren et al. 2003). LDL-derived apoB100 does not require the presence of another apolipoprotein to be secreted. It is directly an acceptor for lipid loading and triggers itself the process of recycling.

The process of apoB100 recycling appears to be rather fast. The fraction of ${ }^{125} \mathrm{I}-$ 
VLDL was recovered after 15 minutes of starting the perfusion of mouse liver with

${ }^{125} \mathrm{I}-\mathrm{LDL}$ (not shown). It is longer, however, than recycling of the ligand transferrin, which occurs with a half life of less than 10 minutes in HepG2 cells. A rapid passage of transferrin molecules can be already observed after 4 minutes (Ciechanover et al. 1983). Apparently, the lipidation of apoB100 determines the time of recycling. In cultured rat hepatocytes the synthesis of apoB takes 7-15 minutes and apoB appears in the medium 30-40 minutes later. The slow step in the passage of apoB through the secretory pathway is movement of the protein in and out of ER (Borchardt and Davis 1987b; Vance 2002). The recycling of apoB100 and its anew lipidation does not require the translocation step and post-translational modification of the protein, consequently it is quicker than de novo VLDL assembly pathway.

\subsection{Cellular localisation of the lipidation of recycled LDL-derived apoB100 and the stored LDL}

Many studies in the recent years have enabled the better understanding of cell and molecular biology of VLDL de novo assembly process (cf. introduction chapter). Nevertheless, a number of reactions involved in this pathway still needs to be elucidated. Important questions still to be addressed include the mechanism of lipidation, the factors required for lipid channeling and apoB transport in the secretory pathway. The route of LDL-derived apoB recycling, described in this thesis, introduces additional complexity in the apoB lipidation and secretion process. The intracellular localisation of endocytosed and stored LDL-derived apoB100 was determined using different approaches. The seperation of homogenised liver perfused with ${ }^{125} \mathrm{I}-$ LDL showed that half of endocytosed ${ }^{125} \mathrm{I}$-apoB colocalised with fractions positive for TGN markers (Fig. 4.8). Since the fraction of recycling endosomes is isolated together with TGN network, this vesicle population could contribute to either the storage of endocytosed apoB100 or its lipidation. $13 \%$ of LDL-derived apoB was colocalised with endosomal and ER compartment. We could not confirm the Golgi-apoB100 colocalisation with immunofluorescence microscopy (Fig. 4.9). We also did not observe any convincing colocalisation immunofluorescence signal with other organelle markers: for ER, early endosomes, cis-Golgi (Fig. 4.10). Opposite to the subcellular fractionation experiment, which was performed on mouse liver, immunofluorescence material was prepared with primary hepatocyte culture. Unlike in the perfused liver the LDL-endocytosed apoB100 was poorely lipidated in cultured hepatocytes (the 


\section{Discussion}

ratio of secreted ${ }^{125} \mathrm{I}$-VLDL to ${ }^{125} \mathrm{I}-\mathrm{LDL}$ was $1: 12$ ). Probably, the fluorescence signal of LDL-derived apoB100 seen in the hepatocytes represents Cy3-LDL which is going to be retroendocytosed and the apoB100 destinated to lipidation is not visible. That is why, the liver perfusion in vivo with fluorescence labelled LDL followed by liver section analysis should be considered as next experiment in the future.

Taking together the subcellular fractionation and immunofluorescence microscopy results, we can hypothesise that the intracellular localisation of retroendocytosed LDLderived apoB100, at least partly, differs from the localisation of recycling apoB100. Particularly, the site of recycled apoB100 storage requires the presence of complex lipidation machinery.

Thus, retroendocytosed LDL might be, at least partly, located in Rab5-negative, Rab11-positive vesicle population, while recycled apoB100 is found in TGN (and) recycling endosomes. The TGN localisation of recycling apoB100 was supported by the finding that MTP inhibitor partly inhibited the assembly process of LDL-derived apoB100-containing VLDL (Fig. 4.11). The activity of microsomal triglyceride transfer protein (MTP) is required in the first step of VLDL de novo assembly, which takes a place in ER. However, its role in the Golgi and in the secretory pathway appears to be not obligatory (Gusarova et al. 2003; Tran et al. 2002). Our results showed that lipidation of recycled apoB100 is partly MTP-idependent, thus it can only take place in the compartment, where MTP-idependent lipidation mechanisms exist, presumably in Golgi network. Furthermore, the targeting of endocytosed and recycling molecules to the TGN has been established as an endocytic pathway in the last years. It has been reported for ricin, a plant toxin (Lauvrak et al. 2002) and the bacterial shiga toxin (Mallard et al. 1998).

The intracellular localisation of recycling apoB cannot be, however, clearly and doubtlessly specified at this phase of this project, in particular that other distinct endosome populations can also participate in the retroendocytosis and the recycling pathways.

Additional experiments were performed to confirm the contribution of the TGN to the process of recycling of apoB100 as VLDL. Primary mouse hepatocytes were incubated in the presence of BFA and monensin, two drugs which are known to affect intracellular membrane traffic at different sites. BFA is a fungal metabolite that blocks trafficking from the endoplasmic reticulum to the Golgi apparatus, which ultimately leads to the dissolution of the Golgi complex. Monensin, a carboxylic acid ionophor, causes a major disruption of the transport of vesicles from the Golgi complex to the plasma membrane (Dinter and Berger 1998). Both drugs inhibited the recycling of LDL-derived apoB as VLDL by more that $50 \%$ (table 4.3 ). This implicates a func- 


\section{Discussion}

tional role for the Golgi apparatus in this process. The inability of these drugs to fully inhibit recycling suggests that an additional mechanism might mantain a part of recycling, even when the Golgi route is interrupted. Sparks et al (1996) reported that $10 \mu \mathrm{g} / \mathrm{ml}$ BFA greatly reduced but did not completely inhibit secretion of albumin, transferrin and de novo synthesised apoB in primary rat hepatocytes. Thus, it is possible that the concentration of drugs used in our experiment did not completely disrupt the Golgi. Consequently, the part of apoB100 could recycle through remnants of the Golgi apparatus.

Low temperature is known to block vesicular transport. We examined how temperature reduction affects recycling of apoB100 and retroendocytosis pathway. Since vesicular transport is involved in all steps along the secretory pathway: ER to cisGolgi, between Golgi subcompartments and from trans-Golgi to the cell surface, it seems plausible that the reduced temperature had a strong, almost $70 \%$ effect on the inhibition of ${ }^{125} \mathrm{I}-\mathrm{VLDL}$ secretion (table 4.4). The retroendocytosis of LDL was inhibited by $30 \%$ when the cells were pulsed at $37^{\circ} \mathrm{C}$ and chased at $16^{\circ} \mathrm{C}$, but it was enhanced when the cells were pulsed and chased at $16^{\circ} \mathrm{C}$. This result together with the data from Golgi-disturbing agents experiment suggest that there are multiple intracellular traficking routes for retroendocytosis of LDL. There may be a rapid re-secretion pathway, in which LDL is internalised, trafficked close to the cell periphery and retroendocytosed. A slower retroendocytosis route would involve retention of apoB100-LDL in the cell. It is possible that recycling endosomes or even the Golgi take a part in this longer pathway. It is not known whether LDL lipid cargo could be modified during passing through this route by partly delipidation and new lipidation. Taking into an account these considerations it appears that the reduced temperature applied just during the chase period affected rather the 'slower' retroendocytosis of LDL than the peripheral one. That is why the inhibition of LDL retroendocytosis accounted under this condition just for $30 \%$. However, the low temperature applied already during pulse period seemed to interfere with targeting a part of LDL to the 'slow' retroendocytosis route. Instead this pool was diverted to a rapid recycling pathway, from peripheral endosomes to the plasma membrane, what resulted in the increase in the amount of LDL recovered in the chase medium at the end of the experiment.

These observations can be supported by other studies. The fact that LDL retroendocytosis is not inhibited after low temperature pulse time has been shown by Aulinskas et al. (1981). The LDL retroendocytosis route from a peripheral cytoplasmic compartment has been proposed by Greenspan and St Clair (1984). Furthermore, Takahashi 
et al. (1989) has observed the involvment of TGN apparatus and secretory vesicles, as well as early endosomal compartment in retroendocytosis of HDL.

\subsection{The significance of LDL-derived apoB recycling pathway in an organism}

ApoB100 is a central apolipoprotein for the hepatic lipid secretion. The plasma concentration of this protein results from the balance between its synthesis rate in the liver and its removal from the circulation by receptor and non receptor-mediated pathways. The homeostasis of apoB100 is critical for the lipid homeostasis in the mammalian organism. Our findings provide a novel pathway for VLDL assembly in the mouse liver prooving that LDL-derived apoB100 can be reutilised and recycled as triacylglyceride-rich VLDL particles.

We propose the following model for this pathway. After endocytosis, the LDL-receptor ligand apoB100 is significantly depleted of LDL-bound cholesteryl esters. A small portion of apoB100 is targeted to lysosomes, immediately after the endocytosis. However, most apoB100 is not hydrolysed but targeted to the TGN/recycling endosomes compartment. A significant fraction od internalised LDL, localised close to the cell periphery, is resecreted in the quick retroendocytosis process. From storage compartment, LDL-derived apoB is either directed to lysosomal dgradation or is loaded with a new lipid cargo molecules and slowly secreted as VLDL/IDL. The same compartment might also play a role in the slow retroendocytosis route of LDL.

It has been known tha apoB de novo synthesis in the liver cells is regulated almost exclusively at the post-transcriptional level and a significant proportion of newly synthesised apoB is intracellularly degraded (Rusinol et al. 1998). Since the amount of apoB synthesised exceeds its secretion, why does the hepatocyte have a mechanism for reutilisation of already translated and secreted apoB?

Degradation of apoB serves as a quality control mechanism. At any point during a long maturation process, from apoB translation to VLDL secretion, an inappropriately folded polypeptide, a incorrect lipidated or abnormal VLDL particle can be destroyed. Whether intracellular degradation of apoB is a regulated process that actively determines the output of hepatic VLDL remains unclear. Furthermore, there appears to be significant variations in the proportion of the newly translated apoB that is degraded intracellularly before secretion among cell lines (Yao et al. 1997). Since the experiments regarding this subject were performed in vitro, the importance of this process in vivo is unclear. Therefore, the degradation can be merely a waste 


\section{Discussion}

disposal process representing a consequence of aborted assembly or failed secretion (Yao et al. 1997). The existence of two mechanisms, degradation of synthesised apoB and its recycling after endocytosis would be independent of each other. An opposite explanation could consider both pathways as collaborative mechanisms which, by regulating the level of degradation and recycling, enable the cell storage of adequate amount of apoB. Consequently, the cell rapidly adjusts to the needs of secretion of triacylglycerol into the circulation without invoking the long translation of huge apoB protein.

Our data indicate that the liver can act as an apoB buffer by controlling not only the de novo synthesis of apoB100, its endocytosis and degradation rate but also by its intracellular storage and reutilization for the assembly of VLDL, IDL. However, the physiologic relevance of the reutilisation and recycling of apoB needs more explanation in the future. 


\section{Summary}

According to the widely accepted model of LDL endocytosis in mammalian cells, LDL is transported to lysosomes and hydrolysed to amino acids, free cholesterol and other lipids. However, it has been shown that in hepatocytes less of the endocytosed protein component of LDL- apoB100 is degraded than in skin fibroblasts (Edge et al. 1986). The aim of this study was to analyse the fate of endocytosed but non-hydrolysed LDL-derived apoB100 in primary mouse hepatocytes and in the mouse liver.

We confirmed the previous observation that cultured primary mouse hepatocytes have a low LDL-derived apoB100 hydrolysis rate, as compared to that observed in mouse embryonic fibroblasts (MEF). But unlike other studies we followed the metabolic route of non-degraded internalised apoB100. We observed that primary mouse hepatocytes target a fraction of endocytosed apoB100 to an intracellular compartment, presumably TGN/recycling endosomes, where it is lipidated and secreted in the form of VLDL and, to a lesser degree, as IDL. These data prove that LDL-derived apoB100 can be reuitilised to assemble VLDL. During this process LDL may be delipidated and is then lipidated with triacylglycerides to become finally secreted as VLDL lipoprotein.

In the perfused mouse liver, after 20 minutes of ${ }^{125} \mathrm{I}-\mathrm{LDL}$ endocytosis and one hour of chase, $10 \%$ of the endocytosed apoB100 is secreted ; out of that an average of $27 \%$ as hydrolysis product and $73 \%$ is secreted as intact apoB100: as VLDL (26\%), IDL $(9 \%)$ and LDL (38 \%). Finally, after the injection of ${ }^{125}$ I-LDL into the living mouse followed by blocking of VLDL catabolism in its blood the increasing amounts of LDL-derived apoB100 containing VLDL particles are detecting in the serum while the amount of ${ }^{125} \mathrm{I}$-apoB100 stored in the liver decreases.

The studies in vitro on primary mouse hepatocytes in conjunction with studies in the perfused mouse liver as well as in the living mouse lead us to the conclusion that LDL-derived apoB100 can be stored in the liver and reutilised by loading it with new lipid cargo to form VLDL particles. The process of recycling of apoB100 has never been shown before and represents a novel pathway of VLDL assembly, which is 
Summary

independent of de novo VLDL sythesis. 


\section{Acknowledgements}

First, I would like to express my deepest gratitude to Dr. Jobst Landgrebe for all the help, support and supervision he has given me during these three years, especially during many tough moments of my $\mathrm{PhD}$.

I am grateful to Prof. Dr. Kurt von Figura that he gave me the opportunity to make the PhD study in Biochemistry II department. I would also like to thank him for advice and discussion throughout my time at Biochemie II.

I also wish to thank Prof. Dr. Wimmer for agreeing to be a co-referent of my thesis.

I thank Peter Braun and Chieh Hsu for their co-operation and assistance in this project.

I thank Markus Mroz for his excellent technical assistance.

I would also like to address my special thanks to the members of my lab, mentioned above, for providing a pleasant working atmosphere, for friendly discussion and moral support. 


\section{Bibliography}

C.A. Alexander, R.L. Hamilton, and R.J. Havel. Subcellular localization of B apoprotein of plasma lipoproteins in rat liver. J Cell Biol, 69(2):241-63, 1976.

R.A. Anderson, C. Joyce, M. Davis, J.W. Reagan, M. Clark, G.S. Shelness, and L.L. Rudel. Identification of a form of acyl-CoA:cholesterol acyltransferase specific to liver and intestine in nonhuman primates. J Biol Chem, 273(41):26747-54, 1998.

L. Asp, C. Claesson, J. Boren, and S.O. Olofsson. ADP-ribosylation factor 1 and its activation of phospholipase D are important for the assembly of very low density lipoproteins. J Biol Chem, 275(34):26285-92, 2000.

L. Asp, B. Magnusson, M. Rutberg, L. Li, J. Boren, and S.O. Olofsson. Role of ADP ribosylation factor 1 in the assembly and secretion of ApoB-100-containing lipoproteins. Arterioscler Thromb Vasc Biol, 25(3):566-70, 2005.

T.H. Aulinskas, D.R. van der Westhuyzen, E.L. Bierman, W. Gevers, and G.A. Coetzee. Retro-endocytosis of low density lipoprotein by cultured bovine aortic smooth muscle cells. Biochim Biophys Acta, 664(2):255-65, 1981.

M.J. Bamberger and M.D. Lane. Possible role of the Golgi apparatus in the assembly of very low density lipoprotein. Proc Natl Acad Sci U S A, 87(7):2390-4, 1990.

S.I. Bannykh, N. Nishimura, and W.E. Balch. Getting into the Golgi. Trends Cell Biol, 8(1):21-5, 1998.

S.M. Bartlett and G.F. Gibbons. Short- and longer-term regulation of very-lowdensity lipoprotein secretion by insulin, dexamethasone and lipogenic substrates in cultured hepatocytes. A biphasic effect of insulin. Biochem J, 249(1):37-43, 1988.

C.L. Bisgaier and R.M. Glickman. Intestinal synthesis, secretion, and transport of lipoproteins. Annu Rev Physiol, 45:625-36, 1983. 


\section{Bibliography}

R.A. Borchardt and R.A. Davis. Intrahepatic assembly of very low density lipoproteins. Rate of transport out of the endoplasmic reticulum determines rate of secretion. J Biol Chem, 262(34):16394-402, 1987a.

R.A. Borchardt and R.A. Davis. Intrahepatic assembly of very low density lipoproteins. Rate of transport out of the endoplasmic reticulum determines rate of secretion. J Biol Chem, 262(34):16394-402, 1987b.

J. Boren, S. Rustaeus, and S.O. Olofsson. Studies on the assembly of apolipoprotein B-100- and B-48-containing very low density lipoproteins in McA-RH7777 cells. $J$ Biol Chem, 269(41):25879-88, 1994.

J. Boren, M.M. Veniant, and S.G. Young. Apo B100-containing lipoproteins are secreted by the heart. J Clin Invest, 101(6):1197-202, 1998.

P. Bradbury, C.J. Mann, S. Kochl, T.A. Anderson, S.A. Chester, J.M. Hancock, P.J. Ritchie, J. Amey, G.B. Harrison, D.G. Levitt, L.J. Banaszak, J. Scott, and C.C. Shoulders. A common binding site on the microsomal triglyceride transfer protein for apolipoprotein B and protein disulfide isomerase. J Biol Chem, 274(5):3159-64, 1999.

MM Bradford. A rapid and sensitive method for the quantitation of microgram quantities of protein utilizing the principle of protein-dye binding. Anal Biochem., 72:248-255, 1976.

J.L. Brodsky, V. Gusarova, and E.A. Fisher. Vesicular trafficking of hepatic apolipoprotein B100 and its maturation to very low-density lipoprotein particles; studies from cells and cell-free systems. Trends Cardiovasc Med, 14(4):127-32, 2004.

M.S. Brown and J.L. Goldstein. A receptor-mediated pathway for cholesterol homeostasis. Science, 232(4746):34-47, 1986.

M.J. Callow, L.J. Stoltzfus, R.M. Lawn, and E.M. Rubin. Expression of human apolipoprotein B and assembly of lipoprotein(a) in transgenic mice. Proc Natl Acad Sci U S A, 91(6):2130-4, 1994.

I.J. Cartwright and J.A. Higgins. Intracellular events in the assembly of very-lowdensity-lipoprotein lipids with apolipoprotein B in isolated rabbit hepatocytes. Biochem J, 310 ( Pt 3):897-907, 1995. 


\section{Bibliography}

D. Cavallo, R.S. McLeod, D. Rudy, A. Aiton, Z. Yao, and K. Adeli. Intracellular translocation and stability of apolipoprotein B are inversely proportional to the length of the nascent polypeptide. J Biol Chem, 273(50):33397-405, 1998.

C.E. Chandler, D.E. Wilder, J.L. Pettini, Y.E. Savoy, S.F. Petras, G. Chang, J. Vincent, and H.J. Harwood, Jr. CP-346086: an MTP inhibitor that lowers plasma cholesterol and triglycerides in experimental animals and in humans. J Lipid Res, 44(10):1887-901, 2003.

S.H. Chen, G. Habib, C.Y. Yang, Z.W. Gu, B.R. Lee, S.A. Weng, S.R. Silberman, S.J. Cai, J.P. Deslypere, M. Rosseneu, and et al. Apolipoprotein B-48 is the product of a messenger RNA with an organ-specific in-frame stop codon. Science, 238(4825): 363-6, 1987.

S.Y. Choi, L.G. Fong, M.J. Kirven, and A.D. Cooper. Use of an anti-low density lipoprotein receptor antibody to quantify the role of the LDL receptor in the removal of chylomicron remnants in the mouse in vivo. J Clin Invest, 88(4):1173-81, 1991.

A. Ciechanover, A.L. Schwartz, A. Dautry-Varsat, and H.F. Lodish. Kinetics of internalization and recycling of transferrin and the transferrin receptor in a human hepatoma cell line. Effect of lysosomotropic agents. J Biol Chem, 258(16):9681-9, 1983.

E. Daro, P. van der Sluijs, T. Galli, and I. Mellman. Rab4 and cellubrevin define different early endosome populations on the pathway of transferrin receptor recycling. Proc Natl Acad Sci U S A, 93(18):9559-64, 1996.

N.O. Davidson, L.M. Powell, S.C. Wallis, and J. Scott. Thyroid hormone modulates the introduction of a stop codon in rat liver apolipoprotein B messenger RNA. $J$ Biol Chem, 263(27):13482-5, 1988.

M.S. Davies, S.C. Wallis, D.M. Driscoll, J.K. Wynne, G.W. Williams, L.M. Powell, and J. Scott. Sequence requirements for apolipoprotein B RNA editing in transfected rat hepatoma cells. J Biol Chem, 264(23):13395-8, 1989.

R.A. Davis. The endoplasmic reticulum is the site of lipoprotein assembly and regulation of secretion. Subcell Biochem, 21:169-87, 1993.

A. Dinter and E.G. Berger. Golgi-disturbing agents. Histochem Cell Biol, 109(5-6): 571-90, 1998. 


\section{Bibliography}

V.P. Dole. A relation between non-esterified fatty acids in plasma and the metabolism of glucose. J Clin Invest, 35(2):150-4, 1956.

E.Z. Du, J. Kurth, S.L. Wang, P. Humiston, and R.A. Davis. Proteolysis-coupled secretion of the $\mathrm{N}$ terminus of apolipoprotein B. Characterization of a transient, translocation arrested intermediate. J Biol Chem, 269(39):24169-76, 1994.

E.Z. Du, J.F. Fleming, S.L. Wang, G.M. Spitsen, and R.A. Davis. Translocationarrested apolipoprotein B evades proteasome degradation via a sterol-sensitive block in ubiquitin conjugation. J Biol Chem, 274(3):1856-62, 1999.

S.B. Edge, J.M. Hoeg, T. Triche, P.D. Schneider, and H.B. Brewer, Jr. Cultured human hepatocytes. Evidence for metabolism of low density lipoproteins by a pathway independent of the classical low density lipoprotein receptor. J Biol Chem, 261(8): 3800-6, 1986.

S. Eisenberg. High density lipoprotein metabolism. J Lipid Res, 25(10):1017-58, 1984.

J.L. Ellsworth, S.K. Erickson, and A.D. Cooper. Very low and low density lipoprotein synthesis and secretion by the human hepatoma cell line Hep-G2: effects of free fatty acid. J Lipid Res, 27(8):858-74, 1986.

J. Elovson, Y.O. Huang, N. Baker, and R. Kannan. Apolipoprotein B is structurally and metabolically heterogeneous in the rat. Proc Natl Acad Sci U S A, 78(1): 157-61, 1981.

E.A. Fisher, M. Zhou, D.M. Mitchell, X. Wu, S. Omura, H. Wang, A.L. Goldberg, and H.N. Ginsberg. The degradation of apolipoprotein B100 is mediated by the ubiquitin-proteasome pathway and involves heat shock protein 70. J Biol Chem, 272(33):20427-34, 1997.

J.F. Fleming, G.M. Spitsen, T.Y. Hui, L. Olivier, E.Z. Du, M. Raabe, and R.A. Davis. Chinese hamster ovary cells require the coexpression of microsomal triglyceride transfer protein and cholesterol 7alpha-hydroxylase for the assembly and secretion of apolipoprotein B-containing lipoproteins. J Biol Chem, 274(14):9509-14, 1999.

J. Folch, M. Lees, and G.H. Sloane Stanley. A simple method for the isolation and purification of total lipides from animal tissues. JBC, 224:497-509, 1957. 


\section{Bibliography}

T.M. Forte, M.R. McCall, B.B. Knowles, and V.G. Shore. Isolation and characterization of lipoproteins produced by human hepatoma-derived cell lines other than HepG2. J Lipid Res, 30(6):817-29, 1989.

I.V. Fuki, R.V. Iozzo, and K.J. Williams. Perlecan heparan sulfate proteoglycan: a novel receptor that mediates a distinct pathway for ligand catabolism. J Biol Chem, 275(33):25742-50, 2000.

G.F. Gibbons. Assembly and secretion of hepatic very-low-density lipoprotein. Biochem J, 268(1):1-13, 1990.

H.N. Ginsberg. Synthesis and secretion of apolipoprotein B from cultured liver cells. Curr Opin Lipidol, 6(5):275-80, 1995.

R.M. Glickman, M. Rogers, and J.N. Glickman. Apolipoprotein B synthesis by human liver and intestine in vitro. Proc Natl Acad Sci U S A, 83(14):5296-300, 1986.

J.L. Goldstein and M.S. Brown. Binding and degradation of low density lipoproteins by human fibroblasts. J Biol Chem, 249(16):5153-5162, 1974.

J.L. Goldstein, S.K. Basu, and M.S. Brown. Receptor-mediated endocytosis of lowdensity lipoprotein in cultured cells. Methods Enzymol, 98:241-60, 1983.

D.A. Gordon, H. Jamil, R.E. Gregg, S.O. Olofsson, and J. Boren. Inhibition of the microsomal triglyceride transfer protein blocks the first step of apolipoprotein B lipoprotein assembly but not the addition of bulk core lipids in the second step. $J$ Biol Chem, 271(51):33047-53, 1996.

P. Greenspan and R.W. St Clair. Retroendocytosis of low density lipoprotein. Effect of lysosomal inhibitors on the release of undegraded 125I-low density lipoprotein of altered composition from skin fibroblasts in culture. J Biol Chem, 259(3):1703-13, 1984 .

V. Gusarova, J.L. Brodsky, and E.A. Fisher. Apolipoprotein B100 exit from the endoplasmic reticulum (ER) is COPII-dependent, and its lipidation to very low density lipoprotein occurs post-ER. J Biol Chem, 278(48):48051-8, 2003.

R.L. Hamilton, J.S. Wong, C.M. Cham, L.B. Nielsen, and S.G. Young. Chylomicronsized lipid particles are formed in the setting of apolipoprotein B deficiency. J Lipid Res, 39(8):1543-57, 1998. 


\section{Bibliography}

A.M. Hebbachi, A.M. Brown, and G.F. Gibbons. Suppression of cytosolic triacylglycerol recruitment for very low density lipoprotein assembly by inactivation of microsomal triglyceride transfer protein results in a delayed removal of apoB-48 and apoB-100 from microsomal and Golgi membranes of primary rat hepatocytes. J Lipid Res, 40(10):1758-68, 1999.

J. Heeren, T. Grewal, S. Jackle, and U. Beisiegel. Recycling of apolipoprotein E and lipoprotein lipase through endosomal compartments in vivo. J Biol Chem, 276(45): 42333-8, 2001.

J. Heeren, T. Grewal, A. Laatsch, D. Rottke, F. Rinninger, C. Enrich, and U. Beisiegel. Recycling of apoprotein E is associated with cholesterol efflux and high density lipoprotein internalization. J Biol Chem, 278(16):14370-8, 2003.

J. Herz and T.E. Willnow. Lipoprotein and receptor interactions in vivo. Curr Opin Lipidol, 6(2):97-103, 1995.

Y. Higashi, H. Itabe, H. Fukase, M. Mori, Y. Fujimoto, and T. Takano. Transmembrane lipid transfer is crucial for providing neutral lipids during very low density lipoprotein assembly in endoplasmic reticulum. J Biol Chem, 278(24):21450-8, 2003.

J.A. Higgins. Evidence that during very low density lipoprotein assembly in rat hepatocytes most of the triacylglycerol and phospholipid are packaged with apolipoprotein B in the Golgi complex. FEBS Lett, 232(2):405-8, 1988.

X.F. Huang and G.S. Shelness. Identification of cysteine pairs within the aminoterminal $5 \%$ of apolipoprotein B essential for hepatic lipoprotein assembly and secretion. J Biol Chem, 272(50):31872-6, 1997.

E. Hurt-Camejo, U. Olsson, O. Wiklund, G. Bondjers, and G. Camejo. Cellular consequences of the association of apoB lipoproteins with proteoglycans. Potential contribution to atherogenesis. Arterioscler Thromb Vasc Biol, 17(6):1011-7, 1997.

T. Ishikawa and N. Fidge. Changes in the concentration of plasma lipoproteins and apoproteins following the administration of Triton WR 1339 to rats. J Lipid Res, 20(2):254-64, 1979.

Y. Ji, B. Jian, N. Wang, Y. Sun, M.L. Moya, M.C. Phillips, G.H. Rothblat, J.B. Swaney, and A.R. Tall. Scavenger receptor BI promotes high density lipoproteinmediated cellular cholesterol efflux. J Biol Chem, 272(34):20982-5, 1997. 
B. Jones, E.L. Jones, S.A. Bonney, H.N. Patel, A.R. Mensenkamp, S. EichenbaumVoline, M. Rudling, U. Myrdal, G. Annesi, S. Naik, N. Meadows, A. Quattrone, S.A. Islam, R.P. Naoumova, B. Angelin, R. Infante, E. Levy, C.C. Roy, P.S. Freemont, J. Scott, and C.C. Shoulders. Mutations in a Sar1 GTPase of COPII vesicles are associated with lipid absorption disorders. Nat Genet, 34(1):29-31, 2003.

V.A. Kosykh, S.N. Preobrazhensky, V.O. Ivanov, V.P. Tsibulsky, V.S. Repin, and V.N. Smirnov. High-affinity association and degradation of 125I-labelled low density lipoproteins by human hepatocytes in primary culture. FEBS Lett, 183(1): 17-20, 1985.

R.M. Krauss and D.J. Burke. Identification of multiple subclasses of plasma low density lipoproteins in normal humans. J Lipid Res, 23(1):97-104, 1982.

Y. Krausz, H. Bar-On, and E. Shafrir. Origin and pattern of glucocorticoidinduced hyperlipidemia in rats. Dose-dependent bimodal changes in serum lipids and lipoproteins in relation to hepatic lipogenesis and tissue lipoprotein lipase activity. Biochim Biophys Acta, 663(1):69-82, 1981.

O. Kuge, C. Dascher, L. Orci, T. Rowe, M. Amherdt, H. Plutner, M. Ravazzola, G. Tanigawa, J.E. Rothman, and W.E. Balch. Sar1 promotes vesicle budding from the endoplasmic reticulum but not Golgi compartments. J Cell Biol, 125(1):51-65, 1994.

U.K. Laemmli. Cleavage of structural proteins during the assembly of the head of bacteriophage T4. Nature, 227(5259):680-5, 1970.

D.L. Lankester, A.M. Brown, and V.A. Zammit. Use of cytosolic triacylglycerol hydrolysis products and of exogenous fatty acid for the synthesis of triacylglycerol secreted by cultured rat hepatocytes. J Lipid Res, 39(9):1889-95, 1998.

S.U. Lauvrak, A. Llorente, T.G. Iversen, and K. Sandvig. Selective regulation of the Rab9-independent transport of ricin to the Golgi apparatus by calcium. J Cell Sci, 115(Pt 17):3449-56, 2002.

C. Lavoie, J. Paiement, M. Dominguez, L. Roy, S. Dahan, J.N. Gushue, and J.J. Bergeron. Roles for alpha(2)p24 and COPI in endoplasmic reticulum cargo exit site formation. J Cell Biol, 146(2):285-99, 1999. 


\section{Bibliography}

R.G. Lee, M.C. Willingham, M.A. Davis, K.A. Skinner, and L.L. Rudel. Differential expression of ACAT1 and ACAT2 among cells within liver, intestine, kidney, and adrenal of nonhuman primates. J Lipid Res, 41(12):1991-2001, 2000.

R. Lehner and R. Verger. Purification and characterization of a porcine liver microsomal triacylglycerol hydrolase. Biochemistry, 36(7):1861-8, 1997.

E. Levy, S. Stan, E. Delvin, D. Menard, C. Shoulders, C. Garofalo, I. Slight, E. Seidman, G. Mayer, and M. Bendayan. Localization of microsomal triglyceride transfer protein in the Golgi: possible role in the assembly of chylomicrons. J Biol Chem, 277(19):16470-7, 2002.

W. Liao and L. Chan. Apolipoprotein B, a paradigm for proteins regulated by intracellular degradation, does not undergo intracellular degradation in CaCo2 cells. $J$ Biol Chem, 275(6):3950-6, 2000.

W. Liao, S.C. Yeung, and L. Chan. Proteasome-mediated degradation of apolipoprotein B targets both nascent peptides cotranslationally before translocation and full-length apolipoprotein B after translocation into the endoplasmic reticulum. $J$ Biol Chem, 273(42):27225-30, 1998.

D. Linden, A. Sjoberg, L. Asp, L. Carlsson, and J. Oscarsson. Direct effects of growth hormone on production and secretion of apolipoprotein B from rat hepatocytes. Am J Physiol Endocrinol Metab, 279(6):E1335-46, 2000.

J. Lippincott-Schwartz, N.B. Cole, and J.G. Donaldson. Building a secretory apparatus: role of ARF1/COPI in Golgi biogenesis and maintenance. Histochem Cell Biol, 109(5-6):449-62, 1998.

P. Lombardi, M. Mulder, H. van der Boom, R.R. Frants, and L.M. Havekes. Inefficient degradation of triglyceride-rich lipoprotein by HepG2 cells is due to a retarded transport to the lysosomal compartment. J Biol Chem, 268(35):26113-9, 1993.

A. Lorentz, D. Plonne, H.P. Schulze, and R. Dargel. Dexamethasone enhanced by insulin, but not by thyroid hormones stimulates apolipoprotein B mRNA editing in cultured rat hepatocytes depending on the developmental stage. FEBS Lett, 391 (1-2):57-60, 1996.

O.H. Lowry, N.J. Rosebrough, A.L. Farr, and R.J. Randall. Protein measurement with the Folin phenol reagent. J Biol Chem, 193(1):265-75, 1951. 
R.W. Mahley and Z.S. Ji. Remnant lipoprotein metabolism: key pathways involving cell-surface heparan sulfate proteoglycans and apolipoprotein E. J Lipid Res, 40 (1):1-16, 1999.

F. Mallard, C. Antony, D. Tenza, J. Salamero, B. Goud, and L. Johannes. Direct pathway from early/recycling endosomes to the Golgi apparatus revealed through the study of shiga toxin B-fragment transport. J Cell Biol, 143(4):973-90, 1998.

P. Martin-Sanz, J.E. Vance, and D.N. Brindley. Stimulation of apolipoprotein secretion in very-low-density and high-density lipoproteins from cultured rat hepatocytes by dexamethasone. Biochem J, 271(3):575-83, 1990.

M.J. Meredith. Rat hepatocytes prepared without collagenase: prolonged retention of differentiated characteristics in culture. Cell Biol Toxicol, 4(4):405-25, 1988.

M.A. Mindham and P.A. Mayes. A simple and rapid method for the preparation of apolipoproteins for electrophoresis. J Lipid Res, 33(7):1084-8, 1992.

D.M. Mitchell, M. Zhou, R. Pariyarath, H. Wang, J.D. Aitchison, H.N. Ginsberg, and E.A. Fisher. Apoprotein B100 has a prolonged interaction with the translocon during which its lipidation and translocation change from dependence on the microsomal triglyceride transfer protein to independence. Proc Natl Acad Sci U S A, 95(25):14733-8, 1998.

T.A. Musliner, C. Giotas, and R.M. Krauss. Presence of multiple subpopulations of lipoproteins of intermediate density in normal subjects. Arteriosclerosis, 6(1): 79-87, 1986.

N. Navaratnam, T. Fujino, J. Bayliss, A. Jarmuz, A. How, N. Richardson, A. Somasekaram, S. Bhattacharya, C. Carter, and J. Scott. Escherichia coli cytidine deaminase provides a molecular model for ApoB RNA editing and a mechanism for RNA substrate recognition. J Mol Biol, 275(4):695-714, 1998. URL http://eutils.ncbi.nlm.nih.gov/entrez/eutils/elink.fcgi?cmd=prlinks\&dbfrom=pubmed\&r

L.B. Nielsen, M. Veniant, J. Boren, M. Raabe, J.S. Wong, C. Tam, L. Flynn, T. VanniReyes, M.D. Gunn, I.J. Goldberg, R.L. Hamilton, and S.G. Young. Genes for apolipoprotein $\mathrm{B}$ and microsomal triglyceride transfer protein are expressed in the heart: evidence that the heart has the capacity to synthesize and secrete lipoproteins. Circulation, 98(1):13-6, 1998. 


\section{Bibliography}

S.O. Olofsson, G. Bjursell, K. Bostrom, P. Carlsson, J. Elovson, A.A. Protter, M.A. Reuben, and G. Bondjers. Apolipoprotein B: structure, biosynthesis and role in the lipoprotein assembly process. Atherosclerosis, 68(1-2):1-17, 1987.

K. Paananen, J. Saarinen, A. Annila, and P.T. Kovanen. Proteolysis and fusion of low density lipoprotein particles strengthen their binding to human aortic proteoglycans. J Biol Chem, 270(20):12257-62, 1995.

C.J. Packard and J. Shepherd. Lipoprotein heterogeneity and apolipoprotein B metabolism. Arterioscler Thromb Vasc Biol, 17(12):3542-56, 1997.

C.J. Packard, T. Demant, J.P. Stewart, D. Bedford, M.J. Caslake, G. Schwertfeger, A. Bedynek, J. Shepherd, and D. Seidel. Apolipoprotein B metabolism and the distribution of VLDL and LDL subfractions. J Lipid Res, 41(2):305-18, 2000.

M. Pan, J.S. Liang Js, E.A. Fisher, and H.N. Ginsberg. The late addition of core lipids to nascent apolipoprotein B100, resulting in the assembly and secretion of triglyceride-rich lipoproteins, is independent of both microsomal triglyceride transfer protein activity and new triglyceride synthesis. J Biol Chem, 277(6):4413-21, 2002 .

R.J. Pease and J.M. Leiper. Regulation of hepatic apolipoprotein-B-containing lipoprotein secretion. Curr Opin Lipidol, 7(3):132-8, 1996.

L.M. Powell, S.C. Wallis, R.J. Pease, Y.H. Edwards, T.J. Knott, and J. Scott. A novel form of tissue-specific RNA processing produces apolipoprotein-B48 in intestine. Cell, 50(6):831-40, 1987.

M Raabe, MM Veniant, MA Sullivan, CH Zlot, J Bjorkegren, LB Nielsen, JS Wong, RL Hamilton, and SG Young. Analysis of the role of microsomal triglyceride transfer protein in the liver of tissue-specific knockout mice. J Clin Invest., 103:12871298, 1999.

C.M. RADDING and D. STEINBERG. Studies on the synthesis and secretion of serum lipoproteins by rat liver slices. J Clin Invest, 39:1560-9, 1960.

P.C. Rensen, M.C. Jong, L.C. van Vark, H. van der Boom, W.L. Hendriks, T.J. van Berkel, E.A. Biessen, and L.M. Havekes. Apolipoprotein E is resistant to intracellular degradation in vitro and in vivo. Evidence for retroendocytosis. J Biol Chem, 275(12):8564-71, 2000. 


\section{Bibliography}

A. Rohlmann, M. Gotthardt, R.E. Hammer, and J. Herz. Inducible inactivation of hepatic LRP gene by cre-mediated recombination confirms role of LRP in clearance of chylomicron remnants. J Clin Invest, 101(3):689-95, 1998.

A. Rusinol, H. Verkade, and J.E. Vance. Assembly of rat hepatic very low density lipoproteins in the endoplasmic reticulum. J Biol Chem, 268(5):3555-62, 1993.

A.E. Rusinol, Z. Cui, M.H. Chen, and J.E. Vance. A unique mitochondria-associated membrane fraction from rat liver has a high capacity for lipid synthesis and contains pre-Golgi secretory proteins including nascent lipoproteins. J Biol Chem, 269(44): 27494-502, 1994.

A.E. Rusinol, R.S. Hegde, S.L. Chuck, V.R. Lingappa, and J.E. Vance. Translocational pausing of apolipoprotein B can be regulated by membrane lipid composition. J Lipid Res, 39(6):1287-94, 1998.

S. Rustaeus, P. Stillemark, K. Lindberg, D. Gordon, and S.O. Olofsson. The microsomal triglyceride transfer protein catalyzes the post-translational assembly of apolipoprotein B-100 very low density lipoprotein in McA-RH7777 cells. J Biol Chem, 273(9):5196-203, 1998.

S. Santamarina-Fojo. The familial chylomicronemia syndrome. Endocrinol Metab Clin North Am, 27(3):551-67, viii, 1998.

R. Schekman and I. Mellman. Does COPI go both ways? Cell, 90(2):197-200, 1997.

F. Schliess, A.K. Kurz, S. vom Dahl, and D. Haussinger. Mitogen-activated protein kinases mediate the stimulation of bile acid secretion by tauroursodeoxycholate in rat liver. Gastroenterology, 113(4):1306-14, 1997.

V.N. Schumaker and D.L. Puppione. Sequential flotation ultracentrifugation. Methods Enzymol, 128:155-70, 1986.

J. Scott, R.J. Pease, L.M. Powell, S.C. Wallis, B.J. McCarthy, R.W. Mahley, B. LevyWilson, and T.J. Knott. Human apolipoprotein B: complete cDNA sequence and identification of structural domains of the protein. Biochem Soc Trans, 15(2):195-9, 1987.

J.P. Segrest, M.K. Jones, V.K. Mishra, G.M. Anantharamaiah, and D.W. Garber. apoB-100 has a pentapartite structure composed of three amphipathic alpha-helical domains alternating with two amphipathic beta-strand domains. Detection by the computer program LOCATE. Arterioscler Thromb, 14(10):1674-85, 1994. 


\section{Bibliography}

G.S. Shelness and J.A. Sellers. Very-low-density lipoprotein assembly and secretion. Curr Opin Lipidol, 12(2):151-7, 2001.

J. Shepherd and C.J. Packard. Receptor-independent low-density lipoprotein catabolism. Methods Enzymol, 129:566-90, 1986.

J.D. Sparks and C.E. Sparks. Insulin modulation of hepatic synthesis and secretion of apolipoprotein B by rat hepatocytes. J Biol Chem, 265(15):8854-62, 1990.

L.L. Swift, K. Valyi-Nagy, C. Rowland, and C. Harris. Assembly of very low density lipoproteins in mouse liver: evidence of heterogeneity of particle density in the Golgi apparatus. J Lipid Res, 42(2):218-24, 2001.

C. Taghibiglou, D. Rudy, S.C. Van Iderstine, A. Aiton, D. Cavallo, R. Cheung, and K. Adeli. Intracellular mechanisms regulating apoB-containing lipoprotein assembly and secretion in primary hamster hepatocytes. J Lipid Res, 41(4):499-513, 2000 .

K. Takahashi, S. Fukuda, M. Naito, S. Horiuchi, K. Takata, and Y. Morino. Endocytic pathway of high density lipoprotein via trans-Golgi system in rat resident peritoneal macrophages. Lab Invest, 61(3):270-7, 1989.

B. Teng, C.F. Burant, and N.O. Davidson. Molecular cloning of an apolipoprotein B messenger RNA editing protein. Science, 260(5115):1816-9, 1993.

R.N. Thrift, T.M. Forte, B.E. Cahoon, and V.G. Shore. Characterization of lipoproteins produced by the human liver cell line, Hep G2, under defined conditions. $J$ Lipid Res, 27(3):236-50, 1986.

U.J. Tietge, A. Bakillah, C. Maugeais, K. Tsukamoto, M. Hussain, and D.J. Rader. Hepatic overexpression of microsomal triglyceride transfer protein (MTP) results in increased in vivo secretion of VLDL triglycerides and apolipoprotein B. J Lipid Res, 40(11):2134-9, 1999.

K. Tran, J. Boren, J. Macri, Y. Wang, R. McLeod, R.K. Avramoglu, K. Adeli, and Z. Yao. Functional analysis of disulfide linkages clustered within the amino terminus of human apolipoprotein B. J Biol Chem, 273(13):7244-51, 1998.

K. Tran, Y. Wang, C.J. DeLong, Z. Cui, and Z. Yao. The assembly of very low density lipoproteins in rat hepatoma McA-RH7777 cells is inhibited by phospholipase A2 antagonists. J Biol Chem, 275(32):25023-30, 2000. 


\section{Bibliography}

K. Tran, G. Thorne-Tjomsland, C.J. DeLong, Z. Cui, J. Shan, L. Burton, J.C. Jamieson, and Z. Yao. Intracellular assembly of very low density lipoproteins containing apolipoprotein B100 in rat hepatoma McA-RH7777 cells. J Biol Chem, 277 (34):31187-200, 2002.

J. Twisk, D.L. Gillian-Daniel, A. Tebon, L. Wang, P.H. Barrett, and A.D. Attie. The role of the LDL receptor in apolipoprotein B secretion. J Clin Invest, 105(4): $521-32,2000$.

J.E. Vance. Assembly and secretion of lipoproteins. In D.E. Vance and J.E. Vance, editors, Biochemistry of Lipids, Lipoproteins and Membranes, pages 505-526. Elsevier, Amsterdam, NL, 2002.

M.M. Veniant, C.H. Zlot, R.L. Walzem, V. Pierotti, R. Driscoll, D. Dichek, J. Herz, and S.G. Young. Lipoprotein clearance mechanisms in LDL receptor-deficient "ApoB48-only" and "Apo-B100-only" mice. J Clin Invest, 102(8):1559-68, 1998.

C.N. Wang, T.C. Hobman, and D.N. Brindley. Degradation of apolipoprotein B in cultured rat hepatocytes occurs in a post-endoplasmic reticulum compartment. $J$ Biol Chem, 270(42):24924-31, 1995a.

C.N. Wang, R.S. McLeod, Z. Yao, and D.N. Brindley. Effects of dexamethasone on the synthesis, degradation, and secretion of apolipoprotein $\mathrm{B}$ in cultured rat hepatocytes. Arterioscler Thromb Vasc Biol, 15(9):1481-91, 1995b.

J.R. Wetterau, K.A. Combs, L.R. McLean, S.N. Spinner, and L.P. Aggerbeck. Protein disulfide isomerase appears necessary to maintain the catalytically active structure of the microsomal triglyceride transfer protein. Biochemistry, 30(40):9728-35, 1991.

A.L. White, D.L. Graham, J. LeGros, R.J. Pease, and J. Scott. Oleate-mediated stimulation of apolipoprotein B secretion from rat hepatoma cells. A function of the ability of apolipoprotein B to direct lipoprotein assembly and escape presecretory degradation. J Biol Chem, 267(22):15657-64, 1992.

D. Wiggins and G.F. Gibbons. Origin of hepatic very-low-density lipoprotein triacylglycerol: the contribution of cellular phospholipid. Biochem J, 320 ( Pt 2):673-9, 1996.

K.J. Williams and I.V. Fuki. Cell-surface heparan sulfate proteoglycans: dynamic molecules mediating ligand catabolism. Curr Opin Lipidol, 8(5):253-62, 1997. 


\section{Bibliography}

M. Yanagishita and V.C. Hascall. Effects of monensin on the synthesis, transport, and intracellular degradation of proteoglycans in rat ovarian granulosa cells in culture. J Biol Chem, 260(9):5445-55, 1985.

L.Y. Yang, A. Kuksis, J.J. Myher, and G. Steiner. Contribution of de novo fatty acid synthesis to very low density lipoprotein triacylglycerols: evidence from mass isotopomer distribution analysis of fatty acids synthesized from [2H6]ethanol. $J$ Lipid Res, 37(2):262-74, 1996.

Z. Yao, K. Tran, and R.S. McLeod. Intracellular degradation of newly synthesized apolipoprotein B. J Lipid Res, 38(10):1937-53, 1997.

S.J. Yeung, S.H. Chen, and L. Chan. Ubiquitin-proteasome pathway mediates intracellular degradation of apolipoprotein B. Biochemistry, 35(43):13843-8, 1996.

S.G. Young. Recent progress in understanding apolipoprotein B. Circulation, 82(5): 1574-94, 1990.

V.I. Zannis, J.L. Breslow, T.R. SanGiacomo, D.P. Aden, and B.B. Knowles. Characterization of the major apolipoproteins secreted by two human hepatoma cell lines. Biochemistry, 20(25):7089-96, 1981.

Y.L. Zhang, A. Hernandez-Ono, C. Ko, K. Yasunaga, L.S. Huang, and H.N. Ginsberg. Regulation of hepatic apolipoprotein B-lipoprotein assembly and secretion by the availability of fatty acids. I. Differential response to the delivery of fatty acids via albumin or remnant-like emulsion particles. J Biol Chem, 279(18):19362-74, 2004.

Y. Zhao, J.B. McCabe, J. Vance, and L.G. Berthiaume. Palmitoylation of apolipoprotein $B$ is required for proper intracellular sorting and transport of cholesteroyl esters and triglycerides. Mol Biol Cell, 11(2):721-34, 2000. 